Revised draft: September 15th, 2009

\title{
Disability, capacity for work and the business cycle: An international perspective*
}

\author{
by \\ Hugo-Benítez-Silva \\ Richard Disney \\ SUNY-Stony Brook \\ Sergi Jiménez-Martín \\ University of Nottingham \\ Universitat Pompeu Fabra and FEDEA
}

\begin{abstract}
Summary
An important policy issue in recent years concerns the number of people claiming disability benefits for reasons of incapacity for work. We distinguish between 'work disability', which may have its roots in economic and social circumstances, and 'health disability' which arises from clear diagnosed medical conditions. Although there is a link between work and health disability, economic conditions, and in particular the 'business cycle' and variations in the risk of unemployment over time and across localities, may play an important part in explaining both the stock of disability benefit claimants and inflows to and outflow from that stock. We employ a variety of cross-country and country-specific household panel data sets, as well as administrative data, to test whether disability benefit claims rise when unemployment is higher, and also to investigate the impact of unemployment rates on flows on and off the benefit rolls. We find strong evidence that local variations in unemployment have an important explanatory role for disability benefit receipt, with higher total enrolments, lower outflows from rolls and, often, higher inflows into disability rolls in regions and periods of above-average unemployment. Although general subjective measures of selfreported disability and longstanding illness are also positively associated with unemployment rates, inclusion of self-reported health measures does not eliminate the statistical relationship between unemployment rates and disability benefit receipt; indeed including general measures of health often strengthens that underlying relationship. Intriguingly, we also find some evidence from the United Kingdom and the United States that the prevalence of self-reported 'objective' specific indicators of disability are often pro-cyclical - that is, the incidence of specific forms of disability are pro-cyclical whereas claims for disability benefits given specific health conditions are counter-cyclical. Overall, the analysis suggests that, for a range of countries and data sets, levels of claims for disability benefits are not simply related to changes in the incidence of health disability in the population and are strongly influenced by prevailing economic conditions. We discuss the policy implications of these various findings.
\end{abstract}

KEYWORDS: DISABILITY, CAPACITY FOR WORK, BUSINESS CYCLE, INTERNATIONAL COMPARISONS.

JEL-CODE: J14, H55

\footnotetext{
${ }^{*}$ Preliminary version of a paper prepared for the $50^{\text {th }}$ meeting od Economic Policy in Tilburg. Our thanks to John Gathergood, Anna Nesterenko, Selcuk Eren, Isabel Sánchez, and Hannes Schwandt for admirable research assistance. Hugo Benítez-Silva and Sergi Jiménez-Martín acknowledge financial help from project ECO200806395-C05-01.
} 


\section{Introduction}

The study of disability program and disability policies has become one of the most important and challenging issues in welfare policy. For the economist, the analysis of these programmes lies at the intersection of several fields including public economics, labour economics and health economics, and interacts with related areas such as public policy, public health and demography. For the policymaker, the apparent inexorable rise in the number of disability claimants in a number of countries, and the looming issue of demographic ageing, which has possible consequences for the overall morbidity of the population, heighten the importance of the issue (Lutz, Sanderson and Scherbov, 2008).

In this paper, we analyse how economic conditions affect claims for work-related disability benefits in a number of OECD countries. In particular, we focus on work-related disability and the business cycle, as measured by variation in unemployment rates. By 'work-related', we do not simply mean claims for disability benefits that arise from narrow work-related causes such as industrial injuries and accidents, but rather the whole range of social insurance-based disability insurance programmes that are available in most developed economies. In doing so, however, we do not explicitly study programmes that are designed to provide care in the community for the elderly or infirm, and for those that have never worked. It is the trend in disability-related social insurance programmes that has tended to cause most concern to policymakers, and these programmes form our primary interest here.

\section{Disability programmes and the business cycle}

Our starting point is the idea that such programmes have been used to cushion recessions and to alleviate transitions into and from economic inactivity in regions of high unemployment, as suggested by a variety of studies including Beale and Nethercott (1988), Beatty and Fothergill (1996), Black, Daniel and Sanders (2002), Disney and Webb (1991), and McVicar (2006). In addition, disability programmes have often been used as an alternative to early retirement through pension programmes, either because of restrictions on early retirement through conventional pension plans, or because disability programmes offer more attractive benefit levels or tax treatment of retirement benefits (Blöndal and Scarpetta, 1999; Gruber and Kubik, 1997; Gruber and Wise, 1999, 2004; Haveman and Wolfe, 1984; Haveman, de Jong and Wolfe, 1991; Jiménez-Martin et al, 2006, JiménezMartin and Vall, 2009, and Riphahn, 1997). This alternative 'route' into inactivity for older people proved particularly attractive when employers were seeking to shed older workers in periods of recession such as the mid-1970s and the early 1980s. 
The link between the size of disability-related social insurance programmes and the business cycle is therefore again of heightened importance since mid-2008 as the world economy enters a major downturn. However, it should not be thought that the business cycle is the only driving force behind the trend in claims for disability benefits. Indeed, for much of the 1990s and the early 2000s, unemployment rates were falling and yet rates of disability claims remained high or even increased in many OECD countries. Other factors, including the trend in the relative generosity of disability benefits relative to other social insurance benefits, and underlying demographic and morbidity trends, are also relevant. In particular, several high profile studies, such as Autor and Duggan (2003, 2006) and Burkhauser and Daly (2001) in the United States, and OECD $(2006,2007)$ more generally, have pointed to trends in the relative generosity of disability benefit programmes as an important explanatory variable in explaining the trend in claimant numbers. In addition, low exit rates from receipt of disability benefits may induce 'ratchet' effects by which the stock remains high after periods of high inflows during economic downturns. The underlying character of this trend, and the need for action, has therefore been noted by OECD:

\begin{abstract}
"Sickness and disability policy should be a key economic concern in all OECD countries...Medical conditions are increasingly proving an obstacle to raising labour force participation rates and keeping public expenditures under control... Unemployment has fallen to very low levels in recent years in the OECD area, yet nowhere has this drop translated into more jobs for disabled people. With increasingly stricter work requirements in unemployment and social assistance programmes, and gradual retrenchment of early retirement systems, the pressure on long-term sickness and disability schemes has increased. This has in turn led to rising numbers of working-age people drawing these benefits and more public spending on them. There is now an urgent need to address this 'medicalisation' of labour market problems." (OECD, 2006, p.5)
\end{abstract}

Disability and the capacity for work

A key issue in this context is the connection between disability and the capacity for work. This in turn requires that we make a distinction between work disability and health disability. The former is likely to be influenced by economic conditions and by welfare programmes while the latter evolves in a slower fashion with medical technology and demographic changes.

The seminal work on incidence of disability is that of Nagi (1964, 1969, and 1991), supplemented by the classifications by the WHO (1980). ${ }^{1}$ Nagi argues that a health disability can have many sources and many different impacts on the ability of an individual to function in society. While many disabling conditions have at source a serious health problem resulting from an illness or

\footnotetext{
${ }^{1}$ Recent discussions of the definition of disability can be found in Wunderlich et al. (2002), Social Security Advisory Board (2003) and Burkhauser et al. (2003).
} 
an accident, in many other cases they are congenital or the result of conditions which might not affect the general health of the individual. The evolution of health disability can in general be identified through the changes in objective health measures in a given population.

In contrast, one of the main challenges of defining work disability as a condition that limits or even prevents work is that measured or self-reported work disability can be a function of the type of work and the attitudes of the individual towards the labour market and life in general. Work disability is a socially evolving concept, related to how society and employers accommodate the needs of individuals with certain conditions. In addition, work disability is also a function of individuals' willingness to continue their attachment to the labour force and can thereby also be a function of economic conditions. Crucially, too, whilst certain types of health disability may be regarded as 'absorbing states', 'work disability' is potentially a temporary state. ${ }^{2}$ This may be an important consideration when designing the administration and incentive structure of a disability insurance programme.

Assessing the potential impact of economic conditions on work disability while controlling for country-level incentive structures, and where possible for the individual-specific characteristics of the populations under investigation, including health disability, is the main objective of this study. Given differences in official definitions of disability across countries then, for the size of the programs to change significantly over the business cycle, it must be the case that the pool of eligible individuals in the programs and outside of the programs evolves over the cycle (i.e. induced entry and, possibly, exit). Of course, this variation in the pool of applicants can be the result of strategic actions by governments (especially by European governments), which in specific circumstances can see it as politically beneficial to relax eligibility conditions for the disability rolls in order to keep the unemployment rate from increasing too sharply (See Hassink, van Ours and Ridder, 1997; Westerhout, 2001; and Koning and van Vuuren, 2007 and 2008). While it is thereby easy to understand that disability applications are likely to increase during recessions, the likelihood of seeing considerable changes in the number of individuals receiving benefits depends on government policies implemented to deal with the flow of individuals who struggle to keep their jobs during bad economic times, and the incentives set up in the first place by the disability programs to screen individuals.

However, while it is natural to focus on the effects that recessions can have on the cost of social insurance programs, we should not also forget the effects of the good times on these programs. Disability programs have to be flexible enough to benefit from the good phase of the

\footnotetext{
2 By an 'absorbing state', we mean that the probability of the individual subsequently exiting that state is close to zero.
} 
cycle, in order to compensate for their increased cost during recessions. In order to do that, systems have to be structured to allow individuals to go back to work easily without excessive penalty. Recent research in this direction shows the savings can be considerable if the system is designed to keep as many people working as possible.

Outline of the paper

Our empirical strategy in order to test these various propositions is as follows. We first examine whether there is a relationship between, on the one hand, disability claim rates and disability claim transitions rates and, on the other hand, unemployment rates across a number of economies, using both cross-country and country-specific panel data. We are looking for broad relationships within and across OECD countries using large-scale household data sets, rather than focusing on the consequences of specific institutional settings (such as the design of disability benefit regimes within countries). This is not therefore primarily a study of incentives within country-specific benefit regimes.

Our general strategy is to control for individual characteristics and to condition on country effects and a common time trend. Although we adopt alternative specifications, our primary identification is off time-varying within-country spatial differences in unemployment rates. We show that there is a reasonably robust relationship between unemployment rates and disability claims, and also a strong relationship between outflows from disability insurance registers and spatial unemployment rates. In contrast, the statistical relationship between inflow rates and unemployment rates is weaker in Europe, but stronger in the United States.

We then explore these relationships using panel data and administrative data in four countries with very different institutional settings: Germany, Spain, the United Kingdom and the United States. The results from these studies broadly confirm the findings of the cross country panel data studies.

We next consider whether these relationships in work disability may arise from, or be affected by, changes in health disability over time. For example, the stress associated with seeking or retaining employment in areas where work is hard to find may have an adverse effect on individual health. In other words, one hypothesis is that changes in work and health disability are highly correlated and vary across differences in unemployment rates. To test this hypothesis, we initially look at general self-reported disability measures. We show, using Labour Force Survey data, that there is a correlation, albeit non-linear, between general measures of self-reported disability and unemployment rates. We also examine whether including such general individual self-reported 
health states affect the relationship between disability insurance claims and unemployment rates that we have already identified.

A natural problem with broad self-reported measures of general 'health disability' is that they suffer from various forms of response bias; notably that individuals who receive disability benefits have an incentive to report a health disability, especially where the 'gateways' to access disability benefits do not adequately screen health disabilities, for whatever reason. In addition, individual may simply rationalise or 'justify' their health ex post as characterised as poor in situations where jobs are hard to find. Self-reported general measures of poor health may therefore be poor 'proxies' for underlying health disability, as argued by many studies include Baker, Stabile and Deri (2004), Bound (1991), Bound et al, (1999), Disney, Emmerson and Wakefield (2006), Dwyer and Mitchell, (1999); and so on.

In the light of this possibility, we examine the interaction between 'health disability' and 'work disability' further by using some of the individual country panels to look at variations in more 'objective' measures of health disability across different levels of unemployment. And we find very little evidence that these measures of individual disabilities are correlated with unemployment rates - indeed, if anything, the opposite is the case for many forms of incapacity and ill-health. This result accords with other statistical and epidemiological literature which notes that accident-related disabilities and the onset of physical incapacities are often pro-cyclical - that is, associated with periods of high economic activity. The exception - and it is an important one - is certain types of stress, depression and mental health issues, which are often related to factors such as an unemployed member of the household or the threat of unemployment (though other indicators of 'boom' periods - such as high household indebtedness may also be a contributing factor).

This last result suggests two conclusions. First, that the changes in health disability and work disability over the business cycle are not positively correlated - changes in health disability are not the primary drivers of changes in spells of disability benefit receipt over the cycle. Second, the observed correlation between overall self-reported health and unemployment rates may indeed by some form of reporting bias or justification bias, insofar as the correlation of the risk of unemployment with individual specific (physical) health conditions is more likely to be negative. This provides strong support for the idea that other factors, most notably explicit or implicit changes in the rules by which disability benefit eligibility is determined over the business cycle, must be the primary driver of the relationship between disability benefit receipt and the unemployment rate.

We conclude with a tentative discussion of the policy issues that arise from these findings. Two broad conclusions stand out. First, the disability insurance regime must be based on a clear 
understanding of the differing character of work and health disability. For example, tight (or tightening of) screening of new applicants for benefits on the presumption that disability, once accepted, will be of long duration, will not handle the potential cyclicality of the underlying demand for disability benefits. Second, disincentives to return to work may be considerable for benefit recipients if health and work disability are confused. Considerations could be given to paying some health-related disability benefits independent of work status, for example, or to consider more carefully an 'availability of work' test rather than simple tests based on 'health-work capacity'.

\section{Prevalence of disability across European countries}

In this section we explore the relationship between receipt of disability benefits (DB) and the business cycle, proxied by the unemployment rate, across the European Union using data from various sources. We commence by looking at the relationship between receipt of disability benefits and local unemployment rates, using unbalanced panels derived from the European Community Household Panel (ECHP), and the Survey of Income and Living Conditions (SILC). Later we look at various national surveys and subsequently examine the relationship between self-reported disability in general, and local economic conditions, using the 2002 Labour Force Survey Special module on disability.

Before moving to the detailed analysis, we present in Table 1 some statistics to show the importance of the Disability Insurance (DB) programme in relation to expenditure on social protection (SPE) and other programmes (Old Age and Health Care) for the EU 27 countries. Social protection expenditure as a \% of GDP varies from 32.0 in Sweden to 12.4 in Latvia. The fraction of SPE devoted to Disability also varies a great deal across EU countries: from 4.8 percent of the GDP in Sweden to 1.3 per cent in the U.S. and 0.7 percent in Cyprus. These variations reflect a combination of variations in underlying programme generosity (such as replacement rates and maximum durations) and in how easy it is to access these particular benefits. 
Table 1: Expenditure on social protection (as \% of GDP). 2005.

\begin{tabular}{|l|c|c|c|c|}
\hline & $\begin{array}{c}\text { Social } \\
\text { protection } \\
\text { expenditure } \\
\text { as \% of GDP }\end{array}$ & $\begin{array}{c}\text { Old-age and } \\
\text { survivors } \\
\text { expenditure } \\
\text { as \% of GDP }\end{array}$ & $\begin{array}{c}\text { Sickness/ } \\
\text { Health } \\
\text { Care } \\
\text { expenditure } \\
\text { as \% of GDP }\end{array}$ & $\begin{array}{c}\text { Disability } \\
\text { benefit } \\
\text { expenditure } \\
\text { as \% of GDP }\end{array}$ \\
\hline EU 27 & 2005 & 2005 & 2005 & 2005 \\
Belgium & $\mathbf{2 7 . 2}$ & $\mathbf{1 2 . 0}$ & $\mathbf{7 . 5}$ & $\mathbf{2 . 1}$ \\
Bulgaria & 29.7 & 12.7 & 7.7 & 2.0 \\
Czech Rep & 16.1 & 7.9 & 4.5 & 1.3 \\
Denmark & 19.1 & 7.9 & 6.5 & 1.4 \\
Germany & 30.1 & 11.0 & 6.1 & 4.2 \\
Estonia & 29.4 & 12.4 & 7.8 & 2.2 \\
Ireland & 12.5 & 5.4 & 3.9 & 1.2 \\
Greece & 18.2 & 4.5 & 6.9 & 0.9 \\
Spain & 24.2 & 12.0 & 6.5 & 1.2 \\
France & 20.8 & 8.4 & 6.4 & 1.5 \\
Italy & 31.5 & 13.0 & 8.8 & 1.8 \\
Cyprus & 26.4 & 15.5 & 6.8 & 1.5 \\
Latvia & 18.2 & 8.3 & 4.5 & 0.7 \\
Lithuania & 12.4 & 5.7 & 3.1 & 1.1 \\
Luxemburg & 13.2 & 6.0 & 3.9 & 1.3 \\
Hungary & 21.9 & 7.9 & 5.5 & 2.8 \\
Malta & 21.9 & 9.1 & 6.4 & 2.1 \\
Netherlands & 18.3 & 9.5 & 4.8 & 1.2 \\
Austria & 28.2 & 11.1 & 8.1 & 2.6 \\
Poland & 28.8 & 13.5 & 7.1 & 2.2 \\
Portugal & 19.6 & 11.5 & 3.8 & 2.0 \\
Romania & $24.7(a)$ & 10.9 & 7.0 & 2.4 \\
Slovenia & 14.2 & 5.7 & 5.0 & 1.0 \\
Slovakia & 23.4 & 10.2 & 7.4 & 2.0 \\
Finland & 16.9 & 7.0 & 4.8 & 1.5 \\
Sweden & 26.7 & 9.6 & 6.7 & 3.4 \\
United Kingdom & 32.0 & 12.5 & 7.5 & 4.8 \\
\hline United States & 26.8 & 11.8 & 8.1 & 2.4 \\
\hline
\end{tabular}

Source: eurostat 2008. Note: (a) data corresponds to 2004. 
Receipt of disability benefits and local unemployment conditions

We now examine the relationship between receipt of disability benefits and local unemployment conditions. We start with European cross-country household panels before moving on to examine specific economies. The general regression specification is of the following type:

$D B$ measure $_{i, t}=\alpha+\beta^{*}$ u-rate $_{r, t}+\gamma^{*}$ controls $_{i, r, t}+\varepsilon_{i t}$

where, using the various disability benefit (DB) measures (DB inflow, DB outflow, DB stock), we focus on the probability that individual $i$ at time $t$ living in region $r$ moves into/exits/remains in receipt of disability benefit. Our primary interest is in $\beta^{*}$ above, namely the impact of the local (or regional) unemployment rate (u-rate) on the observed individual disability benefit state or state transition. The basic controls (depending on the specification) are individual controls for age and gender, country dummies and time dummies.

The reasoning behind these specifications is straightforward: they test using disaggregated spatial data whether, controlling for personal characteristics, there is a relationship between DB probability of DB receipt and the local unemployment rate. Our hypothesis is that the stock of DB recipients will be higher, the higher the local unemployment rate, and that this will arise either because the inflow rate into DB receipt is higher in such circumstances, or because the outflow rate is lower, or some combination thereof.

By using cross-country data sets such as the European Community Household Panel (ECHP) and the Survey of Income and Living Conditions (SILC) in a common regression framework, we are imposing the assumption that the response of DB receipt to economic conditions is common across countries. This is obviously a very strong an assumption given the variety of institutional frameworks that are encountered. Indeed, these institutional conditions may also induce different trends in within-country DB rates over time. Therefore, we argue, by including country dummies (and possibly time trends), we control for these differences in institutional factors, leaving the calculated $\beta$ s to capture variations in local demand conditions - the primary purpose here is not to explain these idiosyncratic or country-specific differences themselves. The basic contention arising from this methodology therefore is that, if, for example, Bavaria is a better-than-average performing region in Germany whereas the North of England is a worse-than-performing region in the UK, we should observe a residual difference in DB claiming rates between these regions once we net out institutional factors that may influence the level of DB claims in Germany relative to the UK. However, to the extent that differential levels and trends in unemployment across countries also contain aggregate demand shocks specific to those countries, our method will not capture fully these demand effects. 
Table 2 reports the coefficients (in bold where significant) of the impact on the probability of DB receipt/inflow/outflow of the regional u-rate ( $\beta$ in the above equation) for various econometric specifications. We illustrate the results for two versions of our data; one is simply using the ECHP panel from 1994 to 2001; the second set of results pools the ECHP with the subsequent SILC panel. Some descriptive statistics for the data sets are contained in the statistical appendix (in particular, of the individual countries comprising each data set), and results on the SILC panel on its own are available on request.

The table suggests that the results are sensitive to the controls that are included in the regression estimates. If we simply include controls for personal characteristics (gender and age), the ECHP results (not shown) suggest a significant and positive relationship between the probability of disability benefit (DB) receipt and the local unemployment rate. The relationship is just significant at the $5 \%$ level with no other controls, but becomes highly robust if we include year and/or country dummies, as illustrated in the table. Once we pool the ECHP with the SILC, the result is 'incorrectly' signed (by our prior hypothesis) unless we include country and time dummies (the SILC contains a different set of countries - see the Statistical Appendix). Nevertheless, these results in broad terms confirm the anticipated positive relationship between DB claims and local unemployment rates across a wide range of countries. The average 'elasticity' of DB claims to the local unemployment rate is $0.16-0.17$ across these countries - a doubling of the unemployment rate is therefore associated with $16-17 \%$ more claimants to disability benefits.

Does this relationship arise because inflow rates into DB are higher when local unemployment rates are higher, or because outflow rates are lower? Subsequent rows of Table 2 test these propositions. Here there are mixed results, depending on the controls used. In specifications without country dummies (not shown here), inflow rates appear to be lower when local unemployment rates are higher whereas when we control for country effects, as in Table 2, the coefficient reverses and we get the 'correct' sign. In both panels we get the predicted negative sign for outflows although it is much stronger when we allow for time as well as country effects. We should reiterate that the pooled regressions are imposing the strong assumption that responses of DB claims to local economic conditions are constant across countries and time. Nevertheless the results suggest, especially when country dummies and a common time trend are incorporated, that inflow rates and, especially, outflow rates behave as might be expected. 
Table 2: Pooled panel estimates of Disability Benefit receipt (DB) and unemployment rates

\begin{tabular}{|c|c|c|}
\hline \multicolumn{3}{|c|}{ 1. ECHP (1994-2001) } \\
\hline Dependent Variable & country dummies & year \& country dummies \\
\hline DB Stock & $0.0017 * * *$ & $0.0017 * * *$ \\
\hline $\mathrm{d}(\ln y) / \mathrm{d}(\ln x)$ & 0.1688 & 0.1645 \\
\hline$p$-value & 0.000 & 0.000 \\
\hline $\mathrm{N}$ & 620,952 & 620,952 \\
\hline$R^{2}$ & 0.10 & 0.11 \\
\hline DB Inflow & -0.0003 & 0.0001 \\
\hline$d(\ln y) / d(\ln x)$ & - & - \\
\hline$p$-value & 0.270 & 0.184 \\
\hline N & 419,943 & 419,943 \\
\hline $\mathrm{R}^{2}$ & 0.03 & 0.03 \\
\hline DB Outflow & $-0.0014^{*}$ & $-0.0025 * * *$ \\
\hline$d(\ln y) / d(\ln x)$ & -0.0403 & -0.0704 \\
\hline$p$-value & 0.067 & 0.001 \\
\hline $\mathrm{N}$ & 38,090 & 38,090 \\
\hline $\mathrm{R}^{2}$ & 0.15 & 0.15 \\
\hline \multicolumn{3}{|c|}{ 2. ECHP (1994-2001) pooled with SILC (2004-2006) } \\
\hline Dependent Variable & $\begin{array}{l}+ \text { country } \\
\text { dummies }\end{array}$ & + year \& country \\
\hline DB Stock & $0.0020 * * *$ & $0.0019 * * *$ \\
\hline$d(\operatorname{lny}) / d(\ln x)$ & 0.1695 & 0.1610 \\
\hline$p$-value & 0.000 & 0.000 \\
\hline $\mathrm{N}$ & 977,393 & 977,393 \\
\hline $\mathrm{R}^{2}$ & 0.09 & 0.10 \\
\hline DB Inflow & -0.0001 & 0.00001 \\
\hline$d(\operatorname{lny}) / d(\ln x)$ & - & - \\
\hline$p$-value & 0.232 & 0.414 \\
\hline $\mathrm{N}$ & 578,391 & 578,391 \\
\hline $\mathrm{R}^{2}$ & 0.03 & 0.03 \\
\hline DB Outflow & -0.0027 & $-0.0031 * *$ \\
\hline$d(\operatorname{lny}) / d(\ln x)$ & - & -0.0862 \\
\hline$p$-value & 0.600 & 0.049 \\
\hline$n$ & 61,964 & 61,964 \\
\hline $\mathrm{R}^{2}$ & 0.06 & 0.07 \\
\hline
\end{tabular}

Notes: All regressions control for age and gender of the respondent. Coefficients are OLS coefficients; similar results are obtained deriving marginal effects from probit maximum likelihood [available on request]. Standard errors are clustered by region. Below significant coefficients, corresponding elasticities are reported. ${ }^{*} \mathrm{p}$-value $<0.1, * * \mathrm{p}$-value $<0.05,{ }^{* * *} \mathrm{p}$ value $<0.001$.

Countries in the ECHP panel (see Appendix) are: Austria, Belgium, Denmark, Finland, France, Germany, Greece, Ireland, Italy, Luxemburg, the Netherlands, Portugal, Spain, Sweden and the United Kingdom.

Countries in the SILC panel are (see Appendix): Austria, Belgium, Cyprus, Czech Republic, Estonia, France, Germany, Greece, Ireland, Italy, Latvia, Luxemburg, Poland, Spain, Sweden and the United Kingdom. 
The regressions in Table 2 impose the assumption that the relationship between DB benefit claimants and the unemployment rate is the same across all countries. This is of course unlikely. We therefore re-estimate the relationship allowing for variation in the estimated $\beta$ s across countries. This also constitutes a test of how robust is the relationship, while allowing for variations in institutional regimes across countries. Formally, we write:

$$
\text { DB measure }{ }_{i, t}=\alpha+\sum_{c=1-21}\left[\beta_{c}^{*}\left(u-r^{2} e_{r, c, t} * \text { country }_{c}\right)\right]+\gamma^{*} \text { controls }_{i, r, t}+\varepsilon_{i t}
$$

with:

- DB measures: DB stock / DB inflow / DB outflow

- subscripts: $\mathrm{i}$ for individual, $\mathrm{t}$ for time, $\mathrm{r}$ for region, $\mathrm{c}$ for country where individual $\mathrm{i}$ lives

- country ${ }_{c}: 21$ country dummies

- controls: age, gender and time dummies

Detailed results of this exercise are contained in the Statistical Appendix in Table B2 in a specification which includes year dummies (and so is closest in spirit to the last column of Table 2), illustrating only the pooled ECHP-SILC results for convenience. The results, not surprisingly, give a variety of coefficient estimates across countries. For the relationship of the unemployment rate to the stock of claimants, the results are significant in all 21 countries, and correctly (i.e. positively) signed in 18 of them - in Cyprus, Greece and Germany we cannot find evidence in the data for the assumed positive relationship (but see the case study of Germany using German panel data in the next section of the paper). Coefficients vary but there are particularly strong relationships between stocks of claimants and unemployment rates in some transition economies, and also in Sweden.

Looking at inflow rates, as before the relationship (which is predicted to be positive) is less clear-cut. We observe the predicted relationship in 11 of the 21 countries, whereas 8 countries have a significant opposite sign between inflows and the unemployment rate. For outflow rates, where we predict a negative association with spatial unemployment rates, we get the 'correct' and the 'wrong' sign in 9 countries each. A caveat is that we are dealing with relatively small sample sizes in some countries (since the base is that the individual concerned was in receipt of DB benefits at $t-1$ ) and the underlying relationships are probably more robust than illustrated here. In fact in the regressions using just the ECHP on the original EU countries (as in the first panel of Table 2), we get a much clearer prediction on outflows, with 11 of the countries report a significant negative relationship between outflows and the unemployment rate, with 3 positive signs and 1 insignificant (these results are available on request). 


\section{Results for individual countries}

Germany

Descriptive evidence

As with the other countries in our sample, a brief description of the German disability insurance programme is contained in Appendix A. As described there, until 2001, the presumption of the programme was that the majority of claimants who entered the disability insurance programme would remain there until retirement. Thus, for some of the data, we focus only on stocks and inflows. In addition, unification implies a change in the size of the measured aggregate stock of claimants and in the aggregated rates across the ex-West German and East German administrative regions. We can however differentiate the regions and provide separate data for 'West Germany' (1970-2007) and 'East Germany' (1993-2007) using data from the German Pension Fund (Deutsche Rentenversicherung).

Examination of the trends in the data show that unemployment in the ex-West German administrative regions rose slowly through much of the period with distinct cyclical peaks in the middle of each decade. The stock of disability benefit claimants also rose through the 1970s and most of the 1980s, thereafter declining, with a sharp fall in inflows in the mid-1980s. In the ex-East German administrative region, both unemployment rates and disability claims remained higher than those in the ex-West German regions from the early 1990s onwards. In what follows, we also see how, post-unification, unemployment in the ex-West Germany also affected disability claims in the ex-East German regions.

In Table 3 we formally study these relationships using German administrative data. Including a trend, the unemployment rate in the ex-West German administrative regions greatly influences the stock but not the inflow. The East German unemployment rate influences positively the stock and negatively (but insignificantly) the inflow. As complementary evidence, we present in the last two columns evidence including the West German unemployment rate in the East German regressions. Although this evidence has to be taken with caution, it is interesting to observe the strong positive reaction of the East German disability benefit inflow rate to the West German unemployment rate. It may be that, as the expected jobs in ex-West Germany post-reunification failed to materialise, an increasing number of the labour force in the ex-East German administrative regions took refuge in the disability benefit programme. 
Table 3:

Time Series Regression of Germany's official DB stock and DB Inflow in ex-East and West Germany

\begin{tabular}{|c|c|c|c|c|c|c|}
\hline \multicolumn{7}{|c|}{ Relation of unemployment rates to DB stocks and inflows } \\
\hline & \multicolumn{2}{|c|}{ West Germany regions } & \multicolumn{4}{|c|}{ East Germany regions } \\
\hline & Stock & Inflow & Stock & Inflow & Stock & Inflow \\
\hline West u-rate & $0.51 * *$ & 0.02 & & & 0.17 & $0.07 * *$ \\
\hline t-stat & 6.49 & 1.53 & & & 1.09 & 3.43 \\
\hline East u-rate & & & $0.28 *$ & -0.01 & 0.20 & $-0.03^{*}$ \\
\hline t-stat & & & 2.61 & -0.60 & 1.63 & -2.40 \\
\hline Trend & $-0.25 * *$ & $-0.03 * *$ & $-0.09 *$ & $-0.03 * *$ & -0.08 & $-0.02 * *$ \\
\hline t-stat & -11.67 & -10.06 & -2.03 & -4.11 & -1.84 & -4.60 \\
\hline Constant & $8.04 * *$ & $1.41 * *$ & $3.48 *$ & $1.67 * *$ & $3.02 *$ & $1.30 * *$ \\
\hline t-stat & 23.75 & 28.31 & 2.68 & 6.99 & 2.22 & 6.38 \\
\hline$n$ & 37 & 38 & 16 & 15 & 16 & 15 \\
\hline $\mathrm{R}^{2}$ & 0.83 & 0.88 & 0.35 & 0.75 & 0.40 & 0.88 \\
\hline $\mathrm{F}$ & 84.02 & 126.35 & 3.42 & 18.41 & 2.71 & 27.23 \\
\hline
\end{tabular}

Source: Administrative data from German Pension Fund 1970-200. Note: * p-value<0.05, ** p-value<0.01.

\section{Evidence from the German Socio-Economic Panel}

For Germany, we also utilise the German Socio-Economic Panel (GSOEP) for the years in which disability questions are available. These years are 1984-89, 1991-92 and 1994-2007, with 16 regions identified. There are 376,581 person-observations available over the period of which just under 350,000 can be utilised in the analysis. (For the inflows and outflows, of course, the sample size is smaller because the initial observations are state dependent). There is no variable directly indicating receipt of disability benefits in the GSOEP, but for the self-reported variable "disabled", respondents are invited to indicate a disability degree/score of $\geq 30 / 100$. In Germany people with a disability degree $\geq 30 / 100$ can apply for disability benefit so we use the answer disabled=1 as a proxy for $\mathrm{DB}=1$. Note that by excluding entrants to disability benefits who initially report spells of sickness or temporary incapacity, we may not be picking up short-term fluctuations in inflow rates arising from local labour market conditions.

Following the specification described in the previous section, we estimate regressions for self-reported disability score incidence in relation to unemployment and basic controls for Germany using the GSOEP. The results are presented in Table 4. 
Table 4:

Panel estimates of disability and local unemployment rates in Germany using GSOEP, 1984-2007

Estimates of $\beta$-coefficient on local unemployment rate

\begin{tabular}{|c|c|c|c|}
\hline Dependent Variable & + sex, age, east & + year dummies & + year \& state dummies \\
\hline DB Stock & $0.0018 * * *$ & $0.0033 * * *$ & $0.0027 * *$ \\
\hline$d(\ln y) / d(\ln x)$ & 0.1386 & 0.2595 & 0.2108 \\
\hline $\mathrm{p}$-value & 0.000 & 0.000 & 0.002 \\
\hline $\mathrm{N}$ & 239,340 & 239,340 & 239,340 \\
\hline $\mathrm{R}^{2}$ & 0.25 & 0.25 & 0.25 \\
\hline $\begin{array}{l}\text { DB Inflow } \\
\qquad d(\ln v) / d(\ln x)\end{array}$ & -0.0001 & 0.0001 & -0.0002 \\
\hline$d(\ln y) / d(\ln x)$ & 0.636 & 0.709 & 0.818 \\
\hline $\mathrm{N}$ & 156,583 & 156,583 & 156,583 \\
\hline $\mathrm{R}^{2}$ & 0.00 & 0.00 & 0.00 \\
\hline DB Outflow & $-0.0045^{* * *}$ & $-0.0037 * * *$ & $-0.0048 * *$ \\
\hline$d(\ln y) / d(\ln x)$ & -0.4525 & -0.3992 & -0.4842 \\
\hline$p$-value & 0.000 & 0.000 & 0.019 \\
\hline $\mathrm{N}$ & 25,656 & 25,656 & 25,656 \\
\hline $\mathrm{R}^{2}$ & 0.004 & 0.004 & 0.004 \\
\hline
\end{tabular}

Notes: Standard errors are clustered by federal states. Elasticities are calculated for significant coefficients in the form of $\mathrm{d}(\operatorname{lny}) / \mathrm{d}(\operatorname{Inx}) .{ }^{*} \mathrm{p}$-value $<0.1,{ }^{* *} \mathrm{p}$-value $<0.05,{ }^{* * *} \mathrm{p}$-value $<0.001$.

The results indicate a positive relationship between the stock of individuals with the given level of disability and the local and time-specific unemployment rate; the coefficient almost doubles when time dummies are added and is now significantly higher than the average effect in Table 2 (with a correspondingly higher elasticity). The coefficients on inflow rates are generally insignificant. It is however of interest to note the robust negative relationship between the outflow rate and the unemployment rate, again with a considerably larger elasticity than in the cross-country analysis, and this despite the fact, described previously, that for much of the period, disability benefit claims were treated as an 'absorbing state'. The key caveat is to mention again that these results focus on self-reported disability that is eligible for a DB claim; we do not know whether the individual in the GSOEP receives the benefit or not. We return to the issue of self-reported disability in later sections of the paper. 
Spain

For Spain, the analysis uses administrative data on eligibility for retirement pensions on the grounds of disability. As described more fully in the Appendix, permanent disability pensions have played an important role in allowing Spanish workers to retire at ages earlier than 60 (the early retirement age in Spain). In particular, they were used extensively during the late 1970s and early 1980s as an early-retirement mechanism for workers in restructured industries (shipbuilding, steel, mining, etc.), or as substitutes for long-term unemployment subsidies in depressed regions, although eligibility was tightened in 1985 . For contributory disability pensions (which are the focus here), eligibility and pension amounts depend on the level of disability. The 1985 reform distinguished four levels of permanent disability characterized by increasing severity. Since then, the legislation has formally reduced them to three, but has also created a special case at the first level to use the disability fund to subsidise the severance of older workers from specific sectors or regions.

Unemployment has been high in Spain by European standards, but was reduced after the mid-1980s with the exception of a sharp dip in growth in 1992. The ratio of new disability claims to GDP growth has therefore fallen since the mid-1980s; a fall heightened by a sharp reduction in new disability claims after the 1985 reform, which brought to an end a period of rising claims relative to GDP. The ratio of new disability claims to retirement pension claims, which is also an important indicator as described above, has tended to remain constant at around $40 \%$ since the late-1980s.

Table 5, Panels A and B utilise regression analysis on administrative data disaggregated by Spanish region. The regressions relate the ratio of new disability pensions to the employment rate by region to regional GDP growth and to the regional unemployment rate over the period 19922008. We can therefore think of these as 'inflow' regressions. The panels differentiate between all claimants and those aged 45-64, although the results are in fact very similar. As expected, the ratio of disability retirements relative to employment is positively related to the local unemployment rate and negatively related to the national GDP growth rate. The coefficient estimates in Panel A for 'all ages' are comparable to those from the cross-country estimates for the stock measures (though considerably more robust than earlier estimates on 'inflow effects'); however, the estimates for those 'aged 45 to 64 ' are considerably higher than those earlier estimates. All these results stem from the institutional regime described earlier whereby the Spanish disability programme has explicitly functioned as a form of early retirement programme. 
Table 5: New disability retirement pension to employment, GDP growth and regional unemployment rates, Spanish administrative data 1992-2008

Panel A: All ages

\begin{tabular}{|l|c|c|c|}
\hline Variable & $(1)$ & $(2)$ & $(3)$ \\
\hline \% growth of regional & $-\mathbf{0 . 0 6 7 * *}$ & & -0.024 \\
GDP & $(-5.94)$ & - & $(-1.26)$ \\
d(Iny)/d(Inx) & -0.7074 & & -0.2481 \\
\hline \% regional & & $\mathbf{0 . 0 2 7 ^ { * * }}$ & $\mathbf{0 . 0 2 0 ^ { * * }}$ \\
unemployment rate & - & $(6.56)$ & $(2.89)$ \\
$\mathrm{d}($ Iny)/d(Inx) & & 0.3500 & 0.2594 \\
\hline Constant & $\mathbf{0 . 0 2 * *}$ & $\mathbf{0 . 0 7 3 * *}$ & $\mathbf{0 . 0 1 1 ^ { * * }}$ \\
& $(16.78)$ & $(11.38)$ & $(3.59)$ \\
\hline $\mathrm{N}$ & 272 & 272 & 272 \\
\hline $\mathrm{R}^{2}$ & 0.1220 & 0.1477 & 0.1501 \\
\hline $\mathrm{F}$ & 35.28 & 43.00 & 22.34 \\
\hline
\end{tabular}

Panel B: Ages 45 to 64

\begin{tabular}{|l|c|c|c|}
\hline Variable & $(1)$ & $(2)$ & $(3)$ \\
\hline \% growth of regional & $-\mathbf{0 . 0 0 2 * *}$ & & $-\mathbf{0 . 0 8 4 ^ { * }}$ \\
GDP & $(-6.83)$ & - & $(-1.77)$ \\
$\mathrm{d}(\operatorname{Iny}) / \mathrm{d}(\operatorname{Inx})$ & -0.6697 & & -0.2880 \\
\hline \% regional & & $\mathbf{0 . 0 7 8 * *}$ & $\mathbf{0 . 0 5 2 ^ { * * }}$ \\
unemployment rate & - & $(7.28)$ & $(2.92)$ \\
$\mathrm{d}(\operatorname{Iny}) / \mathrm{d}(\operatorname{Inx})$ & & 0.3207 & 0.2155 \\
\hline Constant & $\mathbf{0 . 0 6 * *}$ & $\mathbf{0 . 0 2 4 * *}$ & $\mathbf{0 . 0 3 8 ^ { * * }}$ \\
& $(16.78)$ & $(14.40)$ & $(4.73)$ \\
\hline $\mathrm{N}$ & 272 & 272 & 272 \\
\hline $\mathrm{R}^{2}$ & 0.1551 & 0.1725 & 0.1826 \\
\hline $\mathrm{F}$ & 46.61 & 52.95 & 28.27 \\
\hline
\end{tabular}

Notes: Regressions utilise data from administrative data from Spanish regions. ${ }^{*} p$-value $<0.05,{ }^{*} p$ value $<0.001$.

\section{The United Kingdom}

The United Kingdom has experienced a rising trend in claimants for long-term contributory disability benefits (known as 'Invalidity Benefits (IVB)' and, after 1995, 'Incapacity Benefits (ICB)') since the 1970s. The early 1980s in the UK were associated with several administrative reforms, described in more detail in the Appendix, designed to pass onto employers the costs of administering the 'gateways' into short-term sickness spells (IVB/ICB is only available after the claimant has been sick and out of work for at least six 28 weeks). These changes, and growing unemployment in the early 1980s, may have contributed to the growth of claimants although the upward trend continued despite the rapid fall in unemployment in the late 1980s. The 1995 reform 
phased out all claims to disability benefits over state pension age and removed the exemption of disability benefits from income tax liability that had made retirement on IVB more attractive than retirement on the basic state retirement pension. This reform stabilised numbers, but growing eligibility among women, a shift towards older claimants of working age and lengthening durations have meant that later reforms have not reversed the earlier rise in claimant numbers.

The importance of the time trend in claimant numbers at the aggregate level in the UK can be illustrated by running regressions on regional data of the number of DB claims as a fraction of the regional workforce, relative to the regional unemployment rate. Table 6 shows the results of a simple panel regression of DB benefit claims in the 11 regions of Great Britain (excluding Northern Ireland) over time on the regional unemployment rate. When an aggregate time trend is excluded, there is a significant but small positive relationship between DB claims and regional unemployment rates. Inclusion of an aggregate time trend strengthens the result considerably. However, inclusion of fixed effects for regions reverses the sign, suggesting that it is the inter-regional variation in unemployment rates across regions, rather than the aggregate trend in unemployment, that gives the positive relationship between the rate of disability benefit claims and the unemployment rate.

Table 6: DB claims and regional unemployment rates, UK 1980-2008

\begin{tabular}{|c|c|c|c|}
\hline \multirow{2}{*}{$\begin{array}{l}\text { Dependent variable: } \\
\text { DB claims as \% of } \\
\text { regional workforce }\end{array}$} & \multicolumn{2}{|c|}{ Time trend } & \multirow{2}{*}{$\begin{array}{l}\text { Fixed region } \\
\text { effects }\end{array}$} \\
\hline & No & Yes & \\
\hline $\begin{array}{l}\text { Coeff. on regional } \\
\text { unemployment rate }\end{array}$ & $\begin{array}{l}\mathbf{0 . 1 7 *} \\
(0.08)\end{array}$ & $\begin{array}{l}0.76 * * \\
(0.08)\end{array}$ & $\begin{array}{l}-0.40 * * \\
(0.05)\end{array}$ \\
\hline $\mathrm{N}$ & 319 & 319 & 319 \\
\hline $\mathrm{R}^{2}$ & 0.014 & 0.3489 & 0.6075 \\
\hline $\mathrm{F}$ or $\chi^{2}$ & 4.60 & 84.66 & 68.82 \\
\hline
\end{tabular}

Note: From administrative data. Standard errors in brackets ${ }^{* *} p$-value $<0.001$ and ${ }^{*} p$ value $<0.005$

The analysis can be extended by using the British Household Panel Survey (BHPS) to analyse self-reported claimants of disability benefits (DB), and transitions between waves on and off disability benefits. A transition into DB is defined as an individual who reported being in receipt of DB at time $t$ having not so reported at time $t-1$, and an exit from DB is thereby defined consistently. The stock of claimants and the transitions are then regressed on local unemployment rates for the 65 counties of England, Scotland and Wales in which respondents are located. A vector of control variables comprise personal characteristics including age of respondent, gender, marital status, age of children, occupation controls, education and spouse's labour market status. Table 7 contains the key coefficients, namely the $\beta$ s on the county-level unemployment rates. 
Table 7:

Disability benefit claims and county-level unemployment rates in the UK: BHPS 1991-2006

\begin{tabular}{|c|c|c|c|c|c|c|}
\hline $\begin{array}{l}\text { Dependent variable: } \\
\text { Coefficient on } \\
\text { county-level }\end{array}$ & & $\begin{array}{l}\text { Year } \\
\text { dummies } \\
=\text { no }\end{array}$ & & & $\begin{array}{c}\text { Year } \\
\text { dummies } \\
=\text { yes }\end{array}$ & \\
\hline & DB stock & DB inflow & $\begin{array}{c}\text { DB } \\
\text { outflow }\end{array}$ & DB stock & DB inflow & $\begin{array}{c}\text { DB } \\
\text { outflow }\end{array}$ \\
\hline $\begin{array}{l}\text { Coeff. } \\
\text { (s.e.) }\end{array}$ & $\begin{array}{c}0.02 \\
(0.05)\end{array}$ & $\begin{array}{c}0.0002 \\
(0.0006)\end{array}$ & $\begin{array}{c}-0.05^{* *} \\
(0.01)\end{array}$ & $\begin{array}{c}\mathbf{0 . 0 9} * * \\
(0.01)\end{array}$ & $\begin{array}{c}0.05^{* *} \\
(0.01)\end{array}$ & $\begin{array}{c}-0.04^{* *} \\
(0.001)\end{array}$ \\
\hline$d(\ln y) / d(\ln x)$ & 0.16 & - & 0.11 & 0.22 & 0.17 & 0.12 \\
\hline $\mathrm{N}$ & 56886 & 54451 & 2783 & 56886 & 54451 & 2783 \\
\hline
\end{tabular}

Note: Covariates as described in text. ${ }^{* *} p$-value $<0.001$

When the regressions are estimated without year dummies, the DB stock and inflow rates are positively related to the county-level unemployment rate, as expected, but the results are not significant. However the outflow rate from disability benefits is negatively related to the local unemployment rate, and the coefficient is highly significant even without year dummies. When year dummies are also included, all three coefficients are highly significant and correctly signed. The results for Great Britain therefore provide strong support for the proposition that spatial variations in unemployment rates have the predicted signs on DB claim rates, as well as DB inflow and outflow rates but, as with the cross-country results, some of the trends in claimant rates over time at the aggregate level cannot be fully explained by business cycle fluctuations alone. Here, the most robust 'unemployment effect' is on outflow rates rather than inflow rates - higher unemployment, whether across locality or over time, is associated with falling outflow rates and lengthening durations (for further discussion, see Anyadike-Danes and McVicar, 2008) .

\section{The United States}

The growth in both United States (US) disability programs is well documented (see the appendix for a description of the key US programs, the SSDI and SSI). The financial challenges that this represents are discussed at length in every report that the United States Social Security Administration (US SSA) publishes. On top of the increasing burden of the cash benefits paid to beneficiaries, the main concern is the growing health care costs attached to these programs, with the growth of Medicare and Medicaid expected to represent more than $10 \%$ of GDP in the next decades. 
While the increasing cost of a growing stock of beneficiaries should not come as a great surprise given the demographic trends, and in particular the growth in life expectancy in the United States, the inflow of applicants and awardees to the programs is also on the rise, with each program handling around 2 million applications every year, when only a decade ago the number of applicants was around the one million mark. We show these trends in Figure 1. At the same time, between 1997 and 2007, whilst the number of awardees increased by $21.5 \%$ and $39.2 \%$ in the SSI and SSDI programs respectively, there was a decreasing award rate in both programs as can be seen in Figure 2. Figure 2 also includes the national unemployment rate in each year, and we can see that, at least in the late 1970s, mid 80s and early 90s, a fairly clear business cycle effect with award rates increasing with the unemployment rate. In other eras, the relationship is not apparent, such as the early 1980s, when the programme faced severe cutbacks from the Reagan administration, and from the mid-90s onwards.

Figure 1:

Number of Applicants by year to the SSI and SSDI programs in the U.S.

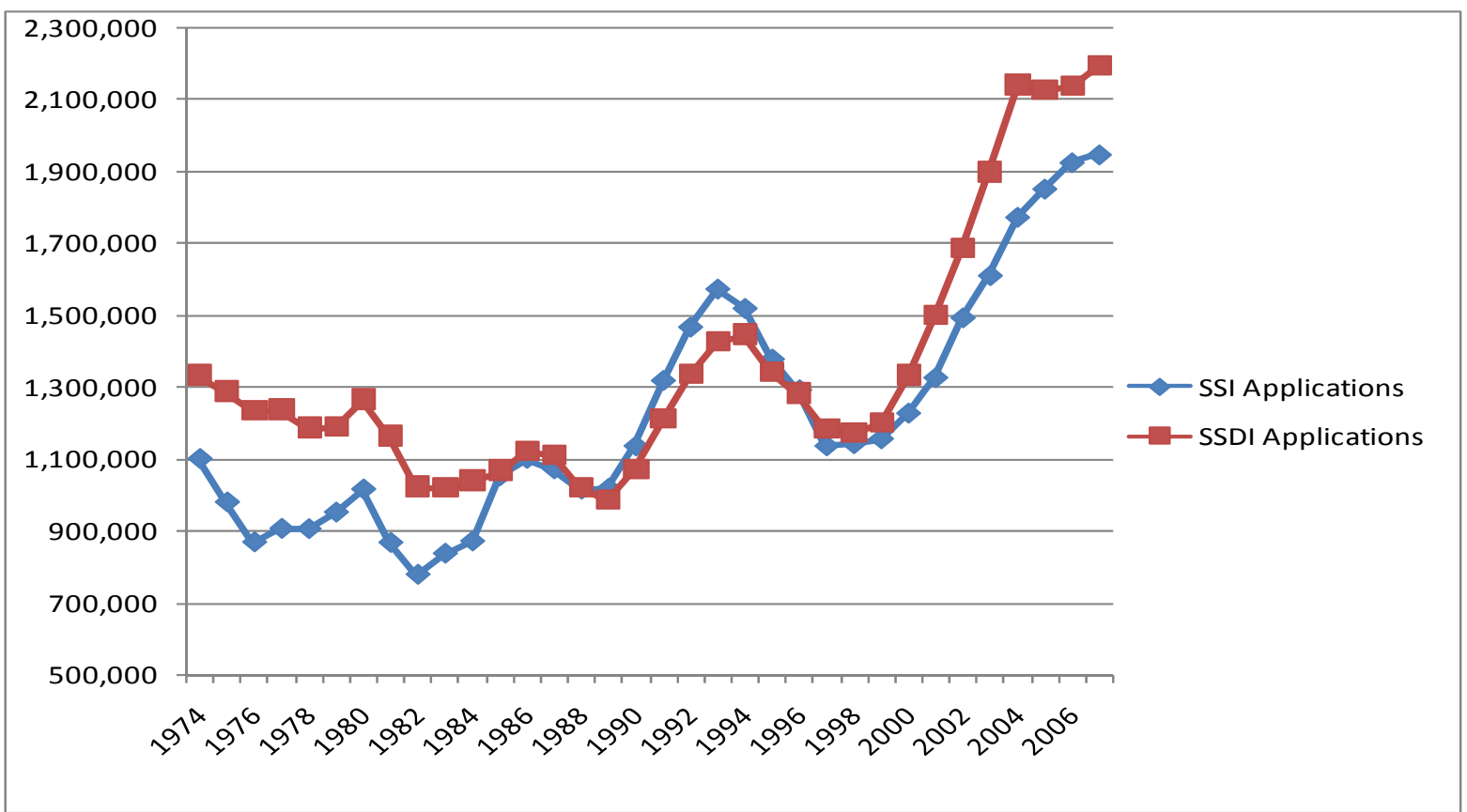

Source: http://www.ssa.gov 
Figure 2:

Award Rates of the SSI and SSDI programs and unemployment in the United States

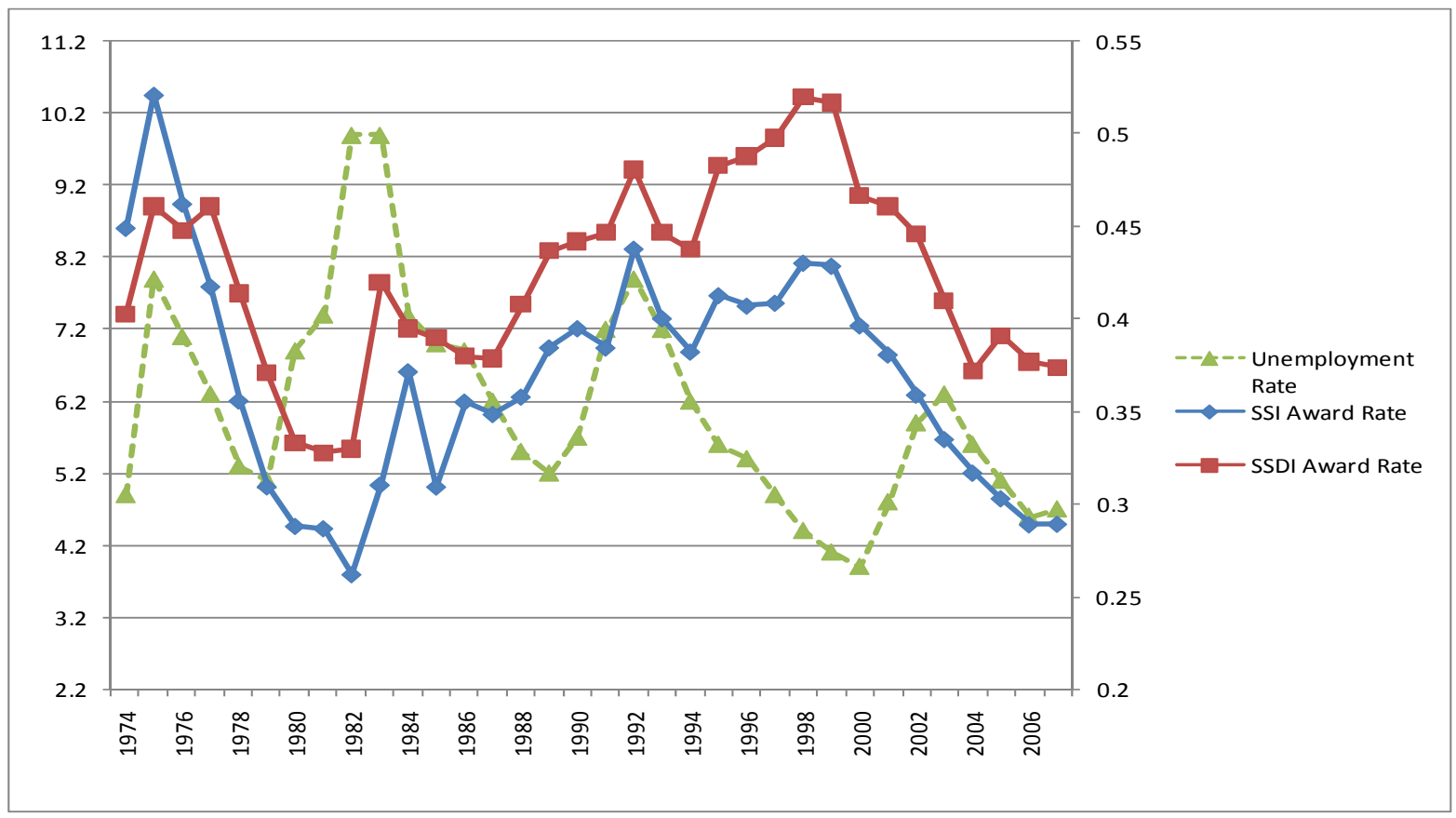

Source: $h t t p: / / w w w . s s a . g o v$

At the same time as the rise in new awards, outflow rates from the programs have been relatively small and decreasing as a function of the covered population and the number of individuals on the rolls, in spite of the efforts of the government to foster work among beneficiaries. In the last few years the Social Security Administration (SSA) has considered a number of policy changes with the objective of fostering work among SSDI recipients. This has become an important priority in the government's agenda regarding disability policy. For example, Jo Anne B. Barnhart, former Commissioner of the SSA, stated in 2003 that expanding the employment opportunities for people with disabilities was one of the main objectives of her administration. Furthermore, in the Social Security $2003-2008$ strategic plan, she also set as an objective to have an increase of $50 \%$ in the number of people with disabilities who achieve employment, by 2008 relative to the 2001 levels.

In Table 8, and in similar vein to our analysis of European countries, aggregate administrative data are used to analyze the business cycle effect on the stock, the inflow, and outflow to the US Disability Program. We use here data published by the Social Security Administration on the number of individuals receiving SSDI as workers, the number of awards in each year, and the terminations in each year. We also use the yearly data on the number of applications to the program. Additionally, we also use the data on the Stock, Inflow, and Applications to the SSI program. Unfortunately, the data on the outflow from SSI is not available 
before 1988, and even those numbers reflect both short and long-term suspensions, clouding the interpretations of our estimates.

The upper panel of Table 8 shows the significant effect (and with the hypothesized sign) of unemployment rates on the stock of beneficiaries, the number of applications, the number of awards (inflow), and the number of terminations (outflow) to the SSDI program, even after controlling for a highly significant time trend. The percentage of the variation explained is very high with R-squares around 0.9 or higher. Notice, however, that we only use 22 years of data ( 27 for the Stock estimation) given that there was a distinct policy change during the Reagan administration which led to a severe period of retrenchment in the programme in the early 1980s at a time of high unemployment rates. If we include the data from that period our results in some cases even reverse in sign. We follow what many other researchers have argued and done (such as Autor and Duggan 2006) and do not use the data from that period and focus on the data since the mid-1980s. For SSI the effect of unemployment rates on the inflow and number of applications is also significant and with the expected positive sign, but is insignificant for the stock of individuals on SSI in each year.

The lower panel estimates the same specifications but using the series relative to the employment level in the United States in the given year (using data for non-farm workers as of December of each year published by the Bureau of Labor Statistics). Although the magnitudes of the effects are different, the significance of the estimates is in most cases even higher, and while the outflow from SSDI does not seem to be correlated with the unemployment rate once we control for the size of the employed population, the effect on the Stock of SSI beneficiaries is now significant.

Overall, the conclusion is that since the mid-1980s there is a significant business cycle effect measured by the unemployment rate on the size, number of applicants, inflow and outflow from the public disability insurance programmes in the United States, even after accounting for a time trend and the size of the working population. We will see later whether these results are also present in the micro-level data using the PSID. 
Table 8:

SSDI and SSI indicators and national unemployment rate: US administrative data 1974-2007

\begin{tabular}{|c|c|c|c|c|c|c|c|}
\hline & \multicolumn{7}{|c|}{ Log of the series } \\
\hline & \multicolumn{4}{|c|}{ SSDI } & \multicolumn{3}{|c|}{ SSI } \\
\hline & Stock & Outflow & Inflow & Applications & Stock & Inflow & Applications \\
\hline \multirow[t]{4}{*}{ unemployment } & 1.79 & -1.91 & 7.61 & 10.77 & 0.63 & 9.89 & 12.02 \\
\hline & (1.91) & $(-2.54)$ & $(7.00)$ & (5.26) & $(0.35)$ & (3.78) & (6.66) \\
\hline & 0.05 & 0.02 & 0.04 & 0.04 & 0.04 & 0.02 & 0.034 \\
\hline & $(16.79)$ & $(16.14)$ & $(21.12)$ & (12.76) & $(11.25)$ & $(5.77)$ & (10.09) \\
\hline \multirow[t]{2}{*}{ Constant } & 14.14 & 12.59 & 11.99 & 12.53 & 14.33 & 12.03 & 12.64 \\
\hline & $(126.24)$ & $(188.08)$ & $(132.01)$ & (76.29) & $(88.75)$ & $(57.37)$ & $(82.82)$ \\
\hline $\mathrm{N}$ & 27 & 22 & 22 & 22 & 22 & 22 & 22 \\
\hline $\mathrm{R}^{2}$ & 0.97 & 0.94 & 0.95 & 0.90 & 0.88 & 0.65 & 0.85 \\
\hline \multirow[t]{4}{*}{$\mathrm{F}$} & 264.27 & 288.06 & 237.57 & 81.45 & 78.21 & 16.86 & 51.68 \\
\hline & \multicolumn{7}{|c|}{ Series relative to employment level } \\
\hline & \multicolumn{4}{|c|}{ SSDI } & \multicolumn{3}{|c|}{ SSI } \\
\hline & Stock & Outflow & Inflow & Applications & Stock & Inflow & Applications \\
\hline \multirow[t]{4}{*}{ unemployment } & 0.15 & 0.00 & 0.05 & 0.15 & 0.09 & 0.05 & 0.16 \\
\hline & (4.01) & $(0.13)$ & $(10.75)$ & (5.17) & (1.75) & $(4.42)$ & (6.85) \\
\hline & 0.001 & 0.001 & 0.001 & 0.001 & 0.001 & 0.001 & 0.001 \\
\hline & (10.07) & (4.19) & (17.65) & (7.29) & (9.34) & $(2.27)$ & (5.32) \\
\hline \multirow[t]{2}{*}{ Constant } & 0.003 & 0.003 & -0.001 & -0.005 & 0.01 & 0.001 & -0.003 \\
\hline & $(0.62)$ & $(12.43)$ & $(-1.56)$ & $(-2.12)$ & $(2.50)$ & $(0.34)$ & $(-1.51)$ \\
\hline $\mathrm{N}$ & 27 & 22 & 22 & 22 & 22 & 22 & 22 \\
\hline $\mathrm{R}^{2}$ & 0.91 & 0.47 & 0.92 & 0.76 & 0.79 & 0.58 & 0.70 \\
\hline $\mathrm{F}$ & 59.33 & 11.63 & 155.81 & 29.12 & 50.13 & 9.82 & 25.27 \\
\hline
\end{tabular}

Notes: t-stats in brackets.

\section{Work disability and health disability}

Self-reported ill-health and disability

So far, the analysis has focussed on what we defined as 'work disability'. We now focus on the relation of work disability to 'health disability'. As argued in the introduction, the two concepts are quite distinct. However there is a natural link between the two concepts insofar as the latter will typically involve a clinical diagnosis, and part of the 'gateway' accessing disability benefits is some form of medical examination or evaluation. As suggested earlier, however, such evaluations may vary according to time and place, and individuals themselves differ in not only in their attitude to given incapacity or disability but also in their willingness to utilise long-standing ill-health conditions as a reason for applying for disability benefits. Finally, as we also discussed earlier, general selfreported measures of 'health problems' or 'disabilities' are not clinical diagnoses, and contain high potential for various types of response bias. 
Nevertheless, it is at least possible that the relationship that we observed in the previous two sections between work disability and unemployment is in part driven by underlying fluctuations in health disability. In this section, the problem is investigated further. Our first analysis looks at evidence on self-reported longstanding health problems or disability using the European Labour Force Survey (ELFS) for 2002. We investigate whether differences in positive responses to the question concerning health problems are associated with differences in unemployment across regional labour markets in a large number of European countries. The exact question asked is: 'do you have a longstanding health problem or disability'? The proportion answering in the affirmative in each regional labour market is regressed on that region's unemployment rate. If the relationship is positive, it is possible that the cross-sectional variation in work disability and unemployment is partly driven by an underlying relationship between health disability and unemployment (although 'response bias' also suggests that there may be a reverse causation). We also use a question from the Survey of Income and Living Conditions (SILC) which asks whether the individual is hampered or strongly hampered by health problems.

As a prelude to this analysis, Table 9 examines the proportions of people aged between 16 and 64 (and various sub-groups) that report that they have a long-standing health problem or disability in the ELFS. For comparison purposes we also construct two generosity indexes: generosity index 1 defined as DI expenditure to GDP / fraction having a longstanding health problem; and generosity index 2 defined as DI expenditure to GDP / fraction hampered by a health problem.

One striking feature is that there is a good deal of variation across countries in these indices. This variation is much larger in the response to the question concerning the prevalence of longstanding health limitations than in the fraction reporting that they are hampered by health problems. Countries such as Denmark, Finland, the Netherlands and the United Kingdom consistently self-report much higher rates of long-standing health problems disability (or fraction hampered) in all age groups than, say, Germany, Italy or Spain. On the other hand, in the United States, using both the Current Population Survey (CPS), and the National Health Interview Survey (NHIS) we find levels of self-reported disability comparable to European countries at the low end of the distribution. ${ }^{3}$ It is hard to believe that these differences across countries simply reflect

\footnotetext{
${ }^{3}$ For the CPS we have compiled yearly data back to 1988 on self-reported disability, and in these two decades has been stable moving between $7 \%$ and $8 \%$ of the population. In the NHIS we have yearly data back to 1982 , and due to definitional changes in the questions the proportion has fluctuated in a wider range, between $10 \%$ and $8 \%$. In both data sets we also measure self-reported health status over time. The analysis of the historical data using these two data sources is available from the authors' upon request. Notice the interesting contrast between the fairly stable figures on self-reported disability, and the highly variable award and application
} 
'objective' differences in the extent of long-term sickness or disability, or can simply be explained by differences in unemployment rates. There is a vast public health and epidemiological literature on whether self-reported experiences of ill-health are directly comparable across countries (such as Salomon, Tandon and Murray, 2004) and an associated growing literature in health economics on variations in self-reported disability (such as Lindeboom and van Doorslaer, 2004, and Kapteyn, Smith and van Soest, 2007), all of which cast doubt on direct comparisons across countries in selfreported health.

Table 9:

Proportion reporting the existence of a long-standing health problem or disability Persons aged 16-64 in the ELFS 2002 supplement. Persons aged 18-64 in the CPS and NHIS 2002

\begin{tabular}{|c|c|c|c|c|c|c|c|}
\hline Country & $16-44$ & $45-54$ & $55-64$ & All & $\begin{array}{l}\text { \%hampered } \\
\text { (SILC data) }\end{array}$ & $\begin{array}{l}\text { Generosity } \\
\text { Index } 1\end{array}$ & $\begin{array}{l}\text { Generosity } \\
\text { Index } 2\end{array}$ \\
\hline Austria & 0.077 & 0.168 & 0.249 & 0.129 & 27.4 & 0.170 & 0.080 \\
\hline Belgium & 0.129 & 0.256 & 0.331 & 0.195 & 23.2 & 0.103 & 0.086 \\
\hline Cyprus & 0.060 & 0.168 & 0.310 & 0.124 & 26.0 & 0.056 & 0.027 \\
\hline Czech Republic & 0.110 & 0.278 & 0.426 & 0.207 & 28.6 & 0.068 & 0.049 \\
\hline Germany & 0.060 & 0.141 & 0.238 & 0.114 & 35.3 & 0.368 & 0.119 \\
\hline Denmark & 0.142 & 0.227 & 0.294 & 0.190 & 13.3 & 0.116 & 0.165 \\
\hline Estonia & 0.137 & 0.319 & 0.497 & 0.246 & 37.9 & 0.049 & 0.032 \\
\hline Spain & 0.051 & 0.120 & 0.224 & 0.093 & 23.6 & 0.214 & 0.085 \\
\hline Finland & 0.214 & 0.385 & 0.586 & 0.322 & 37.5 & 0.106 & 0.091 \\
\hline France & 0.174 & 0.311 & 0.408 & 0.240 & 21.3 & 0.075 & 0.085 \\
\hline Greece & 0.045 & 0.129 & 0.263 & 0.105 & 20.1 & 0.114 & 0.060 \\
\hline Hungary & 0.045 & 0.227 & 0.278 & 0.131 & 35.0 & 0.161 & 0.060 \\
\hline Ireland & 0.071 & 0.151 & 0.259 & 0.113 & 24.6 & 0.079 & 0.037 \\
\hline Italy & 0.030 & 0.090 & 0.152 & 0.070 & 19.7 & 0.215 & 0.076 \\
\hline Latvia & 0.040 & 0.117 & 0.209 & 0.082 & 34.3 & 0.134 & 0.032 \\
\hline Luxemburg & 0.061 & 0.142 & 0.244 & 0.106 & 21.5 & 0.264 & 0.130 \\
\hline Netherlands & 0.186 & 0.301 & 0.403 & 0.248 & 20.9 & 0.105 & 0.124 \\
\hline Norway & 0.102 & 0.195 & 0.333 & 0.161 & 18.9 & 0.280 & 0.238 \\
\hline Portugal & 0.127 & 0.274 & 0.448 & 0.220 & 31.5 & 0.109 & 0.076 \\
\hline Slovenia & 0.160 & 0.234 & 0.294 & 0.199 & 27.7 & 0.100 & 0.072 \\
\hline Slovakia & 0.096 & 0.292 & 0.392 & 0.193 & 26.8 & 0.078 & 0.056 \\
\hline Sweden & 0.041 & 0.147 & 0.200 & 0.093 & 22.0 & 0.517 & 0.218 \\
\hline United Kingdom & 0.194 & 0.334 & 0.492 & 0.276 & 21.0 & 0.091 & 0.119 \\
\hline All European countries & 0.087 & 0.189 & 0.287 & 0.145 & -- & -- & -- \\
\hline U.S. (CPS 2002) & 0.047 & 0.102 & 0.167 & 0.077 & -- & 0.142 & -- \\
\hline U.S. (NHIS 2002) & 0.0512 & 0.1155 & 0.182 & 0.085 & -- & 0.156 & -- \\
\hline
\end{tabular}

Notes: Generosity index 1: DI expenditure to GDP / fraction having a longstanding health problem; Generosity index 2: DI expenditure to GDP / fraction hampered.

numbers to the U.S.'s disability programs, suggesting a role for economic conditions that justifies the deeper analysis performed in this paper. 
Despite these problems with self-reported disability, we believe that our generosity indexes are still informative. Despite some inconsistencies between the indices (the correlation between the indices is 0.69), they reveal that DI generosity is much larger in Nordic European countries that in either Central or Southern countries. Most likely, the large variation has to do with the internalization of the legal requirements for disability in each country's individual self-reported classifications.

We again exploit within-country regional variations in self-reported health to examine whether there are associations between self-reported 'health disability' and unemployment rates. We pool all the regions in the various countries in the ELFS 2002 supplement on Disability and run a simple regression of the proportion report long-standing illness or disability on the regional unemployment rate. The results are graphed in Figure 3, which also (by way of comparison with some of the earlier evidence) specifically identifies the relationship for regions in Spain and Germany because these countries, from Table 9, have comparable overall rates of self-reported long-term illhealth and disability. Figure 3 shows that there is in general a relationship between local unemployment rates and self-reported disability and that it is non-linear, levelling out at higher levels of regional unemployment. Variations in regional unemployment 'explain' around $9 \%$ of the variation in self-reported health proportions across regions in a linear model, and around $12 \%$ in a model specified as a quadratic. 
Figure 3:

Existence of a longstanding health problem or disability and regional unemployment rates


Source: ELFS supplement 2002.

Self-reported disability, disability benefit claims and unemployment

If there is a correlation between self-reported long-standing ill-health and disability on the one hand, and spatial variations in unemployment rates on the other, then this may 'explain' the relationship between disability benefit claims and unemployment rates described in Section 2 of this paper. The implicit hypothesis in that section, derived from the discussion in Section 1, was that the disability benefit regime has been used as a direct way of cushioning variations in labour demand across economics both spatially and over time, and that variation in claim rates did not simply reflect variations in health disability. An alternative hypothesis, if we rule out pure 'reporting bias' in selfreported health, is that the variations in work disability in fact largely reflect variations in health disability - so that inclusion of a proxy for the latter in the disability benefit claim regressions would weaken the direct effect of unemployment rates on disability benefit claims. This is tested in this sub-section. 
We undertake the test by repeating the earlier regressions on the relationship between disability benefit receipt and the local unemployment rate (as in Table 2 ) including self-reported health (SRH) as an additional regressor. This tests whether inclusion of this variable weakens the $\beta \mathrm{s}$ of long-term unemployment identified in those regressions. In Table 10, therefore we run the regression:

$D B$ measure $_{i, t}=\alpha+\beta^{*} u_{- \text {rate }_{r, t}}+\gamma^{*}$ controls $_{i, r, t}+\delta^{*} H E A L T H_{i, t}+\varepsilon_{i t}$

where various health measures are used. There include:

Column 2: Self-reported Health (SRH)= 1 very good, 2 good, 3 fair, 4 bad, 5 very bad

Column 3: bad health $=1$ if SRH is bad or very bad (4 or 5), 0 if SRH $<4$

Column 4: hampered = 1 if individual reports being hampered or strongly hampered by health problems

Other controls and variable definitions as before.

In Appendix Table B3 we allow the $\beta$ s to vary across countries as in Table B2, so consequently:

DBmeasure $_{i, t}=\alpha+\sum_{c=1-21}\left[\beta_{c}^{*}\left(u_{\text {-rate }}{ }_{r, t}\right.\right.$ country $\left.\left._{c}\right)\right]+\gamma^{*}$ controls $_{i, r, t}+\delta^{*} H E A L T H_{i, t}+\varepsilon_{i t}$

Finally, in Table 11 we allow the effect of the unemployment rate to vary with health:

DBmeasure $_{i, t}=\alpha+\beta^{*}$ HEALTH $_{i, t}+\gamma^{*}$ HEALTH $_{i, t} * u$ rate $_{r, t}+\delta^{*}$ controls $_{i, r, t}+\varepsilon_{i t}$

The most striking aspect of Table 10 is that the inclusion of self-reported health measures leaves the significant signs on the DB stock and outflow coefficients unchanged (when using the SRH index) or slightly reduced (when using any other of the two other indicators). The inclusion of the SRH also changes the insignificant and negative coefficient on the inflow rate to the 'correct' sign (albeit the coefficient is small in value). Self-reported health is a significant explanatory variable in terms of disability benefit claims - this should not be too surprising as such a finding is consistent with both a relation between work and health disability and with a 'story' of reporting bias - but it does not eliminate the underlying relationship between unemployment rates and disability claims indeed it certain respects it slightly strengthens it.

When we augment the unemployment rate country interactions both with health measures (SRH, bad health and hampered) and self-reported health measures interacted with countries, simply including self-reported health measures on balance somewhat strengthens the relationship between unemployment rates and disability claims (See Appendix Table B2). For example, when using SRH, 14 instead of 11 countries report positive and significant inflow effects of higher 
unemployment and many of the stock coefficients are strengthened. In contrast, the strength of the negative outflow effects in some countries is slightly weakened. Including both unemployment rate and self-reported health interactions does tend to increase the volatility of coefficients signs and values, suggesting that we are asking too much of the data.

Table 10:

Pooled panel estimates of unemployment rates on disability benefit receipt (DB) allowing for self-reported health

\begin{tabular}{|c|c|c|c|c|}
\hline \multicolumn{5}{|c|}{ ECHP (1994 - 2001) and SILC (2004 - 2006) } \\
\hline & $\begin{array}{c}(1) \\
\text { as Table } 2\end{array}$ & $\begin{array}{c}(2) \\
+\begin{array}{c}\text { Self-reported } \\
\text { health }\end{array}\end{array}$ & $\begin{array}{c}(3) \\
\text { + bad health }\end{array}$ & $\begin{array}{c}(4) \\
+ \text { hampered } \\
\text { by health }\end{array}$ \\
\hline $\begin{array}{l}\text { Dependent Variable: } \\
\text { DB Stock }\end{array}$ & $0.0019 * * *$ & $0.0017^{* * *}$ & $0.0013 * * *$ & $0.0012 * * *$ \\
\hline$d(\ln y) / d(\ln x)$ & 0.1610 & 0.1559 & 0.1196 & 0.1125 \\
\hline p-value & 0.000 & 0.000 & 0.000 & 0.000 \\
\hline $\mathrm{N}$ & 977,393 & 907,616 & 907,616 & 907,616 \\
\hline (Pseudo) $R^{2}$ & 0.09 & 0.19 & 0.20 & 0.22 \\
\hline DB Inflow & 0.00001 & $\begin{array}{r}0.0001 \\
-\end{array}$ & $\begin{array}{r}0.0001 \\
-\end{array}$ & $\begin{array}{r}0.0000 \\
-\end{array}$ \\
\hline $\mathrm{p}$-value & 0.414 & 0.027 & 0.170 & 0.460 \\
\hline $\mathrm{N}$ & 578,391 & 548,408 & 548,408 & 548,408 \\
\hline (Pseudo) $R^{2}$ & 0.03 & 0.04 & 0.04 & 0.05 \\
\hline DB Outflow & $-0.0031 * * *$ & $-0.0022 * * *$ & -0.0019 & -0.0028 \\
\hline$d(\operatorname{lny}) / d(\ln x)$ & -0.0862 & & - & - \\
\hline p-value & 0.049 & 0.000 & 0.218 & 0.184 \\
\hline $\mathrm{N}$ & 61,964 & 57,223 & 57,223 & 57,223 \\
\hline (Pseudo) $R^{2}$ & 0.07 & 0.09 & 0.09 & 0.11 \\
\hline
\end{tabular}

Notes: All regressions include year and country dummies and control for age and gender of the respondent. Notes: All regressions control for age and gender of the respondent. Coefficients are OLS coefficients; very similar results are obtained deriving marginal effects from probit maximum likelihood. Probit results are available on request from the authors. Standard errors are clustered by region. Below significant coefficients, corresponding elasticities are reported. *

Finally, Table 11 explores the interaction between health and the business cycle using two health measures: bad health and hampered. Results in this table are comparable to those reported in Table 8. As expected, for the stock of claimants, introducing these interactions reduces the effect of the business cycle when we control for those in good health condition (good health or not hampered) and increases it for those in bad health conditions. These results are suggestive that the effect of the business cycle is somewhat stronger for those in bad health than for the rest of the population. However, and even more important, the effect of the unemployment rate remains significant for those in fair or good health 
Table 11:

Pooled panel estimates of Disability Benefit receipt (DB) and unemployment rates interacted with health measures ('bad health', 'hampered')

\begin{tabular}{|c|c|c|c|}
\hline \multicolumn{4}{|c|}{ ECHP (1994 - 2001) and SILC (2004 - 2006) } \\
\hline Dependent Variable: & $\begin{array}{l}\text { DB Stock } \\
+ \text { year \& } \\
\text { Country }\end{array}$ & $\begin{array}{c}\text { DB Inflow } \\
+ \text { year \& } \\
\text { country }\end{array}$ & $\begin{array}{c}\text { DB Outflow } \\
+ \text { year } \& \\
\text { country }\end{array}$ \\
\hline $\begin{array}{l}\text { Unemployment rate } \\
\text { Good health } d(\ln y) / d(\ln x) \\
\text { Bad health } \\
\text { urate*goodhealth } \\
\text { urate*badhealth }\end{array}$ & 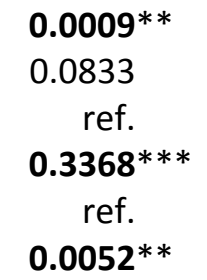 &  & $\begin{array}{l}-0.0040^{* *} \\
-0.1130 \\
\text { ref. } \\
-0.1910^{* * *} \\
\text { ref. } \\
\mathbf{0 . 0 0 4 3 * * *}\end{array}$ \\
\hline $\begin{array}{r}\mathrm{n} \\
\mathrm{R}^{2} \\
\end{array}$ & $\begin{array}{r}907,616 \\
0.20 \\
\end{array}$ & $\begin{array}{r}548,408 \\
0.04 \\
\end{array}$ & $\begin{array}{r}55,570 \\
0.06 \\
\end{array}$ \\
\hline $\begin{array}{l}\text { Unemployment rate } \\
\text { not hampered } d(\ln y) / d(\ln x) \\
\text { Hampered } \\
\text { urate*not hampered } \\
\text { urate*hampered }\end{array}$ & 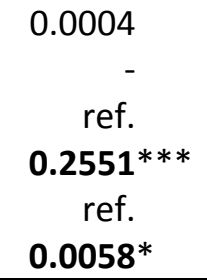 & $\begin{array}{c}0.0001 \\
- \\
\text { ref. } \\
\mathbf{0 . 0 6 4 8 * * *} \\
\text { ref. } \\
-0.0005\end{array}$ & 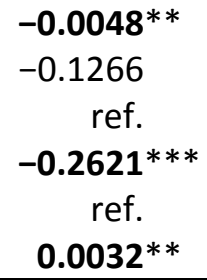 \\
\hline $\begin{array}{r}n \\
R^{2}\end{array}$ & $\begin{array}{r}907,616 \\
0.22\end{array}$ & $\begin{array}{r}556,897 \\
0.05\end{array}$ & $\begin{array}{r}57,223 \\
0.11\end{array}$ \\
\hline
\end{tabular}

Source: ECHP 1994-2001 and SILC 2004-2006. Below significant unemployment rate coefficients, elasticities are reported. ${ }^{*}$ p-value $<0.1,{ }^{* *}$ p-value $<0.05,{ }^{* * *}$-value $<0.001$.

\section{Evidence for the United States}

For comparable estimates for the United States, we used the Panel Survey of Income Dynamics (PSID), which has been collected since 1968. Starting from 1968, the PSID interviewed and re-interviewed the individuals from families in the core sample every year, whether or not they were living in the same dwelling or with the same people. Adults have been followed as they have grown older, and children have been observed as they advance through childhood and into adulthood, forming family units of their own. The PSID data files provide a wide variety of information about both the families and individuals collected over the span of the study. The central focus of the data is economic and demographic, with substantial detail on income sources and amounts, employment, family composition changes, and residential location. Information gathered in the survey applies to the circumstances of the family unit as a whole (e.g., type of housing) or to particular persons in the family unit (e.g., age, earnings). While some information is collected about all individuals in the family unit, the greatest level of detail is ascertained for the primary adults heading the family unit. 
In the estimates below we used information for the 1985 to 2005 period in which we have information on disability, as well as on health status and most of the controls we have discussed for the European data sets, like occupation, demographic characteristics, health status, and of course the local unemployment rate. Up to 1993 the unemployment rate is at the county level, but starting then it is only at the state level. However, we only have disability benefits receipt in the 1985 to 1993 period.

Table 12 reports estimates using a specification very similar to that reported in Table 10. In this case given data limitations we can only use the PSID data for the 1985 to 1993 period, but we are able to control for an array of variables including occupation, time effects, and demographic characteristics. In this period the PSID records the county level unemployment rate, and Table 12 shows that there is a positive and strongly significant effect of local unemployment on the disability benefit (DB) stock (those reporting receiving disability benefits in a given year), and the DB Inflow (those receiving disability in a given year after not receiving it in the previous year), whereas there is an insignificant effect on the DB outflow (those dropping from the rolls). These results are in line with those we find with the other data sets and are strengthened once we control for self-reported good health in the last column (which has a significant negative effect, not shown in the table). However the effect of the business cycle is somewhat smaller in the US than in Europe, which should not come as a great surprise given the Federal nature of the program, and the very strict definition of disability implemented in the US.

And, by way of comparison with Table 11 for the combination of ECHP+SILC, in Table 13 we control for the interaction between a measure of self-reported health and the unemployment rate to check for the residual Business Cycle effect once we control for the underlying health condition of the respondents. The results regarding the effect of the Business Cycle are surprisingly stable, and become in some cases even stronger than in the previous specifications, providing clear evidence of the support for our hypothesis. In addition, in the second panel of Table 13, information is provided on the relation of self-reported disability status to unemployment rates, which can be utilised for a longer period given data limitations on disability benefit receipt. Although self-reported status may suffer from justification bias, the relationship to unemployment rates is also strong, including a correctly signed coefficient on the unemployment state. Overall, therefore, we confirm the findings of the European panels for the US that inclusion of self-reported 'good' and 'bad' health among our explanatory variables does not dampen the effect of the business cycle on receipt of disability benefits. 
Table 12: Pooled panel estimates of Disability Benefit Receipt (DB) and unemployment rates allowing for self-reported health. PSID 1985-1993.

\begin{tabular}{|c|c|c|}
\hline Dependent Variable: & Benchmark & + 'in Good Health' \\
\hline DB Stock & $0.00058 * * *$ & $0.00064 * * *$ \\
\hline$p$-value & 0.009 & 0.004 \\
\hline $\mathrm{n}$ & 78,382 & 78,382 \\
\hline (Pseudo) R & 0.04 & 0.044 \\
\hline DB Inflow & $0.00044 * * *$ & $0.00047 * * *$ \\
\hline p-value & 0.006 & 0.004 \\
\hline $\mathrm{n}$ & 63,141 & 63,141 \\
\hline (Pseudo) $\mathrm{R}^{2}$ & 0.013 & 0.0148 \\
\hline DB Outflow & 0.0001 & 0.0001 \\
\hline p-value & 0.545 & 0.467 \\
\hline $\mathrm{n}$ & 63,141 & 63,141 \\
\hline (Pseudo) $\mathrm{R}^{2}$ & 0.0087 & 0.0094 \\
\hline
\end{tabular}

Table 13: Pooled panel estimates of Disability Benefit receipt (DB) and Self-Reported Disability (DIS) and unemployment rates interacted with health measure (good health)

\begin{tabular}{|c|c|c|c|}
\hline \multicolumn{4}{|c|}{ Disability Benefit receipt: PSID 1985-1993 } \\
\hline Dep. Var. & $\begin{array}{c}\text { DB Stock } \\
\text { + year \& } \\
\text { Occupation }\end{array}$ & $\begin{array}{l}\text { DB Inflow } \\
\text { + year \& } \\
\text { occupation }\end{array}$ & $\begin{array}{l}\text { DB Outflow } \\
+ \text { year \& } \\
\text { Occupation }\end{array}$ \\
\hline Unemployment rate & $0.00096 * * *$ & $0.00055 * * *$ & 0.00015 \\
\hline Good health & $-0.011 * * *$ & $-0.0042 * *$ & $-0.0028 * * *$ \\
\hline U-rate*goodhealth & $-0.001 * * *$ & -0.000287 & -0.0021 \\
\hline $\mathrm{N}$ & 78,382 & 63,141 & 63,141 \\
\hline $\mathrm{R}^{2}$ & 0.044 & 0.0148 & 0.0094 \\
\hline \multicolumn{4}{|c|}{ Self-reported Disability: PSID 1985-2005 } \\
\hline & DIS STOCK & DIS INFLOW & DIS OUTFLOW \\
\hline Unemployment rate & $0.00458 * * *$ & $0.0022 * * *$ & $-0.00152 * * *$ \\
\hline Good health & $0.004 * * *$ & $0.0035 * * *$ & -0.0004 \\
\hline U-rate* goodhealth & $-0.0035 * * *$ & $-0.0015 * * *$ & $0.0009 * * *$ \\
\hline $\mathrm{N}$ & 166,459 & 143,127 & 143,127 \\
\hline $\mathrm{R}^{2}$ & 0.0349 & 0.011 & 0.012 \\
\hline
\end{tabular}

Notes to Tables 12 and 13: All U.S. regressions include year controls and control for age, age-squared, gender, marital status, race (black and white dummies), and occupation of the respondent. Coefficients are OLS coefficients; very similar results are obtained deriving marginal effects from probit maximum likelihood. Probit results are available on request from the authors. Notice that the reported R-squared can be misleading in a Linear Probability Model, the Pseudo-R-squares in the probit estimations move between 0.12 and 0.2 . ***pvalue $<0.001$. 


\section{Self-reported health and health disability}

The analysis in Section 1 suggested that there is a strong relationship between work disability and unemployment rates. The inclusion of self-reported measures of health disability in the previous section did not alter this conclusion to any great degree, although that section suggested that there was also a relationship between self-reported disability and claims for disability benefit. This should not be too surprising, both because independent evaluations of health disability are at least one of the 'gateways' to receipt of disability benefits, but also because 'response bias' would lead us to be believe that individuals who are in receipt of, or applying for, disability benefits, have an obvious incentive to report that they are in poor health. It is however revealing, when examining the ECHP-SILC panel, to note that 25,000 out of 86,000 claimants of disability insurance ( $29 \%$ of the total) self-report that they are in 'good' or 'very good' health, and indeed 127,000 of 1.432 million non-claimants report that they are in 'bad' or 'very bad' health. This, at the very least, suggests that the link between work disability and health disability is not exact.

In this last section, therefore, we utilise data from two country studies (UK and the U.S.) to air some preliminary speculations on the relationship between health disability and economic conditions. This is a topic on which a certain amount has been written, and is part of a much larger topic of how disability and ill-health has evolved over time and across countries (e.g. what health conditions have increased or decreased in prevalence, especially among disability benefit claimants) which cannot be discussed in extensive detail here. Nevertheless it forms a natural sequel to the discussion in this along the following lines: if work disability is related to economic conditions and health disability is (partially) related to work disability, then is health disability also related to economic conditions? Consideration of this last topic has been hampered so far by the use of rather general self-reported questions on health status which are, unfortunately, the only form of health questions available in many of the large socio-economic panels such as those used here.

Some panel data, however, such as the British Household Panel Survey (BHPS) and the English Longitudinal Survey of Ageing (ELSA) in the UK, the new Surveys of Health and Ageing in Europe (SHARE) and, in the United States, the Panel Survey of Income Dynamics (PSID) and the Health and Retirement Survey (HRS), ask much more detailed questions on personal health and disability. Indeed some of these surveys, such as ELSA, also provide independent medical evaluations (primarily nurses' visits) in some of the waves. Some of these panels (ELSA, SHARE and the HRS) only look at sub-sets of older people, and in most cases, most of the detailed questions on health conditions and disability are still primarily self-assessed and subject to various kinds of response or justification bias. Nevertheless it seems plausible to argue that some of these detailed questions elicit more accurate response to particular health conditions. Consequently, a natural 
question to ask is whether we can find any evidence that responses to very detailed questions on health can be used to find evidence of business cycle-type fluctuations in 'objective' measures of health. If we found that specific, objectively-measured health conditions and disabilities tended to be more prevalent where there was higher unemployment, then this would suggest that part of the observed correlation between unemployment rates and disability claims arose from this source; if no such prevalence of health disability in high unemployment areas or periods was observed, then the correlation of health and work disability cannot be the explanation.

We investigate two issues using appropriate panel data. First, are some disabilities pro or counter-cyclical as measured by prevailing unemployment? Second, does the incidence or threat of unemployment induce changes in reporting behaviour and take-up of disability insurance benefits given reported medical conditions?

Past evidence on the first point is mixed but, if anything, suggests that the incidence of disabilities is pro-cyclical: that is, higher incidence is likely when economic activity is booming and unemployment is lower. In early work, Kossoris $(1938,1943)$ pointed to the pro-cyclicality of accident and injury-related disabilities; a result confirmed later by Robinson and Shor's (1989) analysis of accidents at Californian construction sites. However other work which confirms some evidence of pro-cyclicality points rather to the 'fear factor' induced by a threatened loss of job in eras or regions of high unemployment. Brookner, Frank and Tarasuk (1997) argue that back pain and acute claim rates in Canada are pro-cyclical; and Ruhm (2000) has argued using aggregate data that various dimensions of ill-health are commonly associated with 'good times' rather than recession. There is, however, countervailing evidence: for example findings such as those of Beale and Nethercott (1988) and Jenkins et al (1982) that the stress of threatened redundancy increases spells of certificated sickness and Bridges and Disney (2007), who find that stress-related illness is associated with family economic problems such as indebtedness and the threat of unemployment.

\section{Health disability, work disability and unemployment in the BHPS}

For the United Kingdom, the British Household Panel Survey (BHPS) asks respondents for details on 12 specific reported health conditions among a range of self-assessed questions concerning capacity for work. We pool the available waves of the BHPS and examine the correlation of these specific health conditions with unemployment rates (calculated from administrative data) for the 65 counties of England, Scotland and Wales. A positive sign indicates that the condition is counter-cyclical: that is, that higher unemployment induces greater self-reported incidence of the condition; a negative sign the reverse. 
Table 14 shows clearly that the relation of self-reported specific health conditions to unemployment is either significantly negative or insignificant in all cases. There is no evidence that health disability is directly affected by unemployment; indeed the reverse is more likely, especially among some of the most prevalent conditions in receipt of disability benefits (such as heart conditions and depression).

Table 14: Incidence of specific self-reported health conditions in relation to county-level unemployment rates, BHPS 1992-2006

\begin{tabular}{|l||c||c|}
\hline $\begin{array}{l}\text { Probability of reporting given health } \\
\text { condition: }\end{array}$ & $\begin{array}{c}\text { Coefficient on } \\
\text { unemployment rate }\end{array}$ & $\begin{array}{c}\text { Standard error on } \\
\text { coeff. }\end{array}$ \\
\hline A) Arms, Legs, Hands, Feet, Back & $-0.015^{* *}$ & 0.002 \\
B) Sight & 0.006 & 0.004 \\
C) Hearing & -0.004 & 0.003 \\
D) Skin Condition & $-0.019^{* *}$ & 0.002 \\
E) Chest / Breathing Problems & $-0.027^{* *}$ & 0.002 \\
F) Heart/Blood Pressure & $-0.022^{* *}$ & 0.003 \\
G) Stomach / Liver / Kidneys & $-0.019^{* *}$ & 0.003 \\
H) Diabetes & $-0.028^{* *}$ & 0.005 \\
I)Anxiety, Depression, Bad Nerves & $-0.023^{* *}$ & 0.003 \\
J) Alcohol or Drug Related & -0.014 & 0.008 \\
K) Epilepsy & -0.009 & 0.006 \\
L) Migraine & $-0.008^{* *}$ & 0.003 \\
M) Other & 0.003 & 0.003 \\
\hline
\end{tabular}

Note: BHPS data. Demographic controls as in discussion of Table 7 above. ${ }^{* *}$ p value $<0.001$

If this is the case, then it must be true (or at least consistent with the analysis of previous sections) that the probability of claiming disability benefits, conditional on having a specific health condition, is higher in areas and periods of higher unemployment. This can also be tested, and the results are contained in Table 15. In this table, we first test whether the onset of a given condition is associated with a transition into disability benefits. We then test whether the probability of entering disability benefits given the onset of a particular health condition is higher in localities where the unemployment rate is higher. 
Table 15:

Probability of claiming disability benefits conditional on reporting certain specific health conditions and local unemployment rate

\begin{tabular}{|c|c|c|c|}
\hline $\begin{array}{l}\text { Probability of } \\
\text { condition at } t \text { given } \\
\text { not at } t-1\end{array}$ & $\begin{array}{l}\text { Receiving DB } \\
\text { (fixed effects) }\end{array}$ & Starting DB spell & $\begin{array}{l}\text { Starting DB spell with } \\
\text { interaction (health } \\
\text { shock } \times \text { U rate) }\end{array}$ \\
\hline $\begin{array}{l}\text { A) Arms, Legs, Hands, } \\
\text { Feet, Back }\end{array}$ & $0.63^{* *}(0.12)$ & $0.38 * * \quad(0.05)$ & $0.36^{* *}(0.09)$ \\
\hline B) Sight & $0.19 \quad(0.18)$ & $0.28 * * \quad(0.08)$ & $0.36^{*} \quad(0.15)$ \\
\hline C) Hearing & $0.17 \quad(0.22)$ & $0.05 \quad(0.07)$ & $0.17 \quad(0.23)$ \\
\hline D) Skin Condition & $0.04 \quad(0.17)$ & $-0.06 \quad(0.08)$ & $0.03 \quad(0.15)$ \\
\hline $\begin{array}{l}\text { E) Chest / Breathing } \\
\text { Problems }\end{array}$ & $0.23 \quad(0.15)$ & $0.10 \quad(0.07)$ & $0.10 \quad(0.07)$ \\
\hline $\begin{array}{l}\text { F) Heart/Blood } \\
\text { Pressure }\end{array}$ & $0.08 \quad(0.14)$ & $0.22 * * \quad(0.07)$ & $0.28 * \quad(0.13)$ \\
\hline $\begin{array}{l}\text { G) Stomach / Liver / } \\
\text { Kidneys }\end{array}$ & $0.27 \quad(0.15)$ & $0.24 * * \quad(0.07)$ & $0.21 \quad(0.13)$ \\
\hline H) Diabetes & $0.31 \quad(0.39)$ & $0.22 \quad(0.16)$ & $0.01 \quad(0.31)$ \\
\hline $\begin{array}{l}\text { I) Anxiety, Depression } \\
\text { or Bad Nerves }\end{array}$ & $0.89 * *(0.12)$ & $0.58 * * \quad(0.06)$ & $0.79 * * \quad(0.10)$ \\
\hline $\begin{array}{l}\text { J) Alcohol or Drug } \\
\text { Related }\end{array}$ & $0.56 \quad(0.39)$ & - & - \\
\hline K) Epilepsy & $1.09 \quad(0.82)$ & $-0.00 \quad(0.33)$ & $0.68 \quad(0.70)$ \\
\hline L) Migraine & $0.11 \quad(0.16)$ & $0.11 \quad(0.07)$ & $0.21 \quad(0.14)$ \\
\hline M) Other & $0.24 \quad(0.16)$ & $0.17^{*} \quad(0.08)$ & $0.46 * *(0.15)$ \\
\hline
\end{tabular}

Source: analysis of BHPS 1992-2007. Demographic controls as in Table 7. ${ }^{*} p$ value $<0.05,{ }^{* *} p$ value $<0.001$

The table shows that self-reported incidence of conditions is positively associated with disability benefit receipt. As a simple attempt to avoid the role of personal characteristics and preferences in self-reporting of health problems, the first 2 columns use, respectively, fixed effects and transitions into disability benefits as the proxies for specific health disabilities. Signs are almost always positive, although not always significant. Inflows into disability benefits are particularly associated with the onset of problems with limbs, sight, internal organs, and mental health problems such as depression. 
The last column tests the 'business cycle effect' directly from a regression on starting a disability benefit spell for each health conditions which includes as explanatory variables local unemployment rates and interactions of the health condition with the local unemployment rate, as well as other controls for personal characteristics. The coefficients on the interaction terms are quoted in this column. Positive coefficients indicate that the likelihood of starting a disability benefit spell conditional on having a particular self-reported condition in turn depends positively on the local unemployment rate. All the signs on the coefficients are positive; in four categories: limbs, sight, heart problems and mental illness/depression significantly so.

Taken together, Tables 14 and 15 show convincingly that it is not the cyclical correlation of health disability and work disability that underlies the observed correlation between unemployment and work disability. Indeed, if anything, self-reported health disability (once we move away from rather general questions concerning 'good' and 'bad' health) is almost always negatively associated with unemployment rates. Thus the association between health and work disability is pro-cyclical not counter-cyclical, confirming many of the previous studies, and cannot be used to explain the counter-cyclical relationship between disability claims and unemployment. Moreover, these results suggest that answers to rather general questions on self-reported health, of the type illustrated in Figure 5 above, are indeed likely to suffer from various forms of response and justification bias and should be used with caution when 'explaining' differences in disability claim rates.

\section{Health disability, work disability and unemployment in the PSID}

Similarly to the UK study, we analyze using the U.S. Panel Study of Income Dynamics whether some disabilities are pro or counter-cyclical as measured by prevailing unemployment, and also whether the incidence of unemployment induce changes in reporting behaviour of disability insurance benefits given reported medical conditions.

The PSID has a different set of health conditions from those in the UK data, and unfortunately they are only available from the 1999 wave (we utilise data here until 2005). In any case, this period at least captures the ending of a boom cycle, a short recession, and the beginning of another boom cycle. Additionally, in this time period we only have access to the state-level unemployment rate, and we cannot measure disability benefit receipt, only the self-reported disability measure.

In Table 16 we show the relationship between self-reported health conditions and unemployment rate, which in this case is at the state level for this period of analysis. We can see that in the PSID the evidence is a bit more mixed than in the UK, mainly because the type of conditions measured are a bit different and in some cases more in line with a positive link between 
unemployment rates and stressful situations that can lead to health problems. However, in most cases the coefficients are not significant and very small, suggesting a weak relationship, and only in the case of stroke and high blood pressure are the positive coefficients statistically significant. For a number of conditions the effect is negative, and in some cases such as emotional problems and learning disabilities, even statistically significantly so. We conclude from this that in the U.S. during this time period the evidence of a link between the business cycle and health disability is very weak, weaker than in the UK.

Table 16: Incidence of specific self-reported health conditions in relation to state-level unemployment rates, PSID 1999-2005

\begin{tabular}{|l|c||c|}
\hline $\begin{array}{l}\text { Probability of reporting given health } \\
\text { condition: }\end{array}$ & $\begin{array}{c}\text { Coefficient on } \\
\text { unemployment rate }\end{array}$ & $\begin{array}{c}\text { Robust Standard } \\
\text { errors }\end{array}$ \\
\hline A) Stroke & $0.0018^{*}$ & 0.0008 \\
B) Heart Attack & 0.0007 & 0.0009 \\
C) Heart Disease & 0.0024 & 0.0012 \\
D) Asthma & 0.0002 & 0.0015 \\
E) Lung Disease & -0.0013 & 0.0010 \\
F) Diabetes & $0.0046^{*}$ & 0.0013 \\
G) Arthritis & -0.0011 & 0.0018 \\
H) Cancer & -0.0017 & 0.0011 \\
I) Mental problems & -0.0006 & 0.0008 \\
J) High Blood Pressure & $0.0082^{* *}$ & 0.0021 \\
K) Emotional Problems & $-0.0038^{* *}$ & 0.0013 \\
L) Learning Disability & $-0.0012^{*}$ & 0.0007 \\
\hline
\end{tabular}

Note: PSID data 1999-2005. We include demographic controls as in Table 12 and 13 above and also a measure of yearly salary. We report coefficients and standard errors after running LPM for each condition separately. All regressions have 45,462 observations. ${ }^{* *} p$ value $<0.01,{ }^{*} p$ value $<0.05$

Table 17 then links disability reports with reports on health conditions and the unemployment rate, and similarly to table 15 , we test whether the onset of a given condition is associated with disability reports. We then test whether the probability of reporting being disabled given the onset of a particular health condition is higher in states where the unemployment rate is higher. The results are broadly in line to what we obtained in the BHPS, in fact showing a stronger and significant association between self-reported incidence of conditions and disability reports. The effects are quite large in magnitude compared with the predicted probability. We interpret this as 
showing that disability in the U.S. is more clearly related to underlying health conditions, even after controlling for the unemployment rate in the state of residence of the individual.

In the last column and row of the table we can observe the positive association of the unemployment rate with self-reported disability even after controlling for the incidence of conditions, and the interaction of the conditions with the unemployment rate, suggesting a significant direct business cycle effect. Additionally, through the coefficient on the interaction terms we find that the association between health and work disability is likely pro-cyclical but weaker than in the UK, but as in that country, we can conclude that it cannot be used to explain the countercyclical relationship between disability reports and unemployment. Notice that the disability system in the US is a Federal program, and in principle not geared towards responding to variation in economic conditions so the business cycle effect is weaker as could be expected. The fact that the results are in line with the British case is remarkable, and comes to show that our methodology likely uncovers the underlying relationships between these variables that illuminate the policy discussion.

Table 17:

Probability of claiming disability benefits conditional on reporting certain specific health conditions and unemployment rate, PSID 1999-2005

\begin{tabular}{|l|l|l|}
\hline $\begin{array}{l}\text { Probability of condition } \\
\text { at } t \text { given not at } t-1\end{array}$ & $\begin{array}{l}\text { Reporting Disability } \\
\text { (DIS) }\end{array}$ & $\begin{array}{l}\text { DIS with interaction } \\
\text { (health } \times \text { U rate) }\end{array}$ \\
\hline \hline A) Stroke & $0.0013^{* * *}(0.0005)$ & $0.000007(0.00005)$ \\
\hline B) Hearth Attack & $0.00006(0.00008)$ & $-0.000059(0.00005)$ \\
\hline \hline C) Heart Disease & $0.00019^{*}(0.0001)$ & $0.000022(0.00004)$ \\
\hline \hline D) Asthma & $0.00013(0.00009)$ & $0.000036 \quad(0.00004)$ \\
\hline E) Lung Disease & $0.00026^{*}(0.00014)$ & $0.000007(0.00005)$ \\
\hline \hline F) Diabetes & $0.0005^{* * *}(0.00018)$ & $-0.000019(0.00004)$ \\
\hline \hline G) Arthritis & $0.00065^{* * *}(0.00019)$ & $-0.000009(0.00003)$ \\
\hline H) Cancer & $0.00033^{* *}(0.00017)$ & $0.000008 \quad(0.00005)$ \\
\hline \hline I) Mental problems & $0.00079^{* *}(0.00033)$ & $-0.00009(0.00006)$ \\
\hline J) High Blood Pressure & $0.00034^{* * *}(0.00011)$ & $0.000023(0.00003)$ \\
\hline K) Emotional problems & $0.00154^{* * *(0.00046)}$ & $0.000019(0.00004)$ \\
\hline \hline L) Learning Disability & $0.00159^{* *}(0.00064)$ & $-0.00012^{*}(0.00007)$ \\
\hline L) Unemployment Rate & $0.00005^{* *}(0.00002)$ & $0.00005^{*}(0.00003)$ \\
\hline
\end{tabular}


Note: Analysis of PSID 1999-2005. We include the demographic controls as in Table 12 and 13. We report in the table marginal effects after estimating Random Effects Probit Models. The number of observations is 48,088 . The predicted probabilities are $0.018 \%$ and $0.017 \%$, respectively for the two columns. $p$ value $<0.1$, $* * \mathrm{p}$ value $<0.05, * * * \mathrm{p}$ value $<0.01$

\section{Conclusion and policy discussion}

At the heart of the discussion in this paper has been the distinction between 'work disability' and 'health disability'. We have shown that the stocks and flows of disability benefit claimants are highly sensitive to the business cycle, as measured by local variations in unemployment rates and, in the case of Spain, by regional variations in GDP growth. This illustrates the importance of the concept of 'work disability' in understanding the trend and fluctuation in claimant numbers, since there is little evidence that 'health disability' is related to the business cycle in a comparable manner. This is not the first study to show a relationship between disability benefit claims and unemployment rates but other studies have not considered the issue over a variety of cross-country data sets as here and nor have these studies considered the relationship between work and health disability over the business cycle in an integrated manner.

Why are disability benefit claims related to the business cycle? In principle, disability insurance systems are based on a notion of health disability, with 'gateways' and assessments designed to identify and discriminate among applicants on grounds of underlying capacity to work. In some cases such as Spain and Germany, however, such programmes have been national gateways into early retirement in the face of adverse demand shocks - whether as an explicit national policy or as an implicit indirect route which is well-known and tolerated. ${ }^{4}$ More generally, since individuals are more likely to wish to claim disability benefits when job opportunities are fewer and/or real wages are lower, the business cycle 'effect' presumably arises because 'work capacity' assessments are applied in a more discretionary manner at a local level according to economic conditions anecdotal evidence suggests that 'capacity to work' is assessed less stringently in regions where employment opportunities are scarce and where particular individuals are 'hard to place'. Moreover where local managers of re-employment centres are under strong pressure from central government to keep unemployment figures down or to raise outflow rates from the unemployment register in times of recession, assigning individuals to the disability register is one mechanism for achieving these goals.

4 Cremer, Lozachmeur and Pestieau (2009) refer to the comparable use of the unemployment insurance programme in Belgium as an indirect early retirement route as a 'Canada Dry' pension - for an explanation of this nomenclature, see their footnote 5 . 
Of course, 'work disability' and 'health disability' are related because all disability insurance programmes impose some form of work capacity test. Indeed, in the data we observe a relationship between an individual's general self-reported health and the probability of receiving disability benefits. Crucially, however, this relationship does not affect the coefficients on the business cycle variables. Moreover, the incidence of given medical conditions is, if anything, pro-cyclical not counter-cyclical - strongly so in the United Kingdom, less so in the United States. And finally, in the European Labour Force Survey, whilst we observe a link between self-reported health and disability benefit receipt, a significant minority of disability benefit claimants report that they are in good health, and a substantial proportion of non-claimants report that they are in poor health.

Disability insurance programmes are built on the premise that many health disabilities are of long duration or even permanent after the onset of the condition, as in programmes where disability is essentially seen as a 'route' into early retirement. Consequently such programmes place great emphasis on initial evaluations of disability and in determining what constitutes capacity for work at the first screening of the applicant. Indeed many countries have tightened these conditions significantly in recent years, whilst adopting broader criteria for what constitutes 'capacity for work' (that is, a broader range of occupations that that in which the applicant has been employed in the recent past). However the analysis here shows, not just that some health disability is of potentially short duration, but that 'work disability' is related to specific economic and social circumstances which are time-varying. Tightening initial eligibility conditions, especially in recession, may not just be politically unpopular but also genuinely impose hardship on individuals who, for one reason or another, find it hard to find a job. It should be recognised that, de facto, disability insurance programmes do operate like somewhat more generous unemployment insurance (UI) programmes, but perhaps the major difference is that, whereas UI programmes operate on the premise that claimants are, in essence, temporary, disability insurance programmes often work on the basis that disabilities are long-standing. A consequence is that disability programmes can easily ratchet up in size over time - with sharp inflows during 'bad times' but low levels of outflow in 'good times' so that, at the onset of each downturn, the residual number of long duration claimants is higher.

This phenomenon is noted by OECD (2006), as in the earlier long quotation from that document. But arguably, it is the differentiation between health and work disability that lies at the heart of this observation and which should lie at the heart of their analysis. If 'work disability' is the key issue, attempts to tighten up the disability insurance regimes in recession look politically heartless whereas it is always easier to achieve employment targets in 'good times' by absorbing other groups into the workforce (such as married women and late retirees) rather than the more 
hard-to-place long duration disability benefit claimants. New thinking may be required to address the work disability-business cycle relationship.

One possible approach is to reconsider the nature of disability insurance programmes. Disability benefit payments are generally state contingent, in terms of labour market state: that is, applicants will obtain benefits if they can demonstrate that they are unable to work. Benefits are not paid because an individual is assessed as 'disabled' as such but because he or she is assessed as incapable of work (defined with varying degrees of specificity). So disability insurance is not a compensatory payment for long-standing illness or medical condition but, akin, to unemployment insurance, a subsidy for worklessness. Consequently, disability benefit payments are only available so long as the individual does not have a job and, like unemployment insurance, on the margin give an incentive to an individual not to find a job once the individual has passed the various eligibility criteria for disability benefits.

Analyses of incentives attached to disability insurance programmes often understate the costs of finding a job that face individuals who are in receipt of disability benefits. First, disability insurance programmes often offer higher replacement rates than unemployment insurance programmes. Second, an individual with a health disability is more costly to an employer than an individual with the same labour cost (i.e. wage and social insurance contributions) who does not have a health disability. The individual with a health disability is more likely to take time off to visit doctors or hospitals, to have to buy medicine and health treatments (which are more likely to be free if the individual is in receipt of disability benefits) and to take regular periods off work. Certain kinds of health disability (notably medical illness and psychological problems) may be stigmatising in the workplace. Finally, different criteria may be applied by benefit and re-employment offices to disability benefit claimants relative to, say, unemployment insurance claimants, in particular in relation to training and other active labour market policies. Tightly-budgeted labour market programmes may focus on 'easy to place' applicants and policies to re-employment disability benefit claimants may thereby appear less cost effective than those applied to other types of re-entrants.

This suggests policies not just to broaden criteria for 'work capacity' but also to pay greater attention to how 'work capacity' varies over the spell of disability benefit receipt and not simply at the initial application. More radically, still, thought could be given to detaching receipt of disability benefits (either in full or in part) from labour market state (i.e. activity or inactivity). For example, a policy could be implemented whereby a disability benefit recipient continues to receive all or part of 
their benefits even if they find a job - whether for a finite or an unlimited period. ${ }^{5}$ Of course, it is likely to be more expensive to pay disability insurance benefits as form of compensation for health disability rather than in relation to a lack of work capacity (work disability) given the number of people with some form of disability who continue to work. But this might deal with the incentive problems that arise from paying full benefit if the individual is inactive versus 'no benefit' if the person with a health disability continues to work. Such thinking might constitute an effective response to what has become an increasing budgetary problem for many OECD countries.

\footnotetext{
${ }^{5}$ See Benítez-Silva, Buchinsky, and Rust (2008), Benítez-Silva (2008), and Yin (2008) for a discussion of these possibilities within the U.S. Disability system.
} 


\section{Bibliography}

Aarts, L.J.M., and P.R. de Jong (1996): "European Experiences with Disability Policy," in J.L. Mashaw, V. Reno, R.V. Burkhauser, M. Berkowitz (eds.), Disability, Work and Cash Benefits. W.E. Upjohn Institute for Employment Research: Kalamazoo, Michigan.

Alba, A., and Moreno, F. (2004): "Discapacidad y Mercado de Trabajo," Obra Social Caja Madrid. Gente Interactiva. S.L. Madrid.

Anayadike-Danes, M. and McVicar, D. (2008) "Has the boom in incapacity benefit claimant numbers passed its peak?" Fiscal Studies, 29, December, 415-434.

Andrews, E.S. (1998): “Disability Insurance: Programs and Practice," manuscript, World Bank.

Autor, D. and Duggan, M. (2003): "The Rise in the Disability Rolls and the Decline in Unemployment," Quarterly Journal of Economics, February, 157-205.

Autor, D. and Duggan, M. (2006): "The Growth in the Social Security Disability Rolls: A Fiscal Crisis Unfolding," Journal of Economic Perspectives, Vol. 20-3, 71-96.

Baker, M., Stabile, M. and Deri, C. (2004) 'What do self-reported objective measures of health measure?' Journal of Human Resources, 39 (4), 1067-1093.

Beale, N. and Nethercott, S. (1988) "Certificated sickness absence in industrial employees threatened with redundancy", British Medical Journal, 28, May, 1508-1510.

Beatty, C. and Fothergill, S. (1996) "Labour market adjustment in areas of chronic industrial decline: The case of the UK coalfields", Regional Studies, 30, November, 627-640.

Benítez-Silva, H. (2008): "Disability, Social Insurance, and Labor Force Attachment," manuscript, SUNY-Stony Brook.

Benítez-Silva, H., Buchinsky, M. and Rust, J. (2003): "Dynamic structural models of retirement and disability", manuscript, UMD, UCLA and SUNY Stony-Brook.

Benítez-Silva, H., Buchinsky, M., and Rust, J. (2006): “How Large are the Classification Errors in the Social Security Disability Award Process?” manuscript, SUNY-Stony Brook, UCLA, and University of Maryland.

Benítez-Silva, H., Buchinsky, M., and Rust, J. (2008): "Induced Entry Effects of a \$1 for \$2 Offset in SSDI Benefits," manuscript, SUNY-Stony Brook, UCLA, and University of Maryland.

Benítez-Silva, H., Buchinsky, M., Chan, H., Cheidvasser, S., and Rust, J. (1999): “An Empirical Analysis of the Social Security Disability Application, Appeal and Award Process," Labour Economics, Vol. 6, 147-178.

Benítez-Silva, H., Buchinsky, M., Chan, H., Cheidvasser, S., and Rust, J. (2004): "How Large is the Bias in Self-Reported Disability?” Journal of Applied Econometrics, Vol. 19-6, 649-670.

Berkowitz, M. (1996): "Improving the Return to Work of Social Security Beneficiaries," in J.L. Mashaw, V. Reno, R.V. Burkhauser, M. Berkowitz (eds.), Disability, Work and Cash Benefits. W.E. Upjohn Institute for Employment Research: Kalamazoo, Michigan. 
Black, D., Daniel, K. and Sanders, S. (2002) "The impact of economic conditions on participation in disability programmes: Evidence from the coal boom and bust", American Economic Review, 92, March, 27-50.

Blau, D. (2008): "Retirement and Consumption in a Life Cycle Model," Journal of Labor Economics, Vol. 26-1, 35-71.

Blöndal, S. and Scarpetta, S. (1999) "The retirement decision in OECD countries", OECD Economics Department Working Papers no. 202, Organisation for Economic Co-operation and Development: Paris.

Bound, J. (1991) 'Self-reported versus objective measures of health in retirement models', Journal of Human Resources, 26, 106-138.

Bound, J., and R. Burkhauser (1999): “Economic Analysis of Transfer Programs Targeted on People with Disabilities," in O. Ashenfelter and D. Card (eds.), Handbook of Labor Economics, Vol. 3C. Elsevier Science, North Holland: Amsterdam, the Netherlands.

Bound, J., Schoenbaum, M., Stinebrickner, T.R. and Waidmann, T. (1999) 'The dynamic effects of health on the labor force transitions of older workers', Labour Economics, 6, 179-202.

Bridges, S. and Disney, R.: (2007) "Debt and depression", mimeo, University of Nottingham.

Brooker, A-S, Frank J., and Tarasuk, V. (1997): "Back pain claim rates and the business cycle", Social Science and Medicine, 45, 3, August, 429-439

Burkhauser, R. and Daly, M. (2001) "United States disability policy in a changing environment," Working Papers in Applied Economic Theory 2002-21, Federal Reserve Bank of San Francisco.

Burkhauser, R., Houtenville, A. and Wittenburg, D. (2003): "A User's Guide to Current Statistics on the Employment of People with Disabilities," in D.C. Stapleton and R.V. Burkhauser (eds.), The Decline in Employment of People with Disabilities: A Policy Puzzle. W.E. Upjohn Institute for Employment Research: Kalamazoo, Michigan.

Capella-McDonnall, M. (2007): "Effectiveness of the Ticket to Work Program for Beneficiaries Who are Blind or Have Low Vision: Comparisons with Other Beneficiaries," Journal of Visual Impairment \& Blindness, Vol. 101-5, 296-301.

Congressional Budget Office (1997): “Time-Limiting Federal Disability Benefits," Memorandum. Washington D.C.

Cremer, H., Lozachmeur, J-M. and Pestieau, P. (2009) 'Use and misuse of unemployment benefits for early retirement', European Journal of Political Economy, 25, June, 174-185.

Disney, R. and Webb, S. (1991) "Why are there so many long-term sick in Britain?" Economic Journal, 101, March, 252-262.

Disney, R. and Smith, S. (2002) 'The labour supply effect of the abolition of the earnings rule for older workers in the United Kingdom', Economic Journal, 112, March, C136-152.

Disney, R., Emmerson, C. and Wakefield, M. (2006) 'Ill-health and retirement in Britain: A panel databased analysis', Journal of Health Economics, 25, (July), 621-649.

Dwyer, D. S. and Mitchell, O. S. (1999), 'Health problems as determinants of retirement: are selfrated measures endogenous?', Journal of Health Economics, vol. 18, pages 173-193. 
French, E. (2005): "The Effects of Health, Wealth, and Wages on Labor Supply and Retirement Behavior," Review of Economic Studies, Vol. 72-2, 395-428.

GAO (General Accounting Office) (1987): Social Security. Little Success Achieved in Rehabilitating Disabled Beneficiaries. Report to the Chairman, Subcommittee on Social Security, Committee on Ways and Means, House of Representatives.

Gruber, J. and Kubik, J. (1997) "Disability insurance rejection rates and the labour supply of older workers", Journal of Public Economics, 64, April, 1-23.

Gruber, J. and Wise, D.A. (1999): Social Security and Retirement around the World. Editors, The University of Chicago Press: Chicago, Illinois.

Gruber, J. and Wise, D.A. (2004): Social Security and Retirement around the World: Micro-Estimation. Editors, The University of Chicago Press: Chicago, Illinois.

Guillén Estany, M. (ed.) (2007): Longevidad y Dependencia en España: Consecuencias sociales y económicas. Fundación BBVA.

Hassink, W.H.J., J.C. van Ours, and G. Ridder (1997): "Dismissal Through Disability," De Economist, 145-1, 29-46.

Haveman, R. and Wolfe, B. (1984) "Disability transfers and early retirement: A causal relationship?" Journal of Public Economics, 24, June, 47-66.

Haveman, R., de Jong, P. and Wolfe, B. (1991) "Disability transfers and the work decision of older men", Quarterly Journal of Economics, 106, August, 1419-1426.

Haveman, R.H., and B. Wolfe (2000): "The Economics of Disability and Disability Policy," in A.J. Culyer and J.P. Newhouse (eds.), Handbook of Health Economics, Volume 1. Elsevier Science, North Holland: Amsterdam, the Netherlands.

Hoynes, H.W., and R. Moffitt (1996): "The Effectiveness of Financial Work Incentives in Social Security Disability Insurance and Supplemental Security Income: Lessons from Other Transfer Programs," in J.L. Mashaw, V. Reno, R.V. Burkhauser, M. Berkowitz (eds.), Disability, Work and Cash Benefits. W.E. Upjohn Institute for Employment Research: Kalamazoo, Michigan.

Jenkins, R., Macdonald, A., Murray, J. and Strathdee, G. (1982): "Minor psychiatric morbidity and the threat of redundancy in a professional group" Psychological Medicine, 12 4, pp. 799-807.

Jiménez-Martín, S. and Vall-Castelló, J. (2009): “Business Cycle Effects on Labor Force Transitions for Older People in Spain," FEDEA, WP 2009-25.

Jiménez-Martín, S. Labeaga JM and Vilaplana, C. (2006): “"A sequential model for older workers' labor transitions after a health shock", Health Economics, 15(9), 1033-1059.

Jiménez-Martín, S., J.M. Labeaga, and C. Vilaplana Prieto (2006): “Award errors and permanent disability benefits in Spain," Universitat Pompeu Fabra WP-966.

Kapteyn, A., Smith, J.P., and van Soest, A. (2007): "Vignettes and self-reporting on work disability in the United States and the Netherlands", American Economic Review, 97, March, 461-473.

Koning, P., and D.J. van Vuuren (2007): "Hidden Unemployment in Disability Insurance," Labour, 21(4), 611-636. 
Koning, P., and D.J. van Vuuren (2008): "Disability Insurance and Unemployment Insurance as Substitute Pathways," forthcoming in Applied Economics.

Kossoris, M. (1938): "Industrial injuries and the business cycle", Monthly Labor Review, 46, 579-594.

Kossoris, M. (1943): "Changes in injury frequency rates and employment in manufacturing, 19361941", Monthly Labor Review 56 5, pp. 949-954

Lahiri, K., D.R. Vaughan, and B. Wixon (1995): “Modeling SSA's Sequential Disability Determination Process Using Matched SIPP Data," Social Security Bulletin, Vol. 58-4, 3-42.

Lindeboom, M. and van Doorslaer, E. (2004): "Cut point shift and index shift in self-reported health", Journal of Health Economics, 23, November, 1083-1099.

Lutz, W., Sanderson, W. and Scherbov, S. (2008) "The coming acceleration of global population ageing," Nature, Vol. 451-7, 716-719.

Magnac, T. and D. Thesmar (2002): “Identifying Dynamic Discrete Decision Processes,"

Econometrica, Vol. 70-2, 801-816.

Malo, M.A. (2004): “¿Cómo afectan las discapacidades a la probabilidad de ser activo en España? Un análisis empírico con datos de la Encuesta sobre Discapacidades, Deficiencias y Estado de Salud de 1999," Cuadernos de Economía, Vol. 27, 75-108.

McVicar, D. (2006) "Why do disability benefit rolls vary across regions? A review of the evidence from the USA and the UK", Regional Studies, 40, July, 519-533.

McVicar, D. (2008): “Why have UK Disability Benefit Rolls grown so much?" Journal of Economic Surveys, Vol. 22-1, 114-139.

Moffitt, R. (2003): "The Role of Randomized Field Trials in Social Science Research: A Perspective from Evaluations of Reforms of Social Welfare Programs," manuscript, Johns Hopkins University.

Molinas, C. (ed.) (2008): “Instrumentos Financieros para la Jubilación,” Fundación de Estudios Financieros. Working Paper No. 24.

Muller, L.S. (1992): "Disability Beneficiaries Who Work and Their Experience Under Program Work Incentives," Social Security Bulletin, Vol. 55-2, 2-19.

Muller, L.S. (2000): "The Search for Evidence of a Labor Supply Response to a Benefit Offset," Office of Research, Evaluation and Statistics, Social Security Administration.

Muller, L.S., Scott, G., and B.V. Bye (1996): "Work and Earnings of SSI Disability Recipients," Social Security Bulletin, Vol. 59-2, 22-42.

Muñoz Machado, S., J.L. García Delgado, and L. González Seara (1997): Las estructuras del bienestar. Editorial Civitas, Madrid.

Nagi, S.Z. (1964): "A Study in the Evaluation of Disability and Rehabilitation Potential," American Journal of Public Health, Vol. 54-9 1568-1579.

Nagi, S.Z. (1969): Disability and Rehabilitation: Legal, Clinical, and Self-Concepts and Measurement. Ohio State University Press. 
Nagi, S.Z. (1991): "Disability concepts revisited: Implications for prevention," in Disability in America: Toward a National Agenda for Prevention. National Academy Press: Washington, D.C.

National Council of the Handicapped (1986): Disincentives to Work under the Social Security Laws. Report to the President and the Congress of the United States.

National Research Council (2001): Preparing for an Aging World: The Case for Cross-National Research. Panel on a Research Agenda and New Data for an Aging World, Committee on Population, Committee on National Statistics. National Academies Press.

Neumark, D. and E.T. Powers (2003): "The Effects of Changes in State SSI Supplements on PreRetirement Labor Supply," NBER working paper 9851.

OECD (2003): Transforming Disability into Ability: Policies to Promote Work and Income Security for Disabled People. OECD Publications, Paris, France.

OECD (2006): Sickness, Disability and Work: Breaking the Barriers, Volume 1: Norway, Poland and Switzerland, Organisation for Economic Co-operation and Development: Paris.

OECD (2007): Sickness, Disability and Work: Breaking the Barriers, Volume 2: Australia, Luxembourg, Spain and the United Kingdom, Organisation for Economic Co-operation and Development: Paris.

Retirement Behavior of Low-income Households," Journal of Econometrics, Vol. 145, 21-42.

Riphahn, R. (1997) "Disability retirement and unemployment: substitute pathways for labour force exit? An empirical test for Germany" Applied Economics, 29, 5, 551-561.

Robinson, J. and Shor, G. (1989): Business-cycle influences on work-related disability in construction and manufacturing. Milbank Quarterly 67 Supplement 2, pp. 92-111.

Ruhm, C. (2000): “Are recessions good for your health?" Quarterly Journal of Economics, 115, May, 617-650.

Rust, J. (1994): "Structural Estimation of Markov Decision Processes," in R. Engle and D. McFadden (eds.), Handbook of Econometrics, Vol. 4, 3082- 3139, Elsevier Science, North Holland: Amsterdam, the Netherlands.

Rust, J. and C. Phelan (1997): "How Social Security and Medicare Affect Retirement Behavior in a World of Incomplete Markets," Econometrica, Vol. 64-5, 781-832.

Salomon, J., Tandon, A. and Murray, C. (2004): 'Comparability of self-reported health: cross-country multicounty surveys using anchoring vignettes', British Medical Journal, 328, January, 258.

Sánchez Fierro J. (2004): Libro verde sobre la dependencia en España. Madrid: Fundación AstraZeneca.

Smith, R.T. and A.M. Lilienfeld (1971): "The Social Security Disability Program: An Evaluation Study," Research Report 39, Social Security Office of Research and Statistics.

Social Security Advisory Board (2003): The Social Security Definition of Disability. Washington, D.C. Social Security Advisory Board (2006): A Disability System for the 21st Century. Washington, D.C. 
Stapleton, D.C., B. Barnow, K. Coleman, K. Dietrich, and G. Lo (1994): Labor Markets Conditions, Socioeconomic Factors and the Growth of Applications and Awards for SSDI and SSDI Disability Benefits: Final Report. Lewin-VHI, Inc. and the Department of Health and Human Services. Office of the Assistant Secretary for Planning and Evaluation.

Taber, C.R. (2000): "Semiparametric Identification and Heterogeneity in Discrete Choice Dynamic Programming Models," Journal of Econometrics, Vol. 96, 201-229.

Thornton, C. (Project Director) (2007): Evaluation of the Ticket to Work Program: Assessment of PostRollout Implementation and Early Impacts. Mathematica Policy Research Inc., under contract from the Social Security Administration.

Todd, P., and K.I. Wolpin (2006): “Using Experimental Data to Validate a Dynamic Behavioral Model of Child Schooling and Fertility: Assessing the Impact of the School Subsidy Program in Mexico," American Economic Review, Vol. 96-5, 1384-1417.

Todd, P., and K.I. Wolpin (2007): "Ex-Ante Evaluation of Social Programs," forthcoming in Annals of Economics and Statistics.

Tuma, N. (2001): “Approaches to Evaluating Induced Entry into a New SSDI Program with a \$1 Reduction in Benefits for each $\$ 2$ in Earnings," manuscript, Stanford University.

van der Klaauw, W., and K.I. Wolpin (2008): "Social Security, Pensions and the Savings and Westerhout, E. (2001): "Disability Risk, Disability Benefits, and Equilibrium Unemployment," International Tax and Public Finance, Vol. 8-3, 219-243.

WHO (1980): The International Classification of Impairments, Disabilities, and Handicaps-A Manual Relating to the Consequences of Disease. World Health Organisation: Geneva.

Wolpin, K.I. (1996): "Public-Policy Uses of Discrete-Choice Dynamic Programming Models," American Economic Review, Vol. 86, 427-32.

Wolpin, K.I. (2007): "Model Validation and Model Comparison Ex Ante Policy Evaluation, Structural Estimation, and Model Selection," American Economic Review, Vol. 97-2, 48-52.

Wunderlich, G.S., D.P. Rice, and N.L. Amado (eds.) (2002): The Dynamics of Disability: Measuring and Monitoring Disability for Social Security Programs, National Academy Press: Washington, D.C.

Yin, N. (2008): "Partial Benefits in the Social Security Disability Insurance: A Policy Alternative to Foster Work among the Disabled," manuscript, Baruch College-CUNY. 


\section{APPENDIX}

\section{A. Disability rules across the EU and the US}

In this section, we describe briefly disability rules in the four countries that we analyze in depth in this work: Germany, Spain, UK and the US. See table A.1 for details about these countries and MISSOC DISABILITY (ec.europa.eu/employment_social/missoc/) for details about other EU27 countries.

\section{A.1 Disability in Germany}

There are several types of DI benefits in Germany. The most important of them are:

- full disability pension: People that are only able to work less than 3 hours per day receive the full disability pension.

- partial disability pension ( $1 / 2$ of the full d.p.): people that are able to work between 3 and 6 hours per day receive the partial disability pension that equals half the full disability pension.

- disability pension with "qualification guarantee" (Berufsschutz):

People that are born before 1961 have a "qualification guarantee". This means if they are disabled they cannot be forced to take a job, which requires much lower qualifications even if their degree of disability allowed them to continue working in this lower qualified job (e.g. a disabled head of department receives disability pension even if he is able to work as a cashier). Therefore for people with qualification guarantee it is much easier to receive a disability pension.

In our sample $80 \%(9,069$ of 11,210$)$ of the disabled labor force were born before 1961 , thus enjoy the qualification guarantee.

How much is the pension?

- full disability pension: $60 \%$ of the retirement pension that the disabled individual would have gotten if he had worked and paid retirement contributions until age 57.

- partial disability pension: $50 \%$ of the full disability pension ( $30 \%$ of the retirement pension).

Recent policy changes.

- before 2001, everybody enjoyed the "qualification guarantee" (see above), whereas afterwards this guarantee only applies to individuals born before 1961 (which makes it harder for those born after 1960 to receive disability pensions). Therefore as an effect of the policy change we should observe a reduction of disability inflows of people born after 1960.

- before 2001, disability pension were considered as permanent. Only if an improvement of the disability status was extremely likely the pension was paid and considered temporarily. Beginning with 2001, disability pensions are generally considered temporary and only if health improvements are very unlikely, they are considered permanent. As an effect of this policy change we should expect an increased disability outflow beginning after 2001.

\section{A.2 Disability rules in Spain}

The SS system provides insurance against both temporary and permanent illness or disability. 
The subsidy for temporary illness or disability (incapacidad laboral transitoria) was not regulated by the 1985 reform, and its terms of provision have undergone frequent changes. Eligibility requires affiliation to the SS system for a minimum period that depends upon the nature of the covered risk. Common illness requires only 180 days of contributions during the last 5 years, paid maternity/ paternity leave requires at least 9 months before the date of delivery and 180 days during the last 12 months, whereas no minimum eligibility criterion is imposed for work-related accidents or illnesses. The benefit base depends on actual earnings during the last 12 months. In case of common illness or work-unrelated accident, the subsidy is equal to 6 percent of the benefit base for each day of absence between the 4th and the 20th, and to 75 percent of the benefit base afterwards until the maximum period is reached. It is always equal to 75 percent in case of work-related accident or illness and in case of maternity/paternity leave (only one of the parents being allowed to use the subsidy for each child). The maximum period for which the subsidy can be received is 18 months, after which the worker must either return to work or be classified as "permanently disabled".

\section{Contributory disability pensions}

Permanent disability pensions have played an important role in allowing Spanish workers to retire at ages earlier than 60. In particular, they have been used extensively during the late 1970 s and early 1980 s as an early-retirement mechanism for workers in restructuring industries (shipbuilding, steel, mining, etc.), or as substitutes for long-term unemployment subsidies in depressed regions.

The total disability rate (as a percentage of the workforce) doubled in less than ten years, from about 0.7 percent in 1975 to 1.5 percent in 1983 . The 1985 reform, by tightening the requirements, managed to bring the phenomenon under partial control. Disability rates have since decreased, stabilizing around 0.6 percent.

Disability pensions are distinguished into contributory and non-contributory. We limit ourselves to the contributory pensions. Eligibility and pension amounts depend on the level of disability. The 1985 reform distinguished four levels of permanent disability characterized by increasing severity. Since then, the legislation has formally reduced them to three, but has also created a special subcase of the first level with the explicit purpose of using the disability funds to subsidize the dismissal of old workers from certain sectors or geographic areas. The first level (incapacidad permanente total para la profesión habitual, or IPT) corresponds to inability to do the usual job. A special subcase (incapacidad permanente total cualificada para la profesión habitual, or IPTC) applies only to employees older than 55 which are in particular socio-economic situations. The second level (incapacidad permanente absoluta, or IPA) corresponds to inability to do any kind of job. The third level (gran invalidez, or GI) requires, in addition, continued attendance by other persons in order to carry out the basic vital functions.

When disability is caused by an ordinary illness, eligibility to a pension requires from 5 to 15 years of contributions, depending on the age when the person fell ill and the seriousness of the disability. There is no contributory requirement when the disability is caused by an accident, whether or not work-related, or a professional illness.

Eligibility requirements are fairly complicated. We try here to streamline their presentation. In the cases of IPA or GI, 15 years of contributions are required, of which at least 3 during the last 10 years. For the other two cases (IPT and IPTC), eligibility depends on age. For persons aged 26 or younger, the requirement is half of the number of years between the age of 16 and the age when disability began. For persons older than 26, the requirement is either 5 years or a fourth of the number of years between the age of 20 and the age when disability began, whichever is largest. Furthermore, at least a fifth of the required contributory years must have occurred during the last 10 years. 
The benefit base depends on the source of disability. In case of ordinary illness, it is computed as for old-age pensions. For work-unrelated accident, it is the average annual wage over a period of 24 consecutive months chosen by the person within the last 7 years of work. For work-related accident or professional illness, it is the average wage in the last year of work. The pension equals 55 percent of the benefit base under IPT, and increases to 75 percent under IPTC. In case of IPA, it is equal to 100 of the benefit base, whereas for $\mathrm{Gl}$ it is equal to 100 percent of the benefit base plus another 50 percent covering the person taking care of the disabled.

Disability pensions are indexed to inflation like the other pensions of the RGSS. Unlike the latter, however, disability pensions may be kept while earning income from a job different from the one for which the disability (even a complete one) was determined.

Recent reform efforts

In 2005 there was an improvement of the control of sickness leave benefits. In 2007 the government passed a Social Security reform changing various aspects of the DI system regulations. The law introduced some changes in the requirement to get a DI pension for young individuals and increased the link between the contribution period and the pension amount.

\section{A.3 Disability Rules in the UK}

Real public spending on the main National Insurance disability benefits - which are, since 1995, Incapacity Benefit (ICB) and, before that time, Invalidity Benefit (IVB) - more than doubled between the late 1970 s and 1995 , as did the number of claimants.

Two major reforms were introduced between 1971 and the turn of the century: the 1995 reform that replaced ICB with IVB, and the 1999 Welfare Reform and Pensions Act, which increased the stringency of the work test against which potential claimants were evaluated from April 2000, and also introduced a degree of means-testing of benefits from April 2001. However, a new reform was passed in 2008, which is briefly described.

The main changes to the disability programme that arose from the 1995 and 1999 reforms are discussed in greater detail below - but a summary of the key changes is contained in Table A1:

Table A1

The UK benefit regimes 1971-2002: A summary

\begin{tabular}{|c|c|c|c|}
\hline Duration & $\begin{array}{c}\text { Invalidity benefit } \\
1971-1995\end{array}$ & $\begin{array}{c}\text { Incapacity benefit } \\
1995-2001\end{array}$ & $\begin{array}{c}\text { Incapacity benefit } \\
2001-\end{array}$ \\
\hline $\begin{array}{c}\text { Paid at a constant rate } \\
\text { from week 28 of period } \\
\text { of incapacity. }\end{array}$ & $\begin{array}{c}\text { Paid at a short-term higher } \\
\text { rate in weeks } 29-52 \text { and at } \\
\text { a long term rate from week } \\
\text { Age } \\
\text { additions }\end{array}$ & $\begin{array}{c}\text { Three age additions, } \\
\text { payable from week 28. }\end{array}$ & $\begin{array}{c}\text { Paid at a short-term higher } \\
\text { rate in weeks } 29-52 \text { and at } \\
\text { a long term rate from week } \\
52\end{array}$ \\
\hline Age limits & $\begin{array}{c}\text { Payable up to age } 65 \text { for } \\
\text { women and 70 for men. } \\
\text { Earnings-related pension } \\
\text { payable. }\end{array}$ & $\begin{array}{c}\text { Long-term ICB not paid to } \\
\text { people over state pension } \\
\text { age; short-term ICB paid for } \\
\text { up to } 52 \text { weeks if incapacity } \\
\text { began before pension age }\end{array}$ & $\begin{array}{c}\text { Tong-term ICB not paid to } \\
\text { people over state pension } \\
\text { age; short-term ICB paid for } \\
\text { up to 52 weeks if incapacity } \\
\text { began before pension age }\end{array}$ \\
\hline $\begin{array}{c}\text { Tax } \\
\text { treatment }\end{array}$ & All claims are non- \\
taxable & New claims are taxable & New claims are taxable \\
\hline
\end{tabular}




\begin{tabular}{|c|c|c|c|}
\hline $\begin{array}{c}\text { Means- } \\
\text { testing }\end{array}$ & Non means-tested & Non means-tested & $\begin{array}{c}\text { Reduced by 50p for every f1 } \\
\text { of private pension income }> \\
\text { f85 a week }\end{array}$ \\
\hline Work tests & $\begin{array}{c}\text { Eligibility based on own } \\
\text { occupation test (weeks 1 } \\
-28 \text { ) and suitable work } \\
\text { test carried out by own } \\
\text { GP (from week 29) }\end{array}$ & $\begin{array}{c}\text { Eligibility based on own } \\
\text { occupation test (weeks 1 - } \\
\text { 28) and all work test carried } \\
\text { out by govt medical service } \\
\text { (from week 29) }\end{array}$ & $\begin{array}{c}\text { Eligibility based on own } \\
\text { occupation test (weeks 1 - } \\
\text { 28) and personal capability } \\
\text { assessment carried out by } \\
\text { govt medical service (from } \\
\text { week 29) }\end{array}$ \\
\hline
\end{tabular}

Invalidity benefit and incapacity benefit

We consider these reforms in detail and how they affected the incentives for applying for IVB/ICB relative to other social security benefits.

Invalidity Benefit $1971-1995$

Invalidity benefit (IVB) was introduced in 1971. It consisted of two separate benefits - a flat-rate invalidity pension and an invalidity allowance that depended on the age when the person first became incapable for work. Like other National Insurance (NI) benefits, eligibility for IVB required certain $\mathrm{NI}$ contribution requirements to be met. It was not means-tested and, unlike other $\mathrm{NI}$ benefits, it was not subject to tax.

IVB was payable up to age 65 for women and age 70 for men. However, a benefit recipient could choose to defer receipt of their state pension for up to five years and continue to receive IVB instead. If this decision was made, the individual would not be able to augment the value of their basic retirement pension on receipt by deferral. ${ }^{6}$ But the decision to defer could still be advantageous, since IVB was paid at the same rate as the basic state pension but, unlike the basic state pension, was not subject to income tax.

IVB was payable from the $29^{\text {th }}$ week of a period of incapacity for work. Until then, someone would receive either statutory sick pay (or a higher rate of employer's sick pay) or sickness benefit. For the first 28 weeks, incapacity for work was determined on the basis of an own occupation test, i.e. whether someone was able to perform his or her normal job. After 28 weeks, the scope of the test was widened to include other jobs that it was reasonable to expect the person to do given their age, qualifications, skills and health status (the 'suitable work test'). However, in both cases, medical certificates from the individual's doctor were enough to prove incapacity for work although cases could get referred to the Department of Social Security regional medical service. In practice, the criteria used by doctors to determine incapacity for work seemed to permit a wide degree of discretion.

\section{The 1995 reform: The introduction of Incapacity Benefit}

Incapacity benefit (ICB) replaced IVB (and sickness benefit) in April 1995. The effect of the reform was to reduce the benefit's generosity in a number of ways and to tighten the eligibility requirements. ${ }^{7}$

\footnotetext{
${ }^{6}$ On the attraction of deferral, and also the abolition of the 'earnings test', see Disney and Smith (2002).

${ }^{7}$ The changes affected only new claimants after April 1995. Those people already entitled to receive invalidity benefit continued to do so under the old rules.
} 


\section{Reduced generosity}

- ICB is paid at three different rates according to the length of the period of incapacity. Short-term lower rate ICB has replaced sickness benefit for people not eligible for statutory sick pay. A shortterm higher rate of ICB is payable from week 29 to week 52 . In spite of its name, this is less generous than IVB. Long-term ICB, which is as generous as IVB, is only payable from week 52.

- The generosity of the age additions has been reduced. Previously, someone would have been eligible for an age addition to their invalidity pension if the period of incapacity began before age 59 . Since 1995 they are only eligible for an age addition if the period of incapacity begins before age 45 . In addition, the age additions are payable after week 52, when long-term ICB begins, rather than after week 28.

- ICB is taxable. This brings it into line with the other main NI benefits (retirement pensions and unemployment benefits) and income support, which are subject to tax. However, compensatory disability benefits (war disability pension and industrial injuries disablement pension) and extra costs disability benefits (disability living allowance, attendance allowance) are not subject to tax.

- Unlike IVB, long-term ICB is not payable to anyone over state pension age, although people who start receiving short-term ICB before state pension age can continue to do so for the full 52 weeks.

\section{The All Work Test}

The 'suitable work test' that applied to IVB recipients after 28 weeks was replaced by the 'all work test'. Instead of an assessment of a person's ability to perform jobs that it was reasonable to expect them to do given their age, health and qualifications, the 'all work test' required an assessment of the person's ability to do any kind of work. The all work test involved an 'objective' assessment of the level of difficulty the person had in performing different physical and mental activities (for example, walking up and down stairs, bending and kneeling, coping with pressure). Points were awarded for the degree of difficulty they had performing each activity, with a minimum total number of points necessary to be deemed incapable of work.

A second change is that the all work test is carried out by the government medical service rather than the individual's own doctor. As with IVB, the claimant has the right to appeal for their case to be heard by a social security appeals tribunal.

\section{The 1999 Welfare Reform and Pensions Act}

Further changes to ICB were contained in the 1999 Welfare Reform and Pensions Act. The three key elements were:

- Replacement of the all work test with a new personal capability assessment which puts an emphasis on the work that people might be able to do, as well as the work they are incapable of doing.

- Tightening the National Insurance contribution requirements in an attempt to stop people moving from unemployment onto ICB.

- Introduction of an element of means-testing of ICB against private pension income.

\section{The personal capability assessment}

Under the all-work test, anyone eligible for ICB is deemed to be unable to do any type of work at all and likely to be discouraged from trying to get back to work since this could lead to benefit withdrawal. The personal capability assessment introduced from April 2000 places a greater 
emphasis on getting people back to work. Each person is given, in addition to an incapacity report along the lines of the old all work test, a capability report, providing advice on what they might be able to do in the future. This capability report will not be sent to the adjudication officer who decides each claim but to each claimant's personal adviser whose job it is to oversee each claim, to review it at intervals and develop a plan for getting the claimant back to work where appropriate.

\section{Contribution requirements}

Previously, eligibility for ICB required the applicant to have made minimum NI contributions during any one tax year, and to have been contributing - or credited with contributions - during the previous two tax years. This meant that someone who had been unemployed or sick or a carer during the previous two years or more was eligible to claim. From April 2001, the requirements were tightened to require that the person must have made minimum NI contributions in at least one of last three tax years. This brought ICB closer in step with contribution-based job seekers' allowance, for which someone must have paid minimum contributions in either of the last two tax years. (The government's original proposals were for the two contribution requirements to be identical.) The aim of this change was to prevent people moving onto ICB after a long period of unemployment, with the intended effect of increasing the flow of people from job seekers' allowance back into work.

It is possible, however, that the change may have had the perverse effect of encouraging people to move straight from work onto ICB, discouraging them from spending a period unemployed and actively seeking work. In addition, the reform may penalise those for whom a long period of unemployment has a damaging effect on their health.

\section{Means-testing}

The final change was to reduce the level of ICB received by people with income from occupational and personal pensions and permanent health insurance arranged by the employer (but not permanent health insurance taken out by the individual). The initial proposal was for a 50 pence reduction in ICB for every $£ 1$ of pension income above $f 50$ a week, but the threshold was eventually set at $f 85$ a week, the average pension income received by someone on incapacity benefit. To avoid the possibility of people delaying taking their pension, the government said that it would take account of 'notional income' from private pensions in cases where people are thought to be deferring payment, although this may be hard to do in practice.

Means-testing ICB against private pension income represents a deliberate attempt by the government to target limited public resources on the less well-off. In this respect it marked a retreat from the insurance principle behind National Insurance benefits which made benefit receipt a function of contributions and circumstances rather than incomes. Note too that the change did not introduce an element of means-testing against all forms of income.

One argument for introducing the element of means-testing of ICB might be to bring it more in line with contribution-based job seekers' allowance which is means-tested against occupational and personal pension income. An aim might be to avoid people taking ICB - and possibly limiting their job search activities - simply in order to avoid means-testing. However, the 1999 Welfare Reform and Pensions Act do not rule this out since the means-testing will be applied differently to the two benefits; job-seekers allowance is withdrawn at a rate of $100 \%$ for occupational and personal pension income above $f 50$ a week.

Moreover, choosing to means-test ICB only against income from occupational and personal pensions and employer-provided long-term health insurance - and not any other forms of income - is somewhat arbitrary. The government has said that it wants to target resources on the least well-off. But there will inevitably be some households with higher levels of total income (those with working spouses, those with income from individual long-term health insurance plans and those with high levels of financial assets) who will not lose out. Moreover, taking account only of private pension 
income would seem unfairly to penalise people who have chosen to save in the form of a pension compared to those who have chosen to save in other forms. For some people this might act as a disincentive to save in a pension in the first place.

The system Post-2008

In 2008, a new structure was introduced. In the October 2008 reform, Incapacity Benefit is replaced for new claimants by Employment Support Allowance (ESA). This reform involves:

-More generous standard payments (but dependents' additions removed)

-A new and stricter health test.

-National 'rolling out' of Pathways-to-Work, which had been introduced on a trial basis in 2003.

Pathways to work

This programme contained several elements: viz:

1. Intensive programme of Work Focused Interviews (WFIs)

- Earlier WFI (8 weeks after the claim)

- 5 further WFIs (roughly every four weeks) except for the "severely disabled" and "those likely to return to work without help"

2. Optional programmes to boost work prospects (Choices)

- NHS Condition Management Program (CMP)

- New Deal for Disabled People (NDDP)

- Other smaller programmes

3. Financial incentives: Return To Work Credit (RTWC)

- $\quad £ 40$ per week for first year after moving into paid work of at least 16 hours a week for those expecting to earn no more than $f 15 \mathrm{k}$ p.a.

- (also discretionary payments to help individuals find work.

Preliminary evidence from trial evaluations suggested that these programmes had a significant effect on the outflow from DI in the first 6 months of the spell, but little effect thereafter. And that the effect was focussed more on some work disability conditions (mostly physical) than others (mostly mental).

The 2008 Reform: Employment and Support Allowance (ESA)

Outline of the reform:

- Basic allowance: $£ 60.50$ p.w. (same as unemployment benefit)

- In the first 13 weeks: Work Capacity Assessment (WCA)

- If not 'limited capacity for work' => exit ESA

- If 'limited capacity for work' => Work-related activity (Pathways, Work focused interviews) $+£ 24$ p.w.

- If 'limited capacity for work-related activity' => Support group + f29 p.w.

- If low income, these amounts can be supplemented

- Depending on family conditions ( $+£ 12$ single, $+£ 34$ couples) 
- Level of disability ( $+£ 50$ severe dis., $+£ 28$ carers)

- No more dependent additions

- Benefits does not depend anymore on the age of first disability

\section{A.4 Disability Rules in the US}

There are two major publicly provided long-term disability programs in the United States, the Social Security Disability Insurance (SSDI) and the Supplemental Security Income (SSI). While the two programs share one system to decide who will receive benefits, the eligibility criteria are quite different, since SSI is means tested, and it is not considered Social Security, which allows beneficiaries to receive it at the same time as SSDI. ${ }^{8}$

The Social Security Disability Insurance (SSDI) program paid benefits to over 9.5 million Americans during 2006, at a cost of 92 billion dollars. These individuals have some type of severe health problem that, according to the government, is likely to last more than 12 months or result in death, and that prevents them from engaging in any substantial gainful activity (SGA). ${ }^{9}$ The SSDI provides them with earnings of more than $\$ 970$ a month. ${ }^{10}$ This program has work requirements and individuals need to have worked for 5 years out of the last 10 in order to qualify. There is no minimum age to receive the benefits, and when individuals reach the Normal Retirement Age it converts to Old Age Benefits. Individuals are eligible for Medicare two years after joining the program. The growth in the program in the last decade and a half has been impressive. For example, in 1990 there were only 4.9 million beneficiaries, and the SSA forecasts that the number of beneficiaries will increase by around 37\% by 2012 .

SSI is a means-tested cash assistance program enacted in 1974. Unlike SSDI, there is no work requirement for SSI benefits. However, SSI applications are evaluated according to the same process as DI benefits and satisfy the same basic definition of disability. During $2006 \mathrm{SSI}$ paid benefits to 4.1 million individuals of ages 18 to 64, at a cost of 38 billions dollars. In 1990 the number of beneficiaries was 2.45 million. The SSI has very low asset threshold of only $\$ 2,000$ for a single individual. In terms of earnings threshold, for OASDI recipients all benefits above a \$20 disregard are subtracted from their SSI benefit level, and for those receiving labor earnings the disregard is \$85 a month. This low earnings disregards result in the average SSI recipient receiving considerably less than the federal SSI benefit rate of $\$ 623$ a month. As a result of different eligibility requirements, the SSI program serves a different "clientele" than does the SSDI program: $57 \%$ of disabled adults under 65 receiving SSI benefits are women, whereas 52\% of adult SSDI beneficiaries are male. In contrast to SSDI, SSI recipients are not subject to a five-month waiting period to receive benefits, and are immediately eligible for Medicaid benefits. However, monthly SSI benefits are significantly lower, averaging only $\$ 455$ per month in 2006. Notice, however, that as of December of 2006, over 1.2 million Americans were receiving both OASDI Disability benefits and SSI, indicating that a non-trivial

\footnotetext{
${ }^{8}$ We refer the reader to the work of Stapleton et al. (1994), Lahiri et al. (1995), Benítez-Silva et al. (1999, 2004), Bound and Berkhauser (1999), and Haveman and Wolfe (2000) provide careful descriptions and analysis of these programs.

${ }^{9}$ The SGA for nonblind persons is $\$ 980$ a month, and it is $\$ 1,640$ a month for the blind.

${ }^{10}$ As of December of 2006, 7.8 million individuals received SSDI benefits as disabled workers, spouses of disabled workers, or children of disabled workers. Of the total, $87 \%$ were disabled workers. Over $80 \%$ of the impairments among disabled workers were composed of mental disorders, problems of the nervous system, problems of the musculoskeletal system and connective tissue, endocrine diseases, and problems of the circulatory system.
} 
proportion of DI recipients have a history of earnings which provide for a fairly low DI benefit, and current assets level which allows them to receive SSI.

\section{Recent reform efforts in the US}

In the last few years the Social Security Administration (SSA) has considered a number of policy changes with the objective of fostering work among SSDI recipients. This has become an important priority in the government's agenda regarding disability policy. For example, Jo Anne B. Barnhart, former Commissioner of the SSA, stated in 2003 that expanding the employment opportunities for people with disabilities was one of the main objectives of her administration. ${ }^{11}$ Furthermore, in the Social Security 2003-2008 strategic plan, she also set as an objective to have an increase of $50 \%$ in the number of people with disabilities who achieve employment, by 2008 relative to the 2001 levels.

The system has provided some work incentives for some time. For example, disabled beneficiaries are encouraged to return to work by providing a trial work period (TWP), and an extended period of eligibility (EPE). During the TWP, earnings are allowed to exceed the Substantial Gainful Activity (SGA) dollar amount for 9 months. During the 3-year EPE that follows the TWP, benefits are withheld only for those months in which earnings exceed the SGA amount. After the end of the EPE, monthly benefits are terminated when earnings exceed the SGA amount. Certain impairment related expenses that a person needs to make in order to work may be deducted when counting earnings to determine whether the work is substantial. Even if cash benefits are withheld, Medicare and Medicaid coverage can continue. ${ }^{12}$

More recently a number of additional initiatives have started to be implemented, and some are in the pipeline of the policy makers. Five of them are already in place in some degree, and we will discuss in more detail the two other initiatives that might be implemented in the future.

First, the SSA has put in place the Ticket to Work program, which allows SSDI recipients to obtain free vocational counseling from thousands of different agencies located around the U.S. to help them return to work. The agency is paid "prospectively," that is, for every year a DI beneficiary stays off the rolls due to the vocational training and rehabilitation services it had provided up front. The agency receives $40 \%$ of the DI benefit the person would have been paid if they had stayed on the rolls. This initiative received a lot of support from researchers in the mid 1990s when the caseloads where increasing sharply while the rehabilitations and terminations had fallen to all time lows (see for example, Berkowitz (1996)). While the Ticket to Work Act seems like a highly innovative program, it is questionable as to whether it will represent a cost-effective use of government funds, and whether it will help a significant number of DI beneficiaries return to work. Since the policy is already implemented, the only alternative for researchers is to do "ex post" evaluations. These evaluations, so far, seem to show very poor results of this initiative (see for example Thornton (2007), and Capella-McDonnall (2007)).

The second initiative is the Expanded Availability of Health Care Services, which as of October 1, 2000, expands Medicaid and Medicare coverage to more people with disabilities who work. It extends Medicare Part A premium-free coverage for 93 months after the trial work period for most disabled beneficiaries who work. In addition, States now have the option to expand Medicaid coverage to workers with disabilities using income and resource limits set by the States.

The third initiative is the possibility of obtaining Expedited Benefits. Effective January 1, 2001, if a person's Social Security or SSI disability benefits have ended because of earnings from work, and if

\footnotetext{
${ }^{11}$ Stated in her address before the House Committee on Ways and Means Social Security Subcommittee, in September of 2003.

${ }^{12}$ Muller $(1992,2000)$ indicates that only about $11 \%$ of new DI awardees eventually take advantage of the TWP.
} 
he or she becomes unable to work again within 60 months because of his or her medical condition the person would be able to request reinstatement of benefits, including Medicare and Medicaid, without filing a new application.

The fourth initiative is called the Disability Reviews Postponed. Effective January 1, 2001, an individual using a "ticket" does not need to undergo the regularly scheduled disability reviews. Effective January 1, 2002, people who have been receiving Social Security disability benefits for at least 24 months will not be asked to go through a disability review because of the work they are doing. However, regularly scheduled medical reviews could still be performed and benefits could be terminated if earnings were above the limits.

The fifth initiative is the Work Incentives Outreach Program. The law directs the Social Security Administration to establish a community-based work incentives planning and assistance program to disseminate accurate information about work incentives and to give beneficiaries more choice. SSA has established a program of cooperative agreements and contracts to provide benefits planning and assistance to all disabled beneficiaries, including information about the availability of protection and advocacy services.

It is still early to assess the ultimate effect of all these policies, but with the current hard numbers in hand the effect on Social Security terminations due to return to work above the SGA level have actually declined in percentage of initial beneficiaries from 2001 to 2006. Clearly this is disappointing, and seems to indicate that the piece-meal approach to reform is unlikely to lead to the kind of change needed for work to start playing a real role in the lives of millions of disability recipients. Precisely because of this, both among researchers and internally at SSA, there is the sense that more radical reforms are necessary.

While these reforms are discussed, the programs have to face the reality that with the deteriorating economic conditions of the last 18 months the interest in the disability programs is likely to soar, even if officially the disability programs are not supposed to be a source of amelioration of the problems in the labor market. Historically, the trends in the program have broadly responded to the business cycle, with increases in applications and awards during tougher economic years. However, the trends of the last decade are harder to link with the macroeconomic trends given that the explosion in applications has coincided with relatively good economic times. 
Table A2. Key elements of Disability Insurance systems in selected countries.

\begin{tabular}{|c|c|c|c|c|}
\hline & GERMANY & SPAIN & UK & US \\
\hline $\begin{array}{l}\text { Name and } \\
\text { kind of } \\
\text { provision }\end{array}$ & $\begin{array}{l}\text { The main provision is EMR. This is a contributory } \\
\text { insurance benefit. Voluntary insurance is possible } \\
\text { for all persons over the age of } 16 \text { years resident in } \\
\text { Germany and for all Germans abroad. As soon as } \\
\text { the standard retirement age has been reached, the } \\
\text { pension is converted into old-age pension. }\end{array}$ & $\begin{array}{l}\text { Employees. Special scheme for the self-employed. Since } \\
1984 \text { to } 2007 \text { it is required to attend the following } \\
\text { requirements: *To have less than } 65 \text { years of age on the } \\
\text { date in which the person begins the situation of } \\
\text { disability. }{ }^{*} \text { To be affiliated and in enrol or in a similarity } \\
\text { condition. *Benefit requirements that vary according } \\
\text { the degree and the cause of disability. Disability is } \\
\text { define as a permanent incapacity: Situation of a worker } \\
\text { who, after having undergone prescribed treatment, } \\
\text { suffers from physical or functional disabilities, capable } \\
\text { of objective assessment and probably definitive in } \\
\text { character, which render him/her partially or totally } \\
\text { incapable of work. It is necessary to prove at least 33\% } \\
\text { reduction in capacity. }\end{array}$ & $\begin{array}{l}\text { Employed, self-employed and } \\
\text { unemployed persons who have } \\
\text { an incapacity for work by reason } \\
\text { of physical or mental illness or } \\
\text { disability in a period. It is } \\
\text { necessary to be incapable of all } \\
\text { works }(100 \%) \text {. }\end{array}$ & $\begin{array}{l}\text { People are disabled under Social Security rules if: } \\
\text { *cannot do work that they did before; *govern decide } \\
\text { that they cannot adjust to other work because of their } \\
\text { medical condition(s); and *their disability has lasted or } \\
\text { is expected to last for at least one year or to result in } \\
\text { death. Then a person must be unable to engage in } \\
\text { substantial gainful activity (SGA). }\end{array}$ \\
\hline $\begin{array}{l}\text { Calculation } \\
\text { basis }\end{array}$ & $\begin{array}{l}\text { Insured employment income (up to contribution } \\
\text { ceiling) during the entire duration of the insurance. } \\
\text { The monthly contribution ceiling for } 2008 \text { is: West: } \\
5,300 € \text { and east: } 4,500 € \text {. In periods of child-raising } \\
\text { the calculation is based on average earnings. }\end{array}$ & $\begin{array}{l}\text { There are two main forms of income support for } \\
\text { disabled people: *contributory incapacity pensions and } \\
\text { non-contributory invalidity benefits. Nowadays the law } \\
\text { governing both benefits is consolidatek in the General } \\
\text { Law on Social Securtiy. }\end{array}$ & $\begin{array}{l}\text { Incapacity Benefit (IB). Non } \\
\text { contributory pension. }\end{array}$ & $\begin{array}{l}\text { Two programs: *Social Security: pays only for total } \\
\text { disability. No benefits are payable for partial disability } \\
\text { or for short-term disability.*Supplemental Security } \\
\text { Income disability. Both are administered by the Social } \\
\text { Security Administration. }\end{array}$ \\
\hline Generosity & $\begin{array}{l}\text { Partial incapacity: PEP } \times \text { RA (0.5) } \times \text { AR. Total } \\
\text { incapacity: PEP } \times \text { RA }(1,0) \times A R \text {. } \\
\text { Personal Remuneration Points: The sum of } \\
\text { remuneration points results from the insured } \\
\text { earnings for each year divided by the national } \\
\text { average of earnings for the same year and the value } \\
\text { of credited non-contributory periods, multiplied } \\
\text { with the access factor which follows the age of the } \\
\text { insured at the commencement of pension payments } \\
\text { (at a maximum of } 10.8 \% \text { ) and effects reductions of } \\
\text { the pension amount. *RA = Factor of pension type: } \\
\text { Represents the targeted level for each pension type } \\
\text { in relation to the old-age pension. } \\
\text { *AR = Current pension value: Corresponds to the } \\
\text { monthly pension paid to an average earner for each }\end{array}$ & $\begin{array}{l}\text { Result of dividing the sum of the contribution bases of } \\
\text { the } 96 \text { months prior to the month in which the event } \\
\text { occurred by } 112 \text {. The } 24 \text { months immediately prior at } \\
\text { face value, the others will be updated according to the } \\
\text { evolution of the Consumer Price Index. The old-age } \\
\text { percentage rate is applicable. In case of a non-work- } \\
\text { related accident, the calculation basis is the result of the } \\
\text { division of the contribution bases during a continuous } \\
\text { period of } 24 \text { months chosen within the } 7 \text { previous years } \\
\text { by } 28 \text {. Annual pension ceiling: } 33,383.14 € \text {. }\end{array}$ & $\begin{array}{l}\text { No reference earnings. The } \\
\text { amount is determined by care } \\
\text { and mobility needs. }\end{array}$ & $\begin{array}{l}\text { The amount of monthly disability benefit is based on } \\
\text { lifetime average earnings covered by Social Security } \\
\text { and the age of the recipient. }\end{array}$ \\
\hline
\end{tabular}




\begin{tabular}{|c|c|c|c|c|}
\hline & $\begin{array}{l}\text { contribution year. It is adjusted annually in } \\
\text { accordance with the development of wages and } \\
\text { salaries. }\end{array}$ & & & \\
\hline $\begin{array}{c}\text { Covered } \\
\text { Period }\end{array}$ & $\begin{array}{l}\text { From the end of the month in which the conditions } \\
\text { are fulfilled. Total and partial incapacity pensions } \\
\text { are awarded temporarily for a period of three years. } \\
\text { Prolongation possible. }\end{array}$ & $\begin{array}{l}\text { There are four degrees of permanent incapacity and } \\
\text { each of them have different benefits: *Partial } \\
\text { permanent incapacity for the usual occupation: lump } \\
\text { sum equal to } 24 \text { times monthly calculation basis used } \\
\text { for calculation of sickness. *Total permanent incapacity } \\
\text { for the usual occupation: } 55 \% \text { of calculation basis. } \\
\text { Increased by } 20 \% \text { if over } 55 \text { and out of work (pension of } \\
75 \% \text { ). Pension may, at request of beneficiary, be } \\
\text { redempted by a lump-sum payment equal to } 84 \text { times } \\
\text { monthly pension (minus } 12 \text { months for every year the } \\
\text { claimant's age exceeds } 54 \text {, subject to a minimum of } 12 \\
\text { months). *Absolute permanent incapacity: } 100 \% \text { of } \\
\text { calculation basis. *Severe incapacity: amount payable } \\
\text { for absolute permanent incapacity and a supplement } \\
\text { ( } 45 \% \text { of the minimum contribution base for the year } \\
\text { plus } 30 \% \text { of the worker's contribution base). No pension } \\
\text { supplements, but higher amount for the Minimum } \\
\text { Pension if there is a dependent spouse. }\end{array}$ & $\begin{array}{l}\text { Long-term incapacity benefit } \\
\text { (flat rate): } 110 € \text { a week. Age } \\
\text { addition: } 23 € \text { per week if } \\
\text { incapacity began before age } 35 \\
\text { per week; } 12 € \text { if it began } \\
\text { between } 35 \text { and } 44 . \\
\text { Supplements for dependants: } \\
\text { Partner: Increase for spouse } \\
\text { aged } 60 \text { or over or adult caring } \\
\text { for dependent r child: } \\
\text { Short term IB } \quad 51 € \\
\text { Long term IB } \quad 66 € \\
\text { No contributions and no } \\
\text { benefits for persons with } \\
\text { earnings below the Lower } \\
\text { Earnings Limit } 117 € \text { per week or } \\
\text { for self-employed persons with } \\
\text { annual earning less than } 6,253 € .\end{array}$ & $\begin{array}{l}\text { Social Security benefits are paid each month. The } \\
\text { higher monthly SGA amount for statutorily blind } \\
\text { individuals for } 2009 \text { is } \$ 1,640(1,251 €) \text {. For non-blind } \\
\text { individuals, the higher monthly SGA amount for } 2009 \\
\text { is } \$ 980 \text { ( } 747 €) \text {. There also are Supplemental Security } \\
\text { Income (SSI) benefits: if a person has limited income } \\
\text { and resources, he/she may be able to get SSI which is } \\
\text { a federal program that provides monthly payments to } \\
\text { people age } 65 \text { or older and to people who are blind or } \\
\text { disabled. Supplements for spouses and children but } \\
\text { there are a limit (between } 150 \text { and } 180 \text { percent of } \\
\text { your disability benefit) to the total amount of money } \\
\text { that can be paid to a family. }\end{array}$ \\
\hline $\begin{array}{l}\text { Minimum } \\
\text { amount }\end{array}$ & No statutory minimum pension. & $\begin{array}{l}\text { From the date on which the Disability Evaluation Board } \\
\text { (EVI) declares claimant to be permanently incapable. At } \\
\text { the retirement age, the name changes to retirement } \\
\text { pension but this change doesn't imply any alteration } \\
\text { concerning the conditions of the payment. }\end{array}$ & $\begin{array}{l}\text { Short-term IB: } 52 \text { weeks are the } \\
\text { minimum period by entitlement. } \\
\text { Long-term IB: After one year of } \\
\text { incapacity until state pension } \\
\text { age ( } 65 \text { for men, } 60 \text { for women). }\end{array}$ & $\begin{array}{l}\text { *Social Security: disability benefits will continue as } \\
\text { long as medical condition of the recipient has not } \\
\text { improved and he/she cannot work. Benefits will not } \\
\text { necessarily continue indefinitely. When people reach } \\
\text { full retirement age disability benefits automatically } \\
\text { convert to retirement benefits, but the amount } \\
\text { remains the same. }\end{array}$ \\
\hline $\begin{array}{c}\text { Maximum } \\
\text { amount }\end{array}$ & No statutory maximum pension. & $\begin{array}{l}\text { *Total permanent incapacity for the usual occupation: } \\
\text { Minimum pension for persons over } 65: 528.55 € \text { or } \\
658.75 € \text { for beneficiaries with dependent spouse. } \\
{ }^{*} \text { Absolute permanent incapacity: Minimum pension } \\
528.55 € \text { or } 658.75 € \text { for beneficiaries with dependent } \\
\text { spouse. *Severe incapacity: } 792.83 € \text { or } 988.13 € \text { for } \\
\text { beneficiaries with dependent spouse. Monthly amounts } \\
\text { (14 payments per year). }\end{array}$ & Flat-rate benefits. & No statutory minimum pension. \\
\hline
\end{tabular}




\section{B. Statistical appendix}

\section{Data sources:}

ECHP 1994 - 2001:

15 countries, 131 regions (incl. countries, if no regional info), 1,120,572 observations

SILC $2004-2006$ (in some cases $2003-2006$ ):

26 countries, 93 regions (incl. countries, if no regional info), 776,152 observations

Eurostat $1984-2007$ :

Regional unemployment rate for 1,935 regions (at various aggregation levels)

GSOEP 1984 - 2007:

1 country, 16 regions, 376,581 observations

United States' NHIS: 1982-2007. Repeated Cross-Section with over 75,000 observations per crosssection

United States' CPS: 1988-2008. Repeated Cross-Section with over 50,000 observations per crosssection

United States' PSID: 1985-2005. Panel format with around 18,000 individuals at the beginning of the panel in 1968.

\section{Data/Measures of invalidity benefits (IB):}

ECHP:

The variable "HI134 - Sickness/Invalidity Benefits" is used to create a dummy that is 0 if HI134=0 and 1 if $\mathrm{HI} 134>0$ (<.).

Stata-Code:

gen $i b=0$ if invalidbenefit!=.

replace $i b=1$ if invalidbenefit $>0$ \& invalidbenefit $<$.

SILC:

Two separate variables, "PY120N: Sickness benefits" and "PY130N: Disability benefits", are used to create a dummy that is 0 if both variables are zero and 1 if one or both are positive.

Stata-Code:

gen $i b=0$ if invalidityben $==0$ | sicknessben $==0$

replace $i b=1$ if (invalidityben $>0$ \& invalidityben<. ) | ( sicknessben $>0$ \& sicknessben<.)

GSOEP:

There is no variable directly indicating IB, but the variable "disabled" indicates a disability degree >= 30 (/100). In Germany people with a disability degree $>=30$ can apply for IB.

Therefore I use disabled=1 as a proxy for IB=1

PSID:

From 1985 to 1993 there is a measure of Disability Receipt. From 1985 to 2005 there is a measure of self-reported disability in the employment section of the survey 
Table B1.

Descriptive Statistics: Disability Benefit (DB) stocks of claimants, inflows and outflows, pooled across years

1. DB STOCK

\begin{tabular}{|c|c|c|c|c|c|c|c|c|c|}
\hline \multirow[t]{2}{*}{ Country } & \multicolumn{3}{|c|}{ ECHP } & \multicolumn{3}{|c|}{ SILC } & \multicolumn{3}{|c|}{ GSOEP } \\
\hline & Total stock & DB stock & $\%$ & Total stock & DB stock & $\%$ & Total stock & DB stock & $\%$ \\
\hline AT Austria & 27,085 & 1,837 & $6.8 \%$ & 14,033 & 1,082 & $7.7 \%$ & & & \\
\hline BE Belgique & 27,212 & 2,957 & $10.9 \%$ & 12,061 & 988 & $8.2 \%$ & & & \\
\hline CY Cyprus & & & & 7,679 & 374 & $4.9 \%$ & & & \\
\hline CZ Czech rep. & & & & 10,154 & 2,240 & $22.1 \%$ & & & \\
\hline DE Germany & 77,453 & 2,247 & $2.9 \%$ & 26,878 & 1,690 & $6.3 \%$ & 243,115 & 34,073 & $14.0 \%$ \\
\hline DK Denmark & 26,587 & 2,587 & $9.7 \%$ & & & & & & \\
\hline EE Estonia & & & & 17,533 & 3,749 & $21.4 \%$ & & & \\
\hline ES Spain & 60,965 & 5,086 & $8.3 \%$ & 33,146 & 2,112 & $6.4 \%$ & & & \\
\hline FI Finland & 30,755 & 5,942 & $19.3 \%$ & & & & & & \\
\hline FR France & 58,193 & 5,589 & $9.6 \%$ & 28,508 & 2,839 & $10.0 \%$ & & & \\
\hline GR Greece & 41,421 & 1,450 & $3.5 \%$ & 15,177 & 592 & $3.9 \%$ & & & \\
\hline HU Hungary & & & & & & & & & \\
\hline IE Ireland & 31,173 & 2,298 & $7.4 \%$ & 10,430 & 1,722 & $16.5 \%$ & & & \\
\hline IS Iceland & & & & & & & & & \\
\hline IT Italy & 70,886 & 4,705 & $6.6 \%$ & 50,184 & 3,175 & $6.3 \%$ & & & \\
\hline LT Lithuania & & & & & & & & & \\
\hline LU Luxembg & 25,308 & 2,603 & $10.3 \%$ & 17,109 & 1,343 & $7.8 \%$ & & & \\
\hline LV Latvia & & & & 8,205 & 1,046 & $12.7 \%$ & & & \\
\hline NL Netherland & 45,631 & 4,551 & $10.0 \%$ & & & & & & \\
\hline NO Norway & & & & & & & & & \\
\hline PL Poland & & & & 31,500 & 3,840 & $12.2 \%$ & & & \\
\hline PT Portugal & 54,845 & 4,548 & $8.3 \%$ & 13,148 & 1,050 & $8.0 \%$ & & & \\
\hline SE Sweden & 33,086 & 5,545 & $16.8 \%$ & 17,665 & 6,344 & $35.9 \%$ & & & \\
\hline SI Slovenia & & & & 26,621 & 6,653 & $25.0 \%$ & & & \\
\hline SK Slovakia & & & & & & & & & \\
\hline UK U. Kingdom & 64,963 & 9,228 & $14.2 \%$ & 16,411 & 1,554 & $9.5 \%$ & & & \\
\hline & 675,563 & 61,173 & $9.1 \%$ & 356,442 & 42,393 & $11.9 \%$ & & & \\
\hline
\end{tabular}

2. DB INFLOW

\begin{tabular}{|c|c|c|c|c|c|c|c|c|c|}
\hline \multirow[t]{2}{*}{ Country } & \multicolumn{3}{|c|}{ ECHP } & \multicolumn{3}{|c|}{ SILC } & \multicolumn{3}{|c|}{ GSOEP } \\
\hline & total & inflow & $\%$ & total & inflow & $\%$ & total & inflow & $\%$ \\
\hline AT Austria & 19,713 & 164 & $0.8 \%$ & 6,570 & 151 & $2.3 \%$ & & & \\
\hline BE Belgique & 19,601 & 694 & $3.5 \%$ & 5,504 & 125 & $2.3 \%$ & & & \\
\hline CY Cyprus & & & & 3394 & 54 & $1.6 \%$ & & & \\
\hline CZ Czech rep. & & & & 3651 & 388 & $10.6 \%$ & & & \\
\hline DE Germany & 58,997 & 254 & $0.4 \%$ & 9,159 & 208 & $2.3 \%$ & 159,261 & 2,149 & $1.3 \%$ \\
\hline DK Denmark & 18,818 & 460 & $2.4 \%$ & & & & & & \\
\hline EE Estonia & & & & 7966 & 684 & $8.6 \%$ & & & \\
\hline ES Spain & 43,362 & 507 & $1.2 \%$ & 15,965 & 332 & $2.1 \%$ & & & \\
\hline FI Finland & 18,454 & 1,249 & $6.8 \%$ & & & & & & \\
\hline FR France & 42,372 & 1,183 & $2.8 \%$ & 13,505 & 565 & $4.2 \%$ & & & \\
\hline GR Greece & 32,286 & 103 & $0.3 \%$ & 8,796 & 32 & $0.4 \%$ & & & \\
\hline HU Hungary & & & & & & & & & \\
\hline IE Ireland & 21,821 & 253 & $1.2 \%$ & 4,246 & 190 & $4.5 \%$ & & & \\
\hline IS Iceland & & & & & & & & & \\
\hline IT Italy & 54,068 & 355 & $0.7 \%$ & 26,805 & 118 & $0.4 \%$ & & & \\
\hline
\end{tabular}




\begin{tabular}{|l|ccc|ccc|c|} 
LT Lithuania & & & & & & \\
LU Luxembg & 16,752 & 533 & $3.2 \%$ & 9,948 & 101 & $1.0 \%$ & \\
LV Latvia & & & & 2987 & 148 & $5.0 \%$ & \\
NL Netherland & 32,182 & 524 & $1.6 \%$ & & & & \\
NO Norway & & & & & & \\
PL Poland & & & & 12331 & 159 & $1.3 \%$ & \\
PT Portugal & 41,209 & 615 & $1.5 \%$ & 6,902 & 127 & $1.8 \%$ & \\
SE Sweden & 18,641 & 2,192 & $11.8 \%$ & 6,295 & 911 & $14.5 \%$ & \\
SI Slovenia & & & & 8368 & 888 & $10.6 \%$ & \\
SK Slovakia & & & & & & & \\
UK U. Kingdom & 41,920 & 1,014 & $2.4 \%$ & 6,056 & 85 & $1.4 \%$ & \\
\hline \multicolumn{1}{|c|}{ Total } & 480,196 & 10,100 & $2.1 \%$ & 158,448 & 5,266 & $3.3 \%$ & \\
\hline
\end{tabular}

\section{DB OUTFLOW}

\begin{tabular}{|c|c|c|c|c|c|c|c|c|c|}
\hline Country & & ECHP & & & SILC & & & GSOEP & \\
\hline & total & outflow & $\%$ & total & outflow & $\%$ & total & outflow & $\%$ \\
\hline AT Austria & 1438 & 422 & $29.3 \%$ & 570 & 275 & $48.2 \%$ & & & \\
\hline BE Belgique & 2346 & 890 & $37.9 \%$ & 473 & 154 & $32.6 \%$ & & & \\
\hline CY Cyprus & & & & 165 & 60 & $36.4 \%$ & & & \\
\hline CZ Czech rep. & & & & 996 & 364 & $36.5 \%$ & & & \\
\hline DE Germany & 1864 & 441 & $23.7 \%$ & 768 & 354 & $46.1 \%$ & 25,689 & 2,907 & $11.3 \%$ \\
\hline DK Denmark & 2026 & 683 & $33.7 \%$ & & & & & & \\
\hline EE Estonia & & & & 2280 & 1051 & $46.1 \%$ & & & \\
\hline ES Spain & 3984 & 1381 & $34.7 \%$ & 1131 & 478 & $42.3 \%$ & & & \\
\hline FI Finland & 4471 & 1371 & $30.7 \%$ & & & & & & \\
\hline FR France & 4427 & 1406 & $31.8 \%$ & 1386 & 552 & $39.8 \%$ & & & \\
\hline GR Greece & 1155 & 467 & $40.4 \%$ & 362 & 107 & $29.6 \%$ & & & \\
\hline HU Hungary & & & & & & & & & \\
\hline $\begin{array}{l}\text { IE Ireland } \\
\text { IS Iceland }\end{array}$ & 1794 & 411 & $22.9 \%$ & 918 & 285 & $31.0 \%$ & & & \\
\hline IT Italy & 3810 & 1229 & $32.3 \%$ & 1817 & 273 & $15.0 \%$ & & & \\
\hline LT Lithuania & & & & & & & & & \\
\hline LU Luxembg & 1952 & 522 & $26.7 \%$ & 892 & 161 & $18.0 \%$ & & & \\
\hline LV Latvia & & & & 482 & 256 & $53.1 \%$ & & & \\
\hline NL Netherland & 3616 & 845 & $23.4 \%$ & & & & & & \\
\hline NO Norway & & & & & & & & & \\
\hline PL Poland & & & & 1768 & 364 & $20.6 \%$ & & & \\
\hline PT Portugal & 3760 & 1423 & $37.8 \%$ & 611 & 163 & $26.7 \%$ & & & \\
\hline SE Sweden & 3617 & 3211 & $88.8 \%$ & 3578 & 913 & $25.5 \%$ & & & \\
\hline SI Slovenia & & & & 2989 & 1228 & $41.1 \%$ & & & \\
\hline SK Slovakia & & & & & & & & & \\
\hline UK U. Kingdom & 6625 & 1428 & $21.6 \%$ & 629 & 146 & $23.2 \%$ & & & \\
\hline Total & 46,885 & 16,130 & $34.4 \%$ & 21,815 & 7,184 & $32.9 \%$ & & & \\
\hline
\end{tabular}


Table B2: Pooled panel estimates of Disability Benefit receipt (DB) and unemployment rates with country-unemployment rate interactions

\begin{tabular}{|c|c|c|c|c|c|c|}
\hline \multicolumn{7}{|c|}{ ECHP (1994 - 2001) and SILC (2004 - 2006) } \\
\hline Dependent Variable: & \multicolumn{2}{|l|}{$\begin{array}{l}\text { DB STOCK } \\
+ \text { year } \\
\end{array}$} & \multicolumn{2}{|l|}{$\begin{array}{l}\text { DB INFLOW } \\
+ \text { year }\end{array}$} & \multicolumn{2}{|l|}{$\begin{array}{l}\text { DB OUTFLOW } \\
+ \text { year }\end{array}$} \\
\hline \multicolumn{7}{|l|}{ Interaction of u rate* with } \\
\hline Austria & 0.0023 & $* * *$ & -0.0004 & & 0.0159 & $*$ \\
\hline$d(\ln y) / d(\ln x)$ & 0.0041 & & & & 0.0067 & \\
\hline \multirow[t]{2}{*}{ Belgium } & 0.0033 & $* * *$ & 0.0016 & $* * *$ & 0.0003 & \\
\hline & 0.0115 & & 0.0273 & & & \\
\hline \multirow[t]{2}{*}{ Cyprus } & -0.0046 & $* * *$ & -0.0012 & & 0.0247 & $* * *$ \\
\hline & -0.0017 & & & & 0.0009 & \\
\hline \multirow[t]{2}{*}{ Czech Republic } & 0.0158 & $* * *$ & 0.0093 & $* * *$ & 0.0130 & $* *$ \\
\hline & 0.0128 & & 0.0190 & & 0.0046 & \\
\hline \multirow[t]{2}{*}{ Germany } & -0.0030 & $* * *$ & -0.0006 & $* * *$ & -0.0021 & \\
\hline & -0.0299 & & -0.0331 & & & \\
\hline \multirow[t]{2}{*}{ Denmark } & 0.0050 & $* * *$ & 0.0019 & $* * *$ & -0.0087 & \\
\hline & 0.0075 & & 0.0137 & & & \\
\hline \multirow[t]{2}{*}{ Estonia } & 0.0162 & $* * *$ & 0.0094 & $* * *$ & 0.0247 & $* * *$ \\
\hline & 0.0225 & & 0.0381 & & 0.0223 & \\
\hline \multirow[t]{2}{*}{ Spain } & 0.0015 & $* * *$ & -0.0001 & & 0.0005 & \\
\hline & 0.0206 & & & & & \\
\hline \multirow[t]{2}{*}{ Finland } & 0.0106 & $* * *$ & 0.0052 & $* * *$ & -0.0047 & \\
\hline & 0.0355 & & 0.0730 & & & \\
\hline \multirow[t]{2}{*}{ France } & 0.0029 & $* * *$ & 0.0015 & $* * *$ & -0.0008 & \\
\hline & 0.0246 & & 0.0615 & & & \\
\hline \multirow[t]{2}{*}{ Greece } & -0.0030 & $* * *$ & -0.0011 & $* * *$ & 0.0046 & $*$ \\
\hline & -0.0146 & & -0.0317 & & 0.0039 & \\
\hline \multirow[t]{2}{*}{ Iceland } & 0.0034 & $* * *$ & -0.0001 & & -0.0134 & $* * *$ \\
\hline & 0.0107 & & & & -0.0120 & \\
\hline \multirow[t]{2}{*}{ Italy } & 0.0005 & $* * *$ & -0.0006 & $* * *$ & -0.0048 & $* *$ \\
\hline & 0.0051 & & -0.0311 & & -0.0094 & \\
\hline \multirow[t]{2}{*}{ Luxemburg } & 0.0080 & $* * *$ & 0.0018 & & -0.0163 & $* *$ \\
\hline & 0.0109 & & & & -0.0065 & \\
\hline \multirow[t]{2}{*}{ Latvia } & 0.0062 & $* * *$ & 0.0040 & $* * *$ & 0.0319 & $* * *$ \\
\hline & 0.0041 & & 0.0061 & & 0.0063 & \\
\hline \multirow[t]{2}{*}{ Netherlands } & 0.0075 & $* * *$ & 0.0005 & & -0.0237 & $* * *$ \\
\hline & 0.0148 & & & & -0.0200 & \\
\hline \multirow[t]{2}{*}{ Poland } & 0.0034 & $* * *$ & -0.0006 & $* *$ & -0.0016 & \\
\hline & 0.0170 & & -0.0076 & & & \\
\hline Portugal & 0.0009 & $* * *$ & -0.0001 & & 0.0066 & \\
\hline & 0.0023 & & & & & \\
\hline Sweden & 0.0209 & $* * *$ & 0.0155 & $* * *$ & 0.0335 & \\
\hline & 0.0753 & & 0.1048 & & & \\
\hline Slovenia & 0.0277 & $* * *$ & 0.0141 & $* * *$ & 0.0230 & $* * *$ \\
\hline & 0.0468 & & 0.0529 & & 0.0225 & \\
\hline United Kingdom & 0.0116 & $* * *$ & 0.0019 & $* *$ & -0.0166 & $* * *$ \\
\hline & 0.0478 & & 0.0306 & & -0.0330 & \\
\hline $\mathrm{N}$ & 977,393 & & 578,391 & & 64,319 & \\
\hline $\mathrm{R}^{2}$ & 0.10 & & 0.03 & & 0.07 & \\
\hline
\end{tabular}


Notes: Reported coefficients refer to the coefficient of the regional u-rate interacted with country dummies $\left(c_{k}\right.$ in above specification). To save space, $p$-values are not reported but represented by: ${ }^{*} p$-value $<0.1, * * p$-value $<0.05, * * * p$-value $<0.01$ and bold coefficients are significant. Below significant coefficients, corresponding elasticities of the form ' $d(\ln y) / d(\ln x)$ ' are reported. All regressions include year dummies and control for age and gender of the respondent. Standard errors are clustered by region. 
Table B3: Pooled panel estimates of Disability Benefit receipt (DB)

and unemployment rates with country interactions in unemployment rate and HEALTH MEASURES (SRH, BADHEALTH, HAMPERED)

\begin{tabular}{|c|c|c|c|c|c|c|c|c|c|c|c|c|}
\hline \multicolumn{13}{|c|}{ ECHP (1994 - 2001) and SILC (2004 - 2006) } \\
\hline \multirow[t]{2}{*}{ Dep. Var. } & \multicolumn{4}{|c|}{ DB STOCK } & \multicolumn{4}{|c|}{ DB INFLOW } & \multicolumn{4}{|c|}{ DB OUTFLOW } \\
\hline & as Table 3 & $+\mathrm{SRH}$ & + badhealth & + hampered & as Table 3 & $+\mathrm{SRH}$ & + badhealth & + hampered & as Table 3 & $+\mathrm{SRH}$ & + badhealth & + hampered \\
\hline \multicolumn{13}{|l|}{ U rate* with } \\
\hline Austria & $0.0023 * * *$ & $0.0094 * * *$ & $0.0039 * * *$ & $0.0014 * * *$ & $-0.0008^{* * *}$ & $0.0013 * * *$ & 0.0002 & -0.0002 & $0.0135 * * *$ & $0.0084 * * *$ & $0.0086 * * *$ & $0.0142 * * *$ \\
\hline Belgique & $0.0033 * * *$ & $0.0050 * * *$ & $0.0040 * * *$ & $0.0035^{* * *}$ & $0.0016 * * *$ & $0.0022 * * *$ & $0.0020 * * *$ & $0.0021 * * *$ & 0.0003 & -0.0012 & -0.0009 & 0.0002 \\
\hline Cyprus & $-0.0046 * * *$ & $0.0043^{* * *}$ & $-0.0038 * * *$ & $-0.0039 * * *$ & $-0.0015^{* *}$ & 0.0006 & $-0.0012^{* *}$ & $-0.0011 *$ & $0.0247^{* * *}$ & $0.0218 * * *$ & $0.0211 * * *$ & $0.0231 * * *$ \\
\hline Czech rep. & $0.0158^{* * *}$ & $0.0147^{* * *}$ & $0.0147^{* * *}$ & $0.0149 * * *$ & $0.0093^{* * *}$ & $0.0097 * * *$ & $0.0098^{* * *}$ & $0.0098 * * *$ & $0.0130 * * *$ & $0.0111 * * *$ & $0.0110 * * *$ & $0.0096 * * *$ \\
\hline Germany & $-0.0030^{* * *}$ & $-0.0050 * * *$ & $-0.0039 * * *$ & $-0.0060 * * *$ & $-0.0008^{* * *}$ & $-0.0011 * * *$ & $-0.0008^{* * *}$ & $-0.0013 * * *$ & $-0.0021 * *$ & 0.0007 & -0.0008 & 0.0007 \\
\hline Denmark & $0.0050 * * *$ & $0.0143 * * *$ & $0.0073 * * *$ & $0.0038^{* * *}$ & $0.0016 * * *$ & $0.0043 * * *$ & $0.0027^{* * *}$ & $0.0021 * * *$ & $-0.0087^{* * *}$ & $-0.0125 * * *$ & $-0.0109 * * *$ & $-0.0058 * * *$ \\
\hline Estonia & $0.0162 * * *$ & $0.0118^{* * *}$ & $0.0149 * * *$ & $0.0117^{* * *}$ & $0.0092 * * *$ & $0.0086^{* * *}$ & $0.0094^{* * *}$ & $0.0085^{* * *}$ & $0.0247 * * *$ & $0.0234 * * *$ & $0.0214 * * *$ & $0.0224^{* * *}$ \\
\hline Spain & $0.0015^{* * *}$ & $0.0016^{* * *}$ & $0.0013^{* * *}$ & $0.0016^{* * *}$ & $-0.0001 * * *$ & 0.0001 & 0.0001 & $0.0002 * * *$ & 0.0005 & $0.0022 * * *$ & $0.0016 * * *$ & $0.0018 * * *$ \\
\hline Finland & $0.0106 * * *$ & $0.0109 * * *$ & $0.0114^{* * *}$ & $0.0079 * * *$ & $0.0050^{* * *}$ & $0.0056 * * *$ & $0.0056^{* * *}$ & $0.0051 * * *$ & $-0.0047^{* * *}$ & $-0.0063^{* * *}$ & $-0.0062 * * *$ & $-0.0043^{* * *}$ \\
\hline France & $0.0029 * * *$ & $0.0026^{* * *}$ & $0.0033^{* * *}$ & $0.0026^{* * *}$ & $0.0014 * * *$ & $0.0016^{* * *}$ & $0.0018^{* * *}$ & $0.0016 * * *$ & -0.0008 & -0.0007 & $-0.0016^{*}$ & -0.0011 \\
\hline Greece & $-0.0030 * * *$ & $0.0045^{* * *}$ & $-0.0020 * * *$ & $-0.0014^{* * *}$ & $-0.0013^{* * *}$ & $0.0004 * * *$ & $-0.0009 * * *$ & $-0.0008 * * *$ & $0.0046 * * *$ & $0.0111 * * *$ & $0.0089 * * *$ & $0.0088 * * *$ \\
\hline Iceland & $0.0034^{* * *}$ & $0.0093^{* * *}$ & $0.0051^{* * *}$ & $0.0034^{* * *}$ & -0.0001 & $0.0016^{* * *}$ & $0.0006 * * *$ & $0.0005^{* * *}$ & $-0.0134^{* * *}$ & $-0.0175 * * *$ & $-0.0165^{* * *}$ & $-0.0122 * * *$ \\
\hline Italy & $0.0005^{* * *}$ & 0.0001 & $0.0005^{* * *}$ & $0.0016^{* * *}$ & $-0.0008^{* * *}$ & $-0.0006^{* * *}$ & $-0.0005^{* * *}$ & $-0.0004 * * *$ & $-0.0048 * * *$ & $-0.0033^{* * *}$ & $-0.0040 * * *$ & $-0.0062 * * *$ \\
\hline Luxembg & $0.0080 * * *$ & $0.0073^{* * *}$ & $0.0028^{* * *}$ & 0.0007 & $0.0018^{* * *}$ & -0.0003 & $-0.0012 * * *$ & $-0.0016 * * *$ & $-0.0163 * * *$ & $-0.0065^{*}$ & $-0.0073^{*}$ & -0.0056 \\
\hline Latvia & $0.0062 * * *$ & $-0.0016^{* * *}$ & $0.0033^{* * *}$ & $0.0034^{* * *}$ & $0.0039 * * *$ & $0.0024 * * *$ & $0.0035^{* * *}$ & $0.0033^{* * *}$ & $0.0319 * * *$ & $0.0331 * * *$ & $0.0301 * * *$ & $0.0271 * * *$ \\
\hline Netherland & $0.0075^{* * *}$ & $0.0107^{* * *}$ & $0.0106^{* * *}$ & $0.0050 * * *$ & 0.0002 & $0.0016^{* * *}$ & $0.0015^{* * *}$ & $0.0006^{* *}$ & $-0.0286 * * *$ & $-0.0321 * * *$ & $-0.0333 * * *$ & $-0.0247 * * *$ \\
\hline Poland & $0.0034 * * *$ & $0.0014 * * *$ & $0.0020 * * *$ & $0.0039 * * *$ & $-0.0007^{* * *}$ & $-0.0009 * * *$ & $-0.0007 * * *$ & $-0.0004^{* * *}$ & $-0.0016^{* *}$ & 0.0005 & -0.0008 & $-0.0014^{* *}$ \\
\hline Portugal & $0.0009 * * *$ & $-0.0058^{* * *}$ & $-0.0028 * * *$ & $-0.0005^{*}$ & $-0.0003^{*}$ & $-0.0012^{* * *}$ & $-0.0005^{* *}$ & -0.0001 & $0.0066 * * *$ & $0.0172 * * *$ & $0.0135^{* * *}$ & $0.0095 * * *$ \\
\hline Sweden & $0.0209 * * *$ & $0.0259 * * *$ & $0.0220 * * *$ & $0.0193 * * *$ & $0.0150 * * *$ & $0.0158^{* * *}$ & $0.0150 * * *$ & $0.0142^{* * *}$ & $0.0335^{* * *}$ & $0.0304 * * *$ & $0.0345^{* * *}$ & $0.0344 * * *$ \\
\hline Slovenia & $0.0277^{* * *}$ & $0.0268^{* * *}$ & $0.0277^{* * *}$ & $0.0291 * * *$ & $0.0139 * * *$ & $0.0165^{* * *}$ & $0.0168 * * *$ & $0.0169 * * *$ & $0.0266 * * *$ & $0.0210 * * *$ & $0.0212 * * *$ & $0.0162 * * *$ \\
\hline U. Kingdom & $0.0116 * * *$ & $0.0132 * * *$ & $0.0108^{* * *}$ & $0.0114^{* * *}$ & $0.0016^{* * *}$ & $0.0025^{* * *}$ & $0.0021 * * *$ & $0.0024 * * *$ & $-0.0198 * * *$ & $-0.0207 * * *$ & $-0.0203^{* * *}$ & $-0.0200 * * *$ \\
\hline SRH & - & 0.1101 & - & - & - & $0.0213 * * *$ & - & $\ldots$ & - & $-0.0993 * * *$ & - & $\ldots$ \\
\hline badhealth & - & - & $0.3835^{* * *}$ & - & - & - & $0.0759 * * *$ & - & - & - & $-0.1537 * * *$ & - \\
\hline hampered & - & - & - & $0.3039 * * *$ & - & - & - & $0.0605^{* * *}$ & - & - & - & $-0.2337^{* * *}$ \\
\hline$n$ & 977,393 & 907,616 & 907,616 & 907,616 & 590,870 & 556,897 & 556,897 & 556,897 & 64,319 & 57,223 & 57,223 & \\
\hline$R^{2}$ & 0.10 & 0.18 & 0.20 & 0.22 & 0.03 & 0.04 & 0.04 & 0.04 & 0.07 & 0.11 & 0.09 & 0.11 \\
\hline
\end{tabular}

Notes: all regressions include year dummies and control for age and gender of the respondent. Source: ECHP 1994-2001 and SILC 2004-2006. 


\begin{tabular}{|c|c|c|c|c|c|c|c|c|c|c|c|c|}
\hline \multicolumn{13}{|c|}{ ) and SIL } \\
\hline \multirow[t]{2}{*}{ Dep. Var. } & \multicolumn{4}{|c|}{ DB STOCK } & \multicolumn{4}{|c|}{ DB INFLOW } & \multicolumn{4}{|c|}{ DB OUTFLOW } \\
\hline & as Table 3 & $+\mathrm{SRH}$ & + badhealth & + hampered & as Table 1 & $+\mathrm{SRH}$ & + badhealth & + hampered & as Table 1 & $+\mathrm{SRH}$ & + badhealth & + hampered \\
\hline \multicolumn{13}{|l|}{ urate* with } \\
\hline Austria & $0.0023 * * *$ & $0.0094 * * *$ & 0.0039 & $0.0014 * * *$ & $4000.0-$ & $0.0013 * * *$ & 0.0004 & 0.0000 & 0.0159* & 0.0109 & 0.0114 & $0.0170 * * *$ \\
\hline Belgique & $0.0033 * * *$ & $0.0050 * * *$ & $0.0040 * * *$ & $0.0035^{* * *}$ & $0.0016^{* * *}$ & $0.0022 * * *$ & $0.0021 * * *$ & $0.0021 * * *$ & 0.0003 & 0.0004 & 0.0008 & 0.0018 \\
\hline Cyprus & $-0.0046 * * *$ & $0.0043^{* *}$ & $-0.0038 * * *$ & $-0.0039 * * *$ & $2100.0-$ & 0.0006 & -0.0010 & -0.0009 & $0.0247 * * *$ & $0.0197 * * *$ & $0.0191 * * *$ & $0.0209 * * *$ \\
\hline Czech rep. & $0.0158^{* * *}$ & $0.0147^{* * *}$ & $0.0147 * * *$ & $0.0149 * * *$ & $0.0093 * * *$ & $0.0097 * * *$ & $0.0099 * * *$ & $0.0100 * * *$ & $0.013 * *$ & $0.0100 * * *$ & $0.0100 * * *$ & $0.0083^{* * *}$ \\
\hline Germany & $-0.0030 * * *$ & $-0.0050 * * *$ & $-0.0039 * * *$ & $-0.0060 * * *$ & $6000.0-^{* * *}$ & $-0.0011^{* * *}$ & $-0.0007 * * *$ & $-0.0012^{* * *}$ & $1200.0-$ & 0.0018 & 0.0003 & 0.0019 \\
\hline Denmark & $0.0050 * * *$ & $0.0143^{* * *}$ & $0.0073 * * *$ & $0.0038 * * *$ & $0.0019 * * *$ & $0.0043 * * *$ & $0.0029 * * *$ & $0.0023 * * *$ & $7800.0-$ & $-0.0091 * * *$ & $-0.0072^{*}$ & -0.0020 \\
\hline Estonia & $0.0162 * * *$ & $0.0118 * * *$ & $0.0149 * * *$ & $0.0117^{* * *}$ & $0.0094 * * *$ & $0.0086 * * *$ & $0.0095 * * *$ & $0.0087^{* * *}$ & $0.0247 * * *$ & $0.0220 * * *$ & $0.0201 * * *$ & $0.0209 * * *$ \\
\hline Spain & $0.0015^{* * *}$ & $0.0016^{* *}$ & $0.0013 * * *$ & $0.0016^{* * *}$ & $1000.0-$ & 0.0001 & 0.0001 & 0.0002 & 0.0005 & $0.0032 * * *$ & $0.0026^{*}$ & $0.0028^{* * *}$ \\
\hline Finland & $0.0106 * * *$ & $0.0109 * * *$ & $0.0114^{* * *}$ & $0.0079 * * *$ & $0.0052^{* * *}$ & $0.0056^{* * *}$ & $0.0057^{* * *}$ & $0.0052^{* * *}$ & $7400.0-$ & $-0.0043 * * *$ & $-0.0040 * *$ & -0.0022 \\
\hline France & $0.0029 * * *$ & $0.0026 * * *$ & $0.0033^{* * *}$ & $0.0026^{* * *}$ & $0.0015^{* * *}$ & $0.0016^{* * *}$ & $0.0019 * * *$ & $0.0017^{* * *}$ & $8000.0-$ & 0.0008 & -0.0001 & 0.0004 \\
\hline Greece & $-0.0030 * * *$ & $0.0045 * * *$ & $-0.0020 * * *$ & $-0.0014 * * *$ & $1100.0-^{* * *}$ & $0.0004 * * *$ & $-0.0008 * * *$ & $-0.0007 * * *$ & $0.0046^{*}$ & $0.0128 * * *$ & $0.0106 * * *$ & $0.0106^{* * *}$ \\
\hline Iceland & $0.0034 * * *$ & $0.0093^{* * *}$ & $0.0051^{* * *}$ & $0.0034^{* * *}$ & $1000.0-$ & $0.0016^{* * *}$ & 0.0007 & 0.0006 & $4310.0-* * *$ & $-0.0161^{* * *}$ & $-0.0149 * * *$ & $-0.0105^{* * *}$ \\
\hline Italy & $0.0005^{* * *}$ & 0.0001 & 0.0005 & $0.0016 * * *$ & $6000.0-^{* * *}$ & $-0.0006 * * *$ & $-0.0005 * * *$ & $-0.0003 * * *$ & $8400.0-^{* *}$ & -0.0025 & -0.0032 & $-0.0054 * * *$ \\
\hline Luxembg & $0.0080 * * *$ & $0.0073^{* * *}$ & 0.0028 & 0.0007 & 0.0018 & -0.0003 & -0.0011 & $-0.0014^{* * *}$ & $3610.0-* *$ & -0.0109 & -0.0115 & -0.0101 \\
\hline Latvia & $0.0062 * * *$ & -0.0016 & $0.0033^{* * *}$ & $0.0034 * *$ & $0.004 * * *$ & $0.0024 * * *$ & $0.0037^{* * *}$ & $0.0035 * * *$ & $0.0319 * * *$ & $0.0319 * * *$ & $0.0289 * * *$ & $0.0256^{* * *}$ \\
\hline Netherland & $0.0075 * * *$ & $0.0107 * * *$ & $0.0106 * * *$ & $0.0050 * * *$ & 0.0005 & $0.0016 * * *$ & $0.0017 * * *$ & 0.0008 & $7320.0-* * *$ & $-0.0280 * * *$ & $-0.0289 * * *$ & $-0.0201 * * *$ \\
\hline Poland & $0.0034 * * *$ & $0.0014 * * *$ & $0.0020 * * *$ & $0.0039 * * *$ & $6000.0-* *$ & -0.0009 & $-0.0006 * * *$ & -0.0003 & $6100.0-$ & 0.0000 & -0.0013 & -0.0021 \\
\hline Portugal & $0.0009 * * *$ & $-0.0058 * * *$ & $-0.0028 * * *$ & $-0.0005^{*}$ & $1000.0-$ & $-0.0012^{* * *}$ & -0.0002 & 0.0001 & 0.0066 & $0.0196 * * *$ & $0.0158^{* *}$ & $0.0118^{* * *}$ \\
\hline Sweden & $0.0209 * * *$ & $0.0259 * * *$ & $0.0220 * * *$ & $0.0193 * * *$ & $0.0155^{* * *}$ & $0.0158 * * *$ & $0.0157^{* * *}$ & $0.0152^{* * *}$ & 0.0335 & 0.0133 & 0.0178 & 0.0162 \\
\hline Slovenia & $0.0277^{* * *}$ & $0.0268 * * *$ & $0.0277^{* * *}$ & $0.0291 * * *$ & $0.0141 * * *$ & $0.0165^{* * *}$ & $0.0170 * * *$ & $0.0171^{* * *}$ & $0.023 * * *$ & $0.0192 * * *$ & $0.0195 * * *$ & $0.0140 * * *$ \\
\hline U. Kingdom & $0.0116^{* * *}$ & $0.0132 * * *$ & $0.0108^{* * *}$ & $0.0114^{* * *}$ & $0.0019 * *$ & $0.0025^{* * *}$ & $0.0021 * * *$ & $0.0026 * * *$ & $6610.0-* * *$ & $-0.0207 * * *$ & $-0.0203 * * *$ & $-0.0170 * * *$ \\
\hline $\mathrm{SRH}$ & - & 0.1101 & - & - & - & $0.0213 * * *$ & - & ... & - & $-0.0993 * * *$ & - & - \\
\hline Badhealth & - & - & $0.3835^{* * *}$ & - & - & - & $0.0759 * * *$ & - & - & - & $-0.1537 * * *$ & - \\
\hline Hampered & - & - & - & $0.3039 * * *$ & - & - & - & $0.0605^{* * *}$ & - & - & - & $-0.2337^{* * *}$ \\
\hline $\mathrm{N}$ & 977,393 & 907,616 & 907,616 & 907,616 & 590,870 & 556,897 & 556,897 & 556,897 & 64,319 & 57,223 & 57,223 & \\
\hline $\mathrm{R}^{2}$ & 0.10 & 0.18 & 0.20 & 0.22 & 0.03 & 0.04 & 0.04 & 0.04 & 0.07 & 0.11 & 0.09 & 0.11 \\
\hline
\end{tabular}

Notes: all regressions include year dummies and control for age and gender of the respondent. Source: ECHP 1994-2001 and SILC 2004-2006. Standard errors are clustered by region 